University of Louisville

ThinkIR: The University of Louisville's Institutional Repository

Electronic Theses and Dissertations

$12-2015$

\title{
Understanding the meaning of the equal sign : an investigation of elementary students and teachers.
}

Victoria Miller Bennett

University of Louisville

Follow this and additional works at: https://ir.library.louisville.edu/etd

Part of the Curriculum and Instruction Commons

\section{Recommended Citation}

Miller Bennett, Victoria, "Understanding the meaning of the equal sign : an investigation of elementary students and teachers." (2015). Electronic Theses and Dissertations. Paper 2303.

https://doi.org/10.18297/etd/2303

This Doctoral Dissertation is brought to you for free and open access by ThinkIR: The University of Louisville's Institutional Repository. It has been accepted for inclusion in Electronic Theses and Dissertations by an authorized administrator of ThinkIR: The University of Louisville's Institutional Repository. This title appears here courtesy of the author, who has retained all other copyrights. For more information, please contact thinkir@louisville.edu. 
UNDERSTANDING THE MEANING OF THE EQUAL SIGN: AN INVESTIGATION OF ELEMENTARY STUDENTS AND TEACHERS

By

Victoria Miller Bennett

B.A., Indiana University, 1995

M.A., University of Louisville, 2000

A Dissertation Submitted to the Faculty of the College of Education and Human Development of the University of Louisville in Partial Fulfillment of the Requirements for the Degree of

Doctor of Philosophy in Curriculum and Instruction

Teaching and Learning University of Louisville

Louisville, Kentucky

December 2015 
Copyright 2015 by Victoria Miller Bennett

All rights reserved 

UNDERSTANDING THE MEANING OF THE EQUAL SIGN: AN INVESTIGATION OF ELEMENTARY STUDENTS AND TEACHERS

\author{
By \\ Victoria Miller Bennett \\ B.A., Indiana University, 1995 \\ M.A., University of Louisville, 2000 \\ A Dissertation Approved on
}

November 30, 2015

by the following Dissertation Committee

Dissertation Director

Karen Karp

Jennifer M. Bay-Williams

Elizabeth Todd Brown

Maggie B. McGatha

Robert N. Ronau 


\section{DEDICATION}

This dissertation is dedicated

To my Mom and Dad

Saundra and Roy Miller

who taught me to believe in family, opportunity and hard work.

$\&$

To my beautiful children

Jacob Thomas and Brooke Marie

who teach me what life is all about. 


\section{ACKNOWLEDGMENTS}

Completing my dissertation is characterized by many different feelings and emotions, a significant personal and professional accomplishment. Achieving success was not possible without the many people who provided inspiration, encouragement, motivation and intellectual support. Mentors, family and friends have each helped in some way and I would like to recognize them here.

I begin with acknowledging Dr. Charles Thompson, my elementary mathematics methods professor. Dr. Thompson is among the very best of educators and was the one who encouraged me to pursue my doctorate. Though I have not been a student in his classroom for many years, his influences continue to affect me personally and professionally.

I would like to thank Dr. Karen Karp, my advisor and dissertation chair. Dr. Karp has long been a most supportive and encouraging mentor to me. As a student in her class and especially as her doctoral student, Dr. Karp inspired me to think critically and she has always expected me to succeed. I have the deepest respect and admiration for Dr. Karp. My words can never fully express the level of gratitude I have for the innumerable instances of guiding, supporting and teaching I have received from Dr. Karp. I thank Dr. Karp for the role she has played in my academic career.

I would also like to thank my committee members, Drs. Jenny Bay-Williams, E. Todd Brown, Maggie McGatha and Robert Ronau for their support and feedback. I would like to specifically thank Dr. Bay-Williams and Dr. McGatha for their valuable 
guidance as I revised and improved my overall dissertation. I would like to thank Dr. Brown for her help throughout the drafting and revision process but especially for the kindest words of encouragement that always seemed to come at just the right time. I would like to thank Dr. Ronau for offering the particularly challenging exercise in class that sparked the idea for my study. More importantly, Dr. Ronau has offered significant contributions and support at all phases of my dissertation journey. I am especially grateful for all that I have learned from Dr. Ronau.

I would like to thank the following people for the help offered through either support and/or friendship: Sarah Bush, Stefanie Livers and Ryan Higgins. There are three other special people who have been alongside me for this entire journey: Liz Popelka, Shannon Stone and Leah White. I could not have imagined that we would all be here together at the end and I am lucky to call each my friend.

I am truly blessed to have an amazing family and I would like to thank each of my sisters, Dawn, Shannon and Jennifer for their support. I relied on them for lots of help with my children. Each sister also offered encouragement, hugs and truly anything I needed without hesitating.

Finally, I would like to thank my husband and best friend, Johnny. He has been by my side throughout this process. Depending on my need of the moment, he pushed, encouraged, and listened to me all while being a loving father to our two children. Jacob and Brooke are lucky to have a father who would and does traverse to the ends of the earth for them. I am lucky to have a husband who, because of his sacrifice and love for his children and me, afforded me the luxury of accomplishing my goals. 


\section{ABSTRACT \\ UNDERSTANDING THE MEANING OF THE EQUAL SIGN: AN INVESTIGATION OF ELEMENTARY STUDENTS AND TEACHERS

\author{
Victoria Miller Bennett
}

November 30, 2015

The purpose of this study was to investigate the impact of two different policies

for implementing new mathematics standards in two schools, for grades two through five, on student understanding of the equal sign. The study also examined teachers' knowledge of the equal sign. The research used a mixed methods design to explore differences in student understanding of the equal sign as a result of how standards were implemented in two adjoining states with two different decisions as to when the standards would be implemented. This dissertation shares research that may be of interest to teachers, administrators, teacher educators and other stakeholders.

The main constructs under investigation were student understanding of the equal sign, teacher knowledge regarding the equal sign including how it is taught and assessed, and the impact of different implementation schedules for new mathematics standards on student performance on their knowledge of the meaning of the equal sign - a standard that was not previously explicit in either state.

The study was conducted in two adjoining Midwestern states in three separate schools (fifth grade students from one of the states are housed in a middle school building 
for overcrowding reasons and are equivalent to fifth grade students in an elementary setting). Each school as per their state mandates, followed the timeline for new mathematics standards implementation with one school in the fourth year of implementation and the other two (same district) in their first year.

The sample was 1,182 students in second, third, fourth and fifth grade and their forty-two classroom teachers. Students and teachers from the three schools were given the Mathematical Equivalence Knowledge Assessment (MEKA) as a measurement of teacher knowledge and student understanding of the equal sign. Data from teacher interviews and surveys were used to complement findings related to their students' understanding of the equal sign and their classroom practices related to this topic. A hierarchical linear model was used to detect differences between student scores on the MEKA in each school in the two states.

To determine the impact of teacher knowledge of the equal sign on student understanding of the equal sign an unconditional hierarchical linear model and a follow up ANCOVA were conducted using the MEKA results from both teacher and student participants. The same model was also used to detect significant differences found between student scores on the MEKA in one state and student scores on the MEKA from another state where each state followed a different timeline for new standard implementation.

Findings from the study reveal that the different timeline for the implementation of the mathematics standards in the two states appears to have an impact on students' 
understanding of the equal sign and indicated that teacher knowledge was not a significant predictor of student understanding of the equal sign. However, the results also show that state implementation timeline and a students' grade level were significant predictors of student understanding of the equal sign. Through the interviews teachers were also found to have difficulty predicting their students' performance on the MEKA, had varying definitions of the meaning of the equal sign, and many suggested that they did not explicitly teach or assess the meaning of the equal sign. 


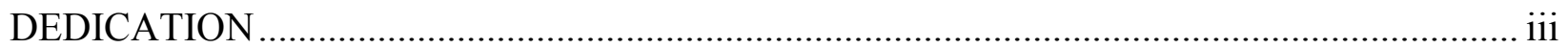

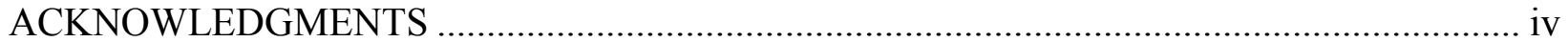

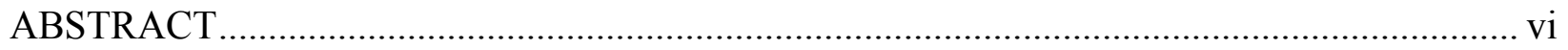

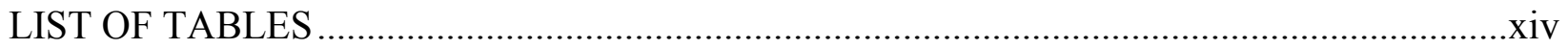

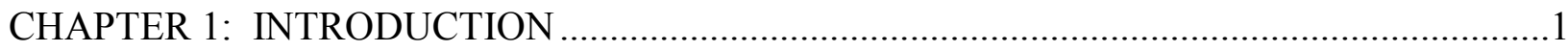

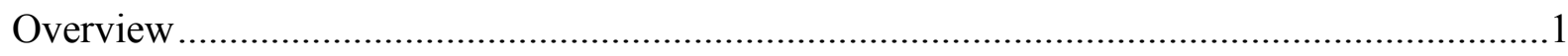

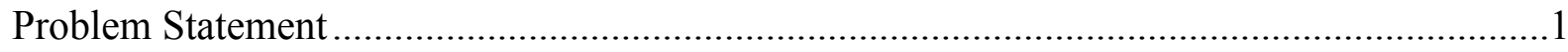

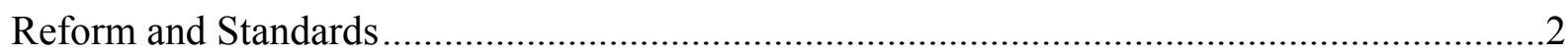

Standards for School Mathematics ...............................................................................

Emphasizing Mathematical Processes and Practices .............................................................5

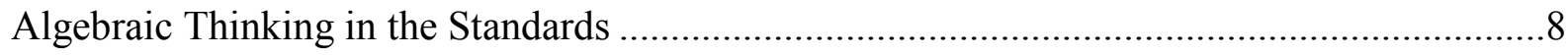

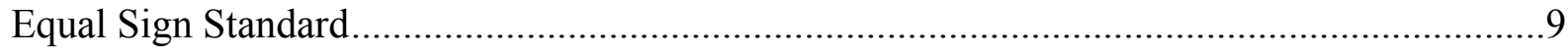

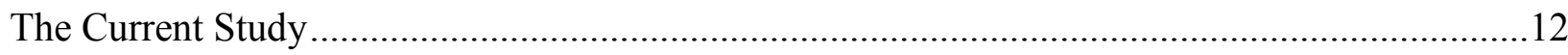

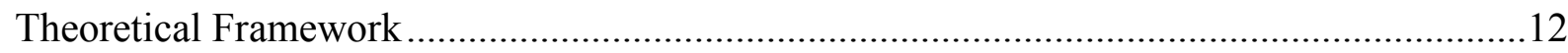

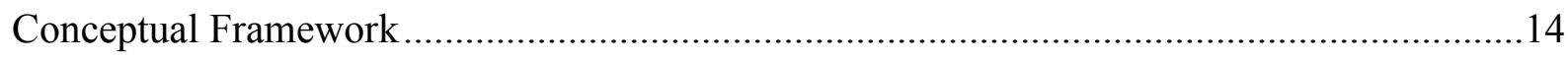

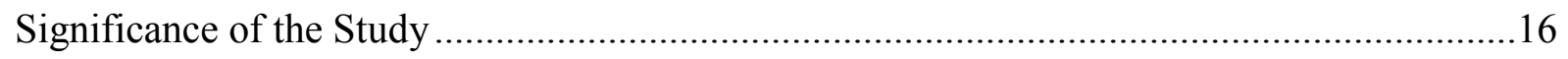

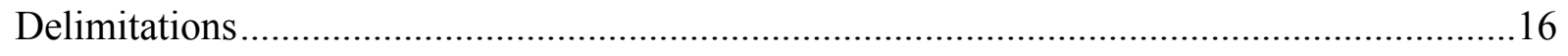

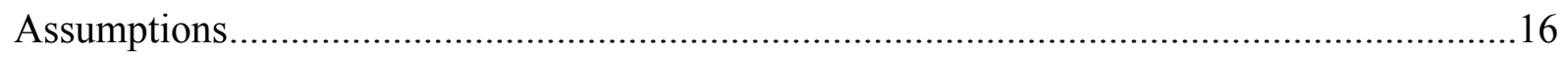

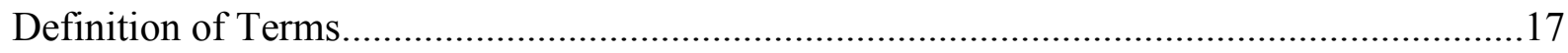

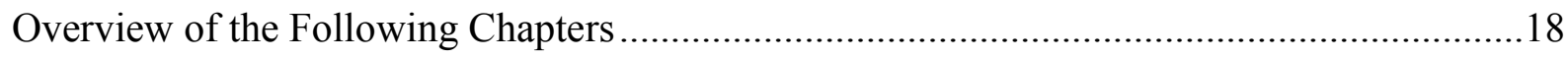

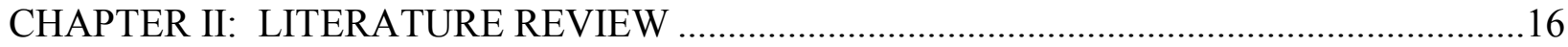


Introduction to the Literature ................................................................................... 19

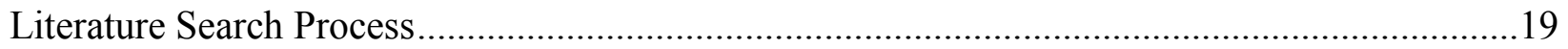

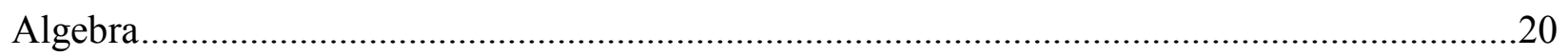

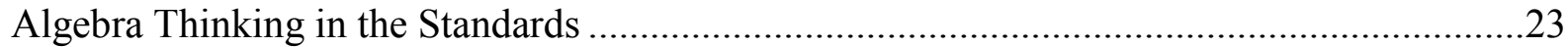

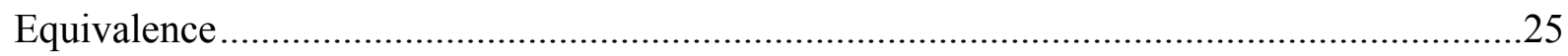

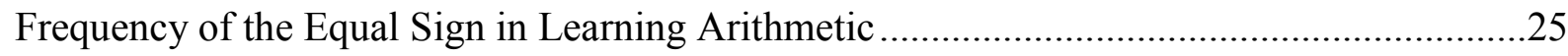

The Meaning of the Equal Sign along a Continuum......................................................26

Students' Misconceptions About the Equal Sign..................................................................29

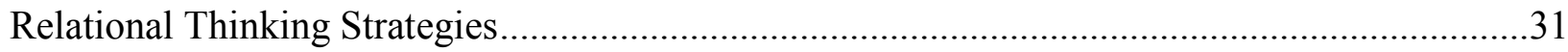

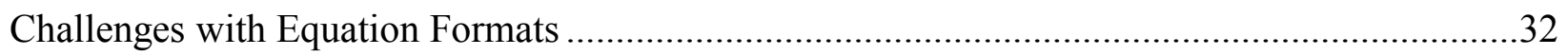

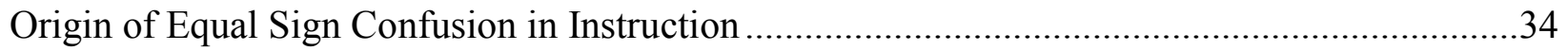

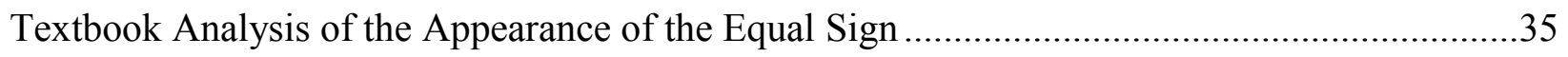

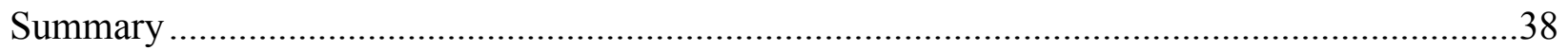

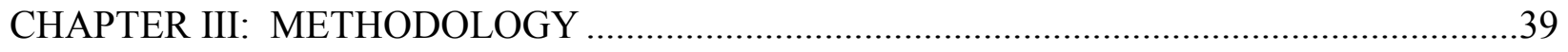

Restatement of Purpose and Research Questions ............................................................39

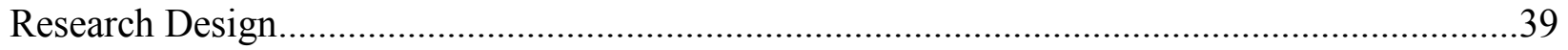

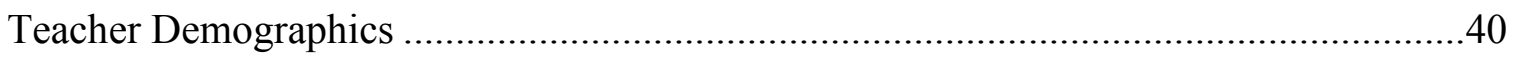

Mathematical Equivalence Knowledge Assessment ................................................40

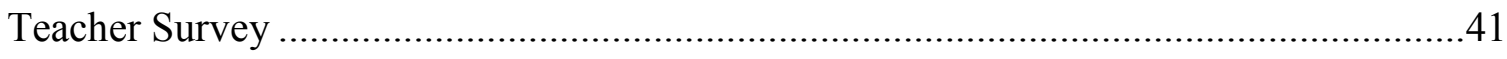

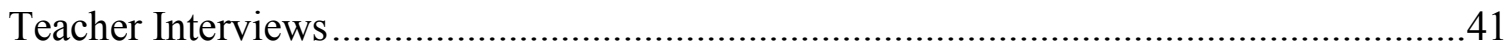

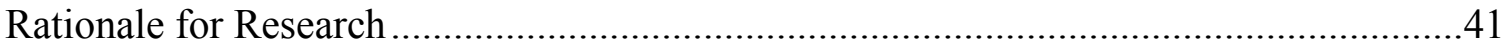

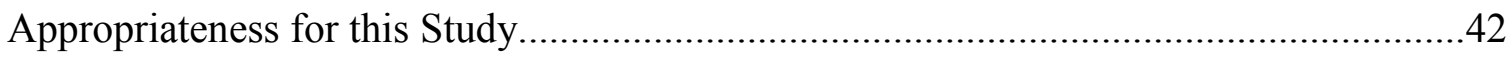

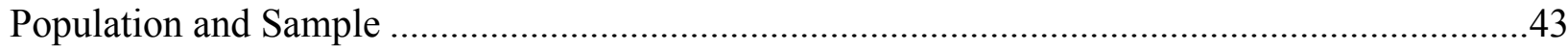




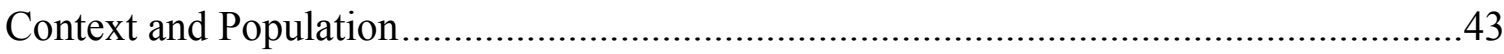

Sample

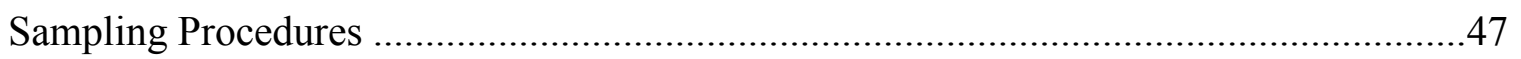

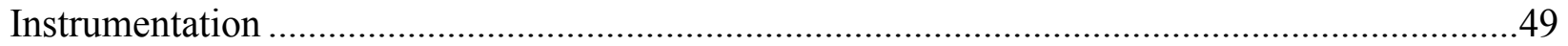

Research Question 1 Instrumentation .......................................................................49

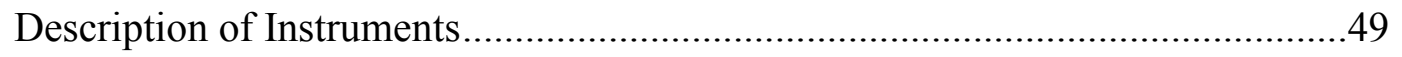

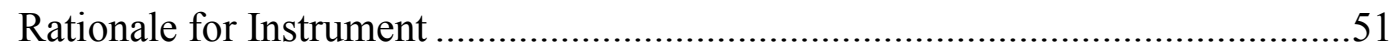

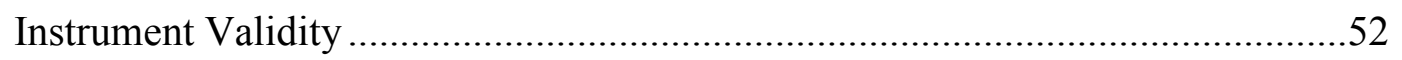

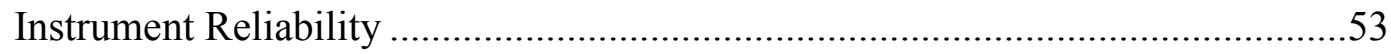

Data Collection Procedures for Research Question 1 ....................................................54

Research Question 2 Instrumentation ...........................................................................56

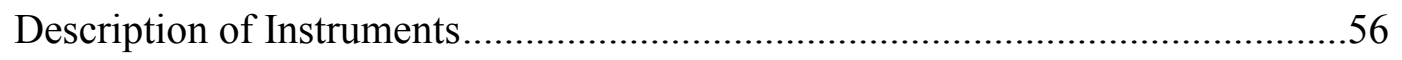

Data Collection Procedures for Research Question Two ................................................59

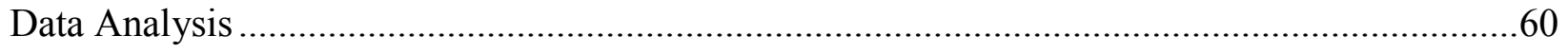

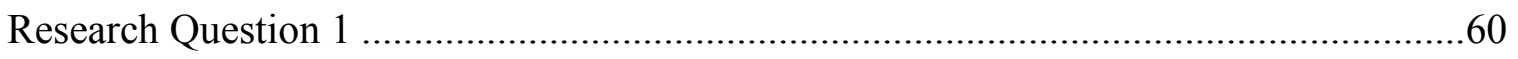

Research Question 2 .............................................................................................61

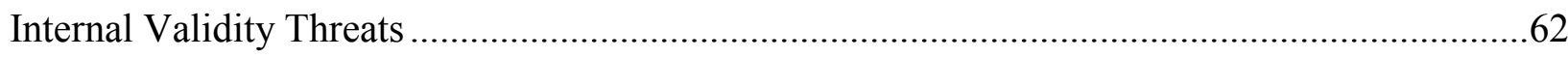

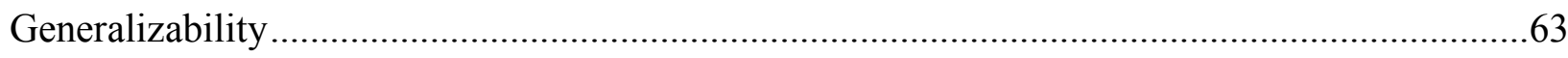

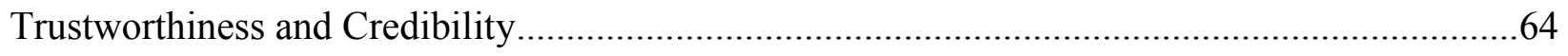

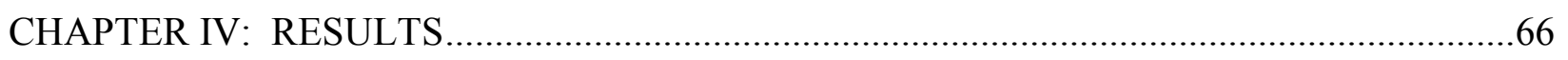

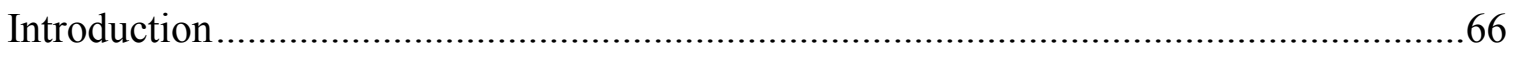

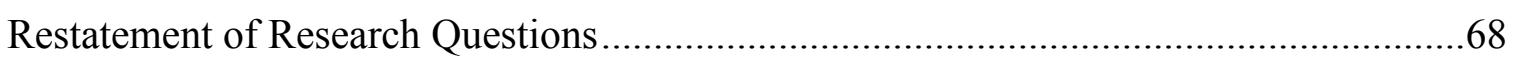

Teacher and Student Scores on the Mathematical Equivalence Knowledge Assessment. 


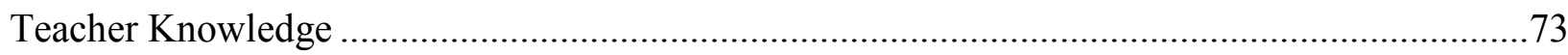

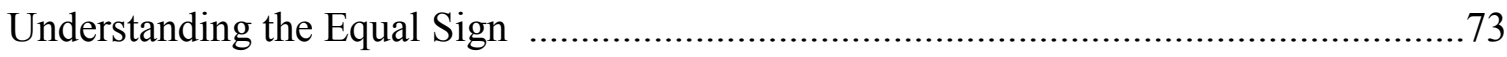

Predicting Student Success ……………………………............................................76

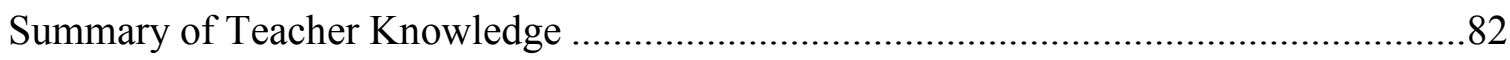

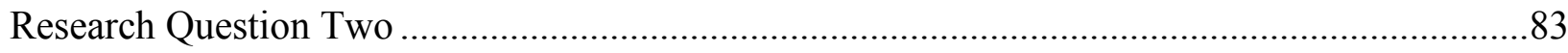

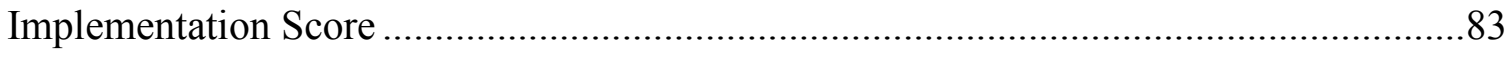

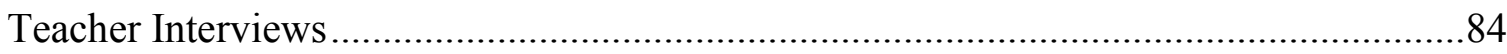

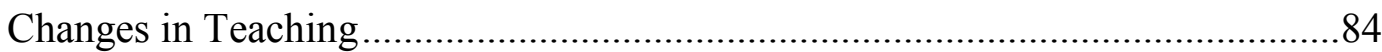

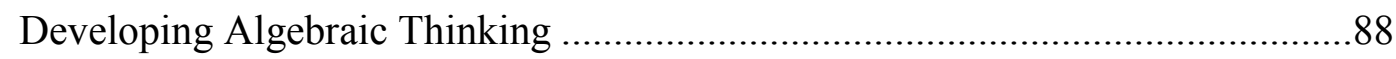

Assessing Student Understanding ......................................................................90

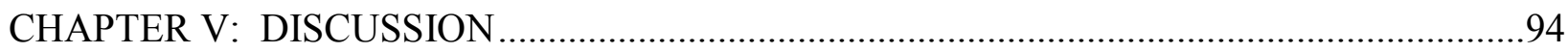

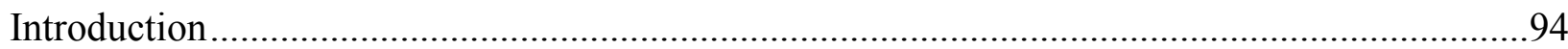

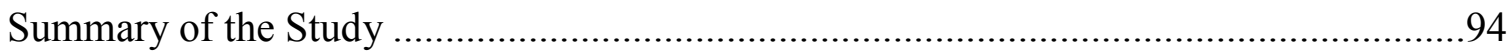

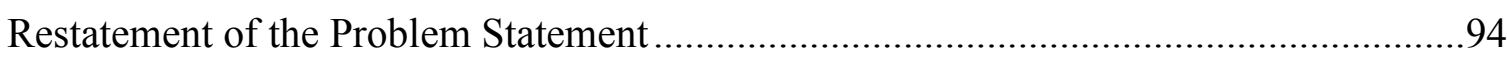

Restatement of Purpose and Research Questions ...........................................................94

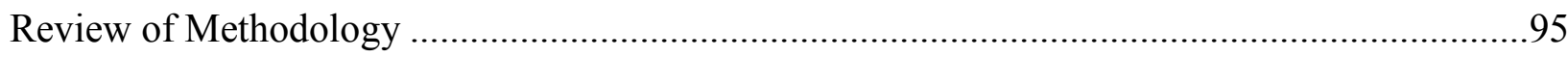

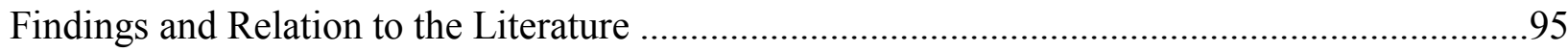

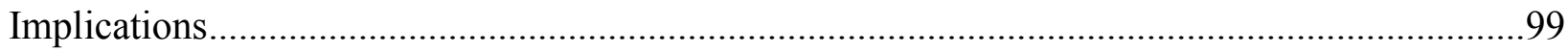

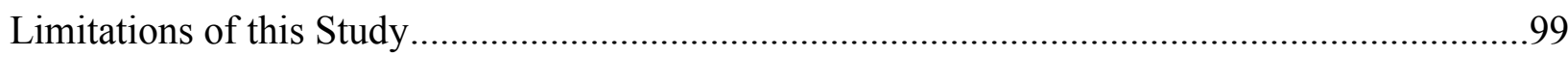

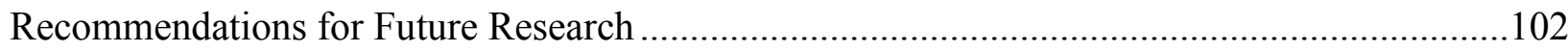

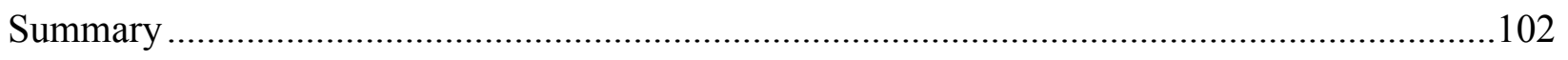

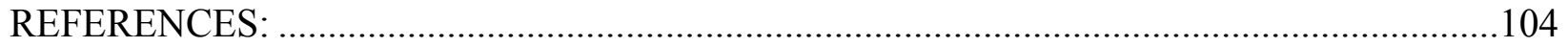


APPENDICES:

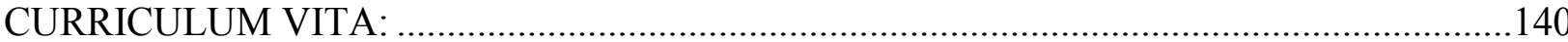




\section{LIST OF TABLES}

1. Comparison of CCSSM Standards for Mathematical Practice, NCTM Process

Standards \& NRC Strands of Mathematical Proficiency.................................................

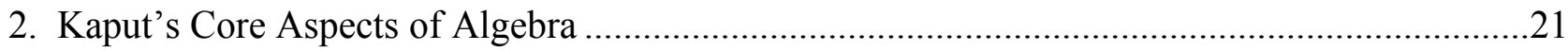

3. NMAP's Critical Foundation of Algebra and Benchmarks ..................................................22

4. Construct Map for Mathematical Equivalence Knowledge ..............................................28

5. Textbook analysis results: Percentages of the Equal Sign in Each Equation Structure

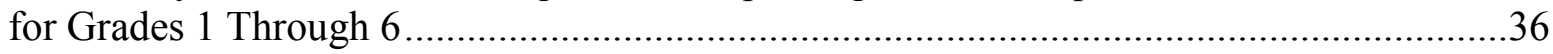

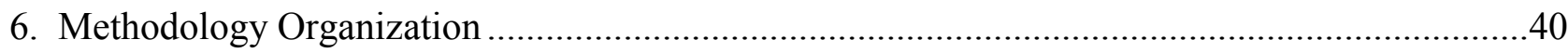

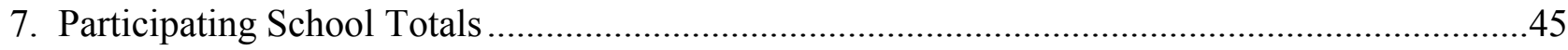

8. Marie Elementary and Thomas Middle Standards Implementation Timeline..........................47

9. Schulz Elementary Standards Implementation Timeline...................................................47

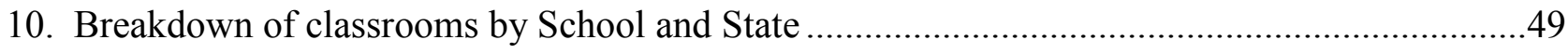

11. Mathematical Equivalence Knowledge Assessment ...................................................51

12. Marie Elementary, Thomas Middle and Schulz Elementary Schools, Grade 2 through

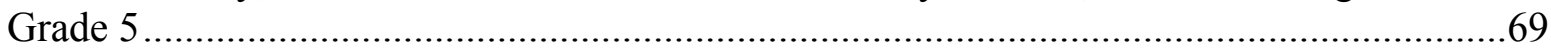

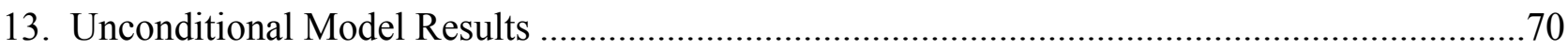

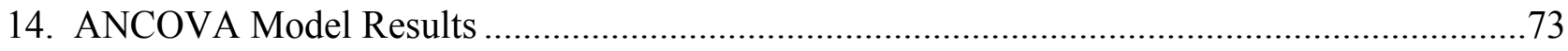

15. Percentages and Examples of Teacher Responses, Understanding the Equal Sign..................74

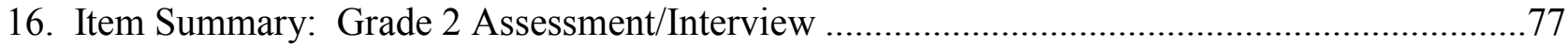

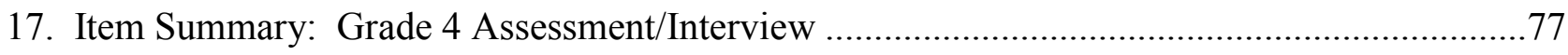


18. Marie Elementary, Grades 2/3, Teacher Predictions/Actual Correct Responses to Selected Items

19. Schulz Elementary, Grades 2/3, Teacher Predictions/Actual Correct Responses to Selected Items

20. Marie Elementary (Grade 4) and Thomas Middle (Grade 5), Teacher Predictions/Actual Correct Responses to Selected Items

21. Schulz Elementary, Grades 4/5, Teacher Predictions/Actual Correct Student

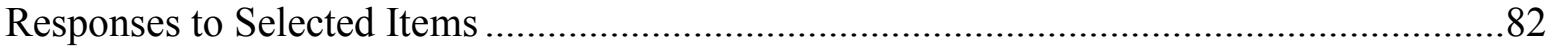

22. Teacher Self-Reports for CCSSM/CCRS Implementation by Practice 84

23. Percentages and Example Teacher Responses, Change as a Result of CCSSM/CCRS Implementation .85

24. Percentages and Examples Teacher Responses, Developing Algebraic Thinking 88

25. Percentages and Example Teacher Responses, Assessing Student Understanding of the Equal Sign 


\section{CHAPTER I}

\section{INTRODUCTION}

\section{Overview of the Study}

The purpose of this study was to investigate the impact of two varied policies for implementing new mathematics standards in two schools, for grades two through five, on student understanding of the equal sign. The study also examined teachers' knowledge of the equal sign including if their knowledge had an impact on students' performance on an assessment about the meaning of the equal sign. The research used a mixed methods design to explore differences in student understanding of the equal sign as a result of how standards were implemented in two adjoining states with two different decisions as to when the standards would be implemented. This introduction presents the problem statement, theoretical framework, purpose, research questions and significance of the study. Lastly, the delimitations, assumptions and definitions are provided.

\section{Problem Statement}

Several studies have documented that students in elementary, middle school, high school and college do not fully understand the equal sign (Jones, Inglis, Gilmore \& Evans, 2013; Kaplan \& Alon, 2004; Knuth, Alibali, Hattikudur, McNeil \& Stephens, 2008; Knuth, Alibali, Hattikudur, McNeil \& Stephens, 2007; Molina, Castro \& Castro, 2007; Rittle-Johnson, Matthews, Taylor \& McEldoon, 2011; Sherman \& Bisanz, 2009; Stephens et al., 2013). Studies have determined that the development of the common student misconception about the equal sign as an operation sign or signal for "the answer 
comes next" (Carpenter, Levi, Franke \& Zeringue, 2001, p. 2) may initially occur in the early years of elementary school (Baroody \& Ginsburg, 1983; Behr, Erlwanger \& Nichols, 1975; Carpenter \& Levi 2000; Erlwanger \& Berlanger 1983; Falkner, Levi \& Carpenter, 1999; Kieran, 1981; Knuth, Stephens, McNeil \& Alibali, 2006; Molina \& Ambrose, 2008). A possible explanation for this confusion includes the limited instructional time devoted to the meaning of the equal sign with elementary students. Students often see and interact with number sentences only presented in canonical form $a$ $+b=\_$or $a-b=\ldots$ (Baroody \& Ginsburg, 1983; Kieran 1981). Other studies have determined that the lack of attention given to this critical topic by textbooks used by students in the classroom may support the incomplete development of student understanding (Asquith, Stephens, Knuth \& Alibali, 2007; McNeil et al., 2006). Finally, preservice and practicing teachers are often unaware of the misconception that students have about the meaning of the equal sign (Asquith et al., 2007; Falkner, Levi \& Carpenter, 1999; Stephens, 2006). Given that teachers are unaware of students' misconception of the equal sign, there is little evidence of explicit instructional time on developing an understanding of the concept and that textbooks do not devote enough pages to support student understanding, changes in instructional practices and school mathematics curricula are necessary if all students are to develop a rich understanding of the meaning of the equal sign.

\section{Reform and Standards}

Efforts to improve mathematics education for students in the United States are not new. In particular, improving the achievement levels demonstrated in mathematics by students in all grades has been a longtime goal for stakeholders including school 
administrators, teachers, parents, and policymakers. Often, assessments are used in education to measure progress and change over time. Begun in 1969, the Nation's Report Card communicates achievement data from the National Assessment of Educational Progress (NAEP). Since 2003, representative samples of students in fourth, eighth and twelfth grades have been taking the reading, mathematics and other content areas NAEP every two years. Included in this mathematics assessment are questions meant to assess student understanding in algebra as well as number properties, data analysis, geometry and measurement. In 2015, the NAEP data show a decrease in average scale scores in mathematics for grades four, and eight. For example, fourth grade students in the national sample earned an average scale score of 240 in 2015. The average scale score for fourth grade students in 2013 was 242. Eighth grade students also dropped from 285 to 282 within the same timeframe. From 2009 to 2013, twelfth grade students' score remained unchanged at 153 (U.S. Department of Education, 2009, 2011, 2013, 2015). Now that the most recent Nation's Report Card documents have shown a decrease in mathematics achievement for students in grades 4,8 and 12, improved mathematics education for all remains a focus.

Another assessment that is considered to be useful in tracking student success is the Trends in International Mathematics and Science Study (TIMSS). Measuring U.S. fourth and eighth grade students' mathematics and science achievement data and making international comparisons are among the purposes of the TIMSS. Mathematical content areas assessed on the TIMSS are algebra as well as number, data, measurement and geometry. According to results in recent years, American fourth grade students have improved their overall mathematics average score from 529 in 2007 to 541 in the year 
2011 (International Association for the Evaluation of Educational Achievement, 2011). American eighth grade students improved from 508 in 2007 to 509 in the year 2011 (International Association for the Evaluation of Educational Achievement, 2011). Achievement data from the TIMSS support an overall improved performance for American students in mathematics but may not be a complete indication of the current status of mathematics education in the United States. Unlike the more recent Nation's Report Card, TIMSS data does not reflect what has happened in terms of student achievement since the implementation of the Common Core State Standards for Mathematics.

\section{Standards for School Mathematics}

In light of the insights gleaned from TIMSS administrations and the NAEP, the National Council of Teachers of Mathematics (NCTM) published Principles and Standards for School Mathematics in 2000. As one way to improve mathematics education for all students, this NCTM publication sought to articulate high standards for all students. Particular learning goals in the content areas of algebra as well as number and operations, geometry, measurement and data analysis and probability for students at each grade level. They also outlined what they called process standards in the areas of problem solving, reasoning and proof, communication, connections and representation were outlined (NCTM, 2000). Developed after the Principles and Standards for School Mathematics, NCTM published Curriculum Focal Points (2006), which further delineates the specific mathematical content to be learned pre-K through eighth grade by designating topics and concepts that should be mastered at individual grades. 
Continuing with efforts to improve mathematics education for all students, the Council of Chief State School Officers published Common Core State Standards for Mathematics (CCSSM) (National Governors Association (NGA), 2010). The CCSSM document is similar to Curriculum Focal Points in its organizational structure based on individual grade level expectations. The CCSSM were developed using input from many extant sources including NCTM's PSSM as well as Mathematics Learning in Early Childhood: Paths Toward Excellence and Equity from the National Research Council (NRC) (2009). The release of CCSSM signaled a call for rigorous content and aligned with NCTM's process standards and NRC's strands of mathematical proficiency in their Standards for Mathematical Practice. The CCSSM positions the Number and Operations in Base Ten domain and the Operations and Algebraic Thinking domain as part of the kindergarten through grade five expectations (Blanton, Levi, Crites \& Dougherty, 2011). Taken together, PSSM and CCSSM clearly call for mathematics instruction pre-K through grade 12 that is intentional and coherent and that includes the concept of equality and its representation by an equal sign.

\section{Emphasizing Mathematical Processes and Practices}

Three major documents outline the important content expectations as well as a set of processes or practices that students must demonstrated to develop mathematical proficiency. When putting the new mathematics standards into action in any state it is these practices and processes that signal the full implementation of the standards. The CCSSM outlines eight Standards for Mathematical Practice referred to as "varieties of expertise that mathematics educators at all levels should seek to develop in their students" (NGA, 2010, Introduction). The NCTM standards for prekindergarten through 
grade 12 in the PSSM specify five processes which children must experience in order to learn mathematics (referred to as the Process Standards). In these Process Standards, NCTM suggests that all students engage in: problem solving, reasoning and proof, communication, connections and representation (NCTM, 2000). Finally, Adding It Up (National Research Council, 2001) specifies five strands of mathematical proficiency as: "conceptual understanding, procedural fluency, strategic competence, adaptive reasoning and productive disposition" (p. 116).

The organization and comparison chart for CCSSM Standards for Mathematical Practice, NCTM Process Standards and NRC Strands of Proficiency shown in Table 1 has been adapted from these three separate sources (Hull, Harbin Miles, \& Balka, 2012, p.50; NCTM, 2012, p. 12; Van de Walle, Karp, \& Bay-Williams, 2013, pp. 26-28). Also the descriptions shown in Table 1 "represent what students are doing as they learn mathematics" (NCTM, 2014, p. 8).

Starting with the Standards for Mathematical Practice, each practice is specific in terms of what students should be doing and/or developing as the learning of mathematics occurs. In the columns that follow, connections are made to both the more general NCTM Process Standards and NRC Strands of Mathematical Proficiency. Used in the context of teaching children in a mathematics classroom, children who are engaged in inquiry-based problem solving activities should also be communicating, considering and using multiple representations, and developing a positive outlook toward working hard and persevering in mathematics (productive disposition). 
Table 1

Comparison of CCSSM Standards for Mathematical Practice, NCTM Process Standards \& NRC Strands of Mathematical Proficiency

\begin{tabular}{|c|c|c|}
\hline $\begin{array}{l}\text { Standards for Mathematical Practice } \\
\text { (NGA, 2010) }\end{array}$ & $\begin{array}{l}\text { Process Standards } \\
\text { (NCTM, 2000) }\end{array}$ & $\begin{array}{l}\text { Strands of Proficiency } \\
\text { (NRC, 2001) }\end{array}$ \\
\hline $\begin{array}{l}\text { 1. Make sense of problems and persevere in } \\
\text { solving them }\end{array}$ & $\begin{array}{l}\text { Communication } \\
\text { Problem solving } \\
\text { Representation }\end{array}$ & $\begin{array}{l}\text { Conceptual understanding } \\
\text { Productive disposition }\end{array}$ \\
\hline 2. Reason abstractly and quantitatively & $\begin{array}{l}\text { Problem solving } \\
\text { Reasoning and Proof }\end{array}$ & $\begin{array}{l}\text { Adaptive reasoning } \\
\text { Procedural fluency }\end{array}$ \\
\hline $\begin{array}{l}\text { 3. Construct viable arguments and critique the } \\
\text { reasoning of others }\end{array}$ & $\begin{array}{l}\text { Communication } \\
\text { Reasoning and proof } \\
\text { Representation }\end{array}$ & Adaptive reasoning \\
\hline 4. Model with mathematics & $\begin{array}{l}\text { Connections } \\
\text { Problem solving } \\
\text { Reasoning and proof } \\
\text { Representation }\end{array}$ & $\begin{array}{l}\text { Conceptual understanding } \\
\text { Strategic competence }\end{array}$ \\
\hline 5. Use appropriate tools strategically & $\begin{array}{l}\text { Problem solving } \\
\text { Representation }\end{array}$ & Strategic competence \\
\hline 6. Attend to precision & $\begin{array}{l}\text { Communication } \\
\text { Problem solving }\end{array}$ & Procedural fluency \\
\hline 7. Look for and make use of structure & $\begin{array}{l}\text { Connections } \\
\text { Problem solving } \\
\text { Reasoning and proof }\end{array}$ & $\begin{array}{l}\text { Conceptual understanding } \\
\text { Procedural fluency }\end{array}$ \\
\hline $\begin{array}{l}\text { 8. Look for and express regularity in repeated } \\
\text { reasoning }\end{array}$ & Problem solving & $\begin{array}{l}\text { Adaptive reasoning } \\
\text { Productive disposition }\end{array}$ \\
\hline
\end{tabular}


Common among the intent of the three documents is a strong recommendation to fully integrate the mathematical practices, process standards and strands of mathematical proficiencies into daily lessons so that students learn the important mathematics content outlined in the standards documents. Recommendations also include for teachers to help students make connections between the CCSS Standards for Mathematical Practice and the Standards for Mathematical Content. According to CCSSM (NGA, 2010), "expectations that begin with the word "understand" are often especially good opportunities to connect the practices to the content" (NGA, 2010, p. 8). Skemp (2006) used the terms "relational" and "instrumental" to describe types of understanding. When students become engaged in the Standards for Mathematical Practice the type of understanding likely to be developed is "relational" and students are therefore more likely to retain and apply the knowledge across multiple settings. Principles to Action (NCTM, 2014) specifies that all students be engaged in the processes collectively known as the mathematical practices as part of effective mathematics learning. Due to the importance of the Standards for Mathematical Practice for effective implementation of the CCSSM, they shall be used as a proxy for the level of fidelity of implementation as documented in the teacher self-reported measure Standards of Student Practice in Mathematics Proficiency/ Process Standards for Mathematics Proficiency survey.

\section{Algebraic Thinking in the Standards}

Algebraic thinking is included as early as pre-kindergarten as a mathematics expectation that students know and be able to do (NGA, 2010; NCTM, 2006). Although Principles and Standards for School Mathematics and Curriculum Focal Points highlight 
the importance of algebraic thinking and algebra in the early grades by including the algebra standard in grades Pre-kindergarten through grade 12 mathematics, prior to the CCSSM, the expectation for students to understand the equal sign was not explicitly addressed. Understanding of the equal sign is however, a specifically stated standard for first grade students as suggested by the CCSSM (NGA, 2010, p. 15). Algebraic thinking is a continuous strand woven throughout the kindergarten through grade five standards in the Number and Operations and Algebraic Thinking domain. Individual CCSSM standards do not repeat but they build upon one another. The kindergarten through fifth grade strand of operations and algebraic thinking of this domain becomes the Expressions and Equations domain for students in grades six through eight. This focus on the role of the equation places further emphasis upon the essential understanding of the meaning of the equal sign.

\section{Equal Sign Standard}

An appropriate foundation must be established in the elementary years in order to obtain future success in higher level mathematics. Progressing from the early stages of number recognition and counting to the more sophisticated nature of algebra and other high school mathematics courses requires opportunities and engagement with high quality mathematics instruction that develops algebraic thinking. For example, application of the complete understanding of the meaning of equal sign is requisite to student achievement in algebra (Molina \& Ambrose, 2006).

In order for algebraic reasoning to develop in children, a conceptual understanding of equality and symbolic algebraic notation is critical (Blanton et al., 2011; Falkner, Levi \& Carpenter, 1999). Although children likely have many informal 
experiences with equality before entering kindergarten, they often encounter their first formal experiences with equality and the symbol for it in the context of arithmetic. Through experience with different types of equations, including open number sentences and equations with the unknown situated on the left and right of the equal sign, a relational view of the equal sign is supported (Blanton et al., 2011). Specific problem types (common addition and subtraction situations) that are to be used in instruction with elementary students and their corresponding equations are provided in the glossary of CCSSM. For example, first grade students should "use addition and subtraction within 20 to solve word problems involving situations of adding to, taking from, putting together, taking apart, and comparing, with unknowns in all positions, e.g., by using objects, drawings, and equations with a symbol for the unknown number to represent the problem" (NGA, 2010, p.15). However, Behr, Erlwanger and Nichols (1976) caution that exposure alone to the "various forms of equality sentences" will not suffice in helping children develop a complete understanding of the equal sign (p. 10).

The CCSSM document explicitly brings the importance of students' understanding of the meaning of the equal sign to the forefront. This is different from previous standard documents that did not state a direct learning target related to knowledge of the meaning of this symbol and the use of multiple equation formats. When reading CCSSM, "using the equal sign consistently and appropriately" first appears in the sixth standard for Mathematical Practice: Attend to precision (NGA, 2010, p. 7). Numerous other references to equality and equations are present throughout the document meant to specify requirements for students in kindergarten through grade twelve. From primary school through the end of high school, students should be 
developing a lasting understanding of the equal sign as a convention used to communicate relationships in mathematics (NGA, 2010). In other words, students should apply what is learned about equivalence at an early age and connect it to new experiences and problem solving situations like those presented in courses such as Algebra 1 and beyond.

Students' shallow or surface level demonstration of their understanding of the equal sign may not be initially apparent even to an especially astute teacher (Falkner, Levi \& Carpenter, 1999). Yet as a more sophisticated type of thinking about the equal sign is needed in order to succeed in higher-level mathematics, such as in middle school where students transition toward more complex/abstract reasoning with expressions and equations, this misconception of the equal sign may become more problematic and apparent to teachers. So the expectation of the development of a relational view and complete understanding of the equal sign is necessarily situated early in the standards for young elementary students.

The early exposure to the equal sign and multiple equation formats may help students to develop an understanding that is more robust over time. In other words, the process of developing a complete understanding of the formal language and representations of mathematics such as the equal sign begins before students are formally engaged with arithmetic exercises - often prior to children enter kindergarten (Carpenter, Franke \& Levi, 2003). Young students often encounter numerous mathematical ideas such as equivalence and its convention, the equal sign, at home and through shared experiences with books, calculators and environmental print. 


\section{The Current Study}

From the literature, it is known that having an incomplete understanding of the equal sign can be problematic (Knuth, Stephens, McNeil \& Alibali, 2006). This incomplete understanding has been well documented across grades and ages prior to the release of the explicit standard regarding the equal sign in the CCSSM (Knuth, Alibali, Hattikudur, McNeil \& Stephens, 2008; Molina, Castro \& Castro, 2009; Rittle-Johnson, Matthews, Taylor \& McEldoon, 2011; Stephens et al., 2013). Few studies have been conducted with elementary students since 2011 which was the year some states started to implement the CCSS (Rittle-Johnson et al., 2011; Stephens et al., 2013). Knowing about the impact of the CCSSM on elementary students' understanding can guide elementary teachers and teacher educators to make decisions about giving explicit attention to teaching and learning the equal sign through intentional instruction designed to support full understanding of the meaning of the equal sign. Also teachers of older students can begin to see the need to assess their students' knowledge of the meaning of the equal sign, particularly if the new standards in mathematics were not implemented when they were in first grade.

\section{Theoretical Framework}

The theoretical framework used for this study is adopted from the construct map for mathematical equivalence knowledge developed by Rittle-Johnson, Matthews, Taylor and McEldoon (2011). The construct map for mathematical equivalence knowledge specifies four continuous levels of understanding that range from less sophisticated to more advanced knowledge. The four levels are: rigid operational, flexible operational, basic relational and comparative relational see Figure 1. Students described as having 
rigid operational view of the equal sign only define the equal sign operationally. Children who demonstrate a comparative relational level of understanding of the equal sign can successfully compare expressions on two sides of the equal sign and recognize a relational definition as the best definition for the meaning of the equal sign. (RittleJohnson, Matthews, Taylor \& McEldoon, 2011). They also developed an instrument called the Mathematical Equivalence Knowledge Assessment (MEKA) which is designed to measure children's understanding of the equal sign across grade levels two through six and is also aligned with this construct map.

Figure 1. Rittle-Johnson et al.'s Construct Map for Mathematical Equivalence Knowledge

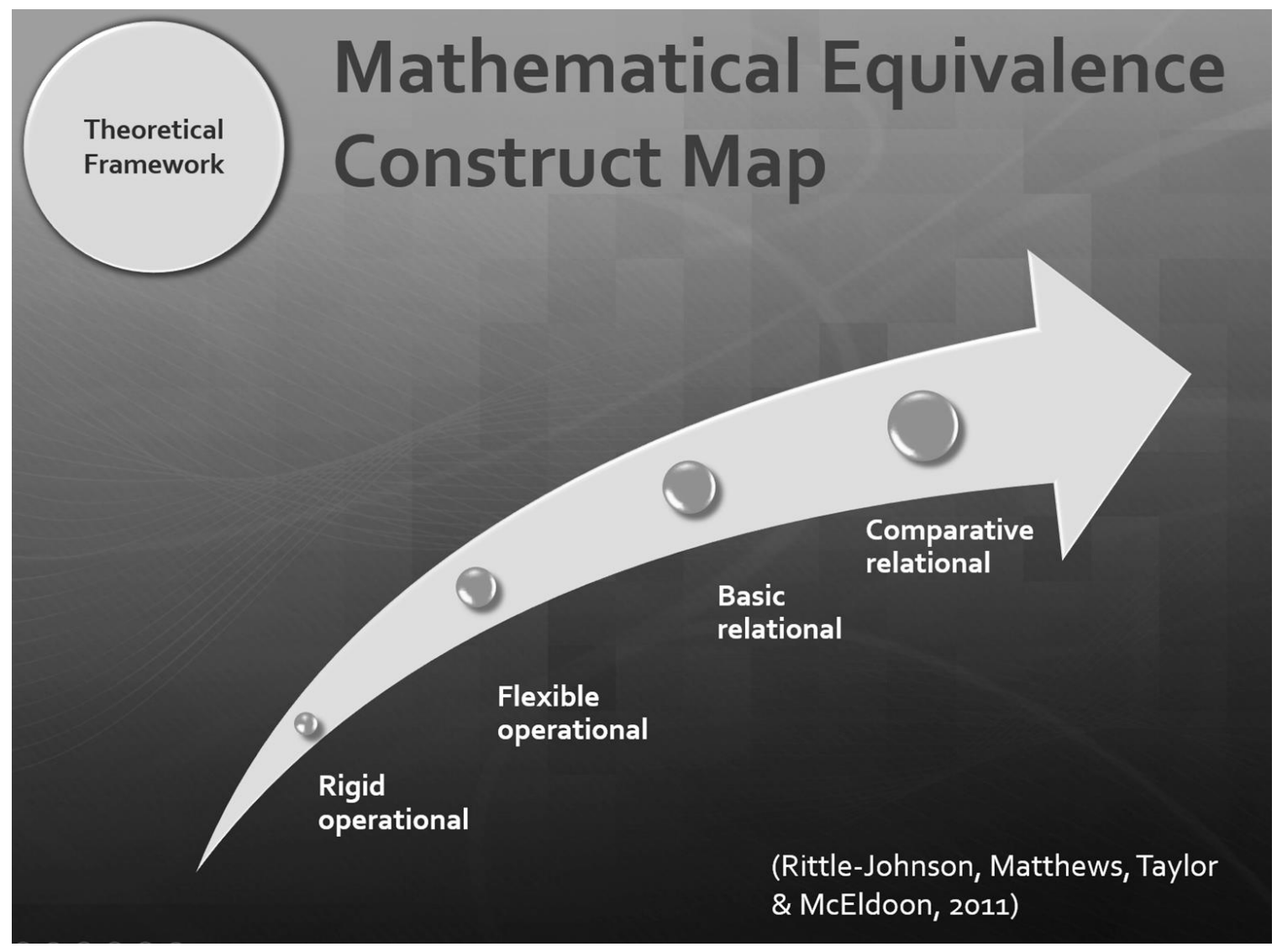




\section{Conceptual Framework}

The identified constructs in this study are: teacher knowledge of the equal sign including its definition, student understanding of the equal sign, teacher understanding of instructional practices and assessments related to the equal sign, and classroom implementation of new state standards. Figure 2 is a visual representation of this study's conceptual framework representing the constructs, variables and relationships. The main construct measured in the study is student understanding of the meaning of the equal sign, represented by the oval on the right side of the diagram. Teacher knowledge of the equal sign is also represented by an oval. The arrow that goes from teacher knowledge to student understanding indicates the possible influence that teacher knowledge has upon student understanding. The three rectangles in the diagram represent measures that were used to collect data on the constructs.

The level of implementation of current state standards may be influenced by the standards themselves and possibly individual teacher knowledge of how to teach and assess students' understanding of the equal sign. The teachers' understanding of a standard (CCSSM/CCRS), for example, potentially influences implementation and teachers refer to their knowledge of standards when deciding what to teach or assess. Teachers have direct contact with the CCSSM/CCRS therefore, CCSSM/CCRS implementation necessitates understanding CCSSM/CCRS. Finally, the level of explicit presentation of a standard during their implementation may have some impact upon student understanding of the equal sign. 
Figure 2. Conceptual Framework

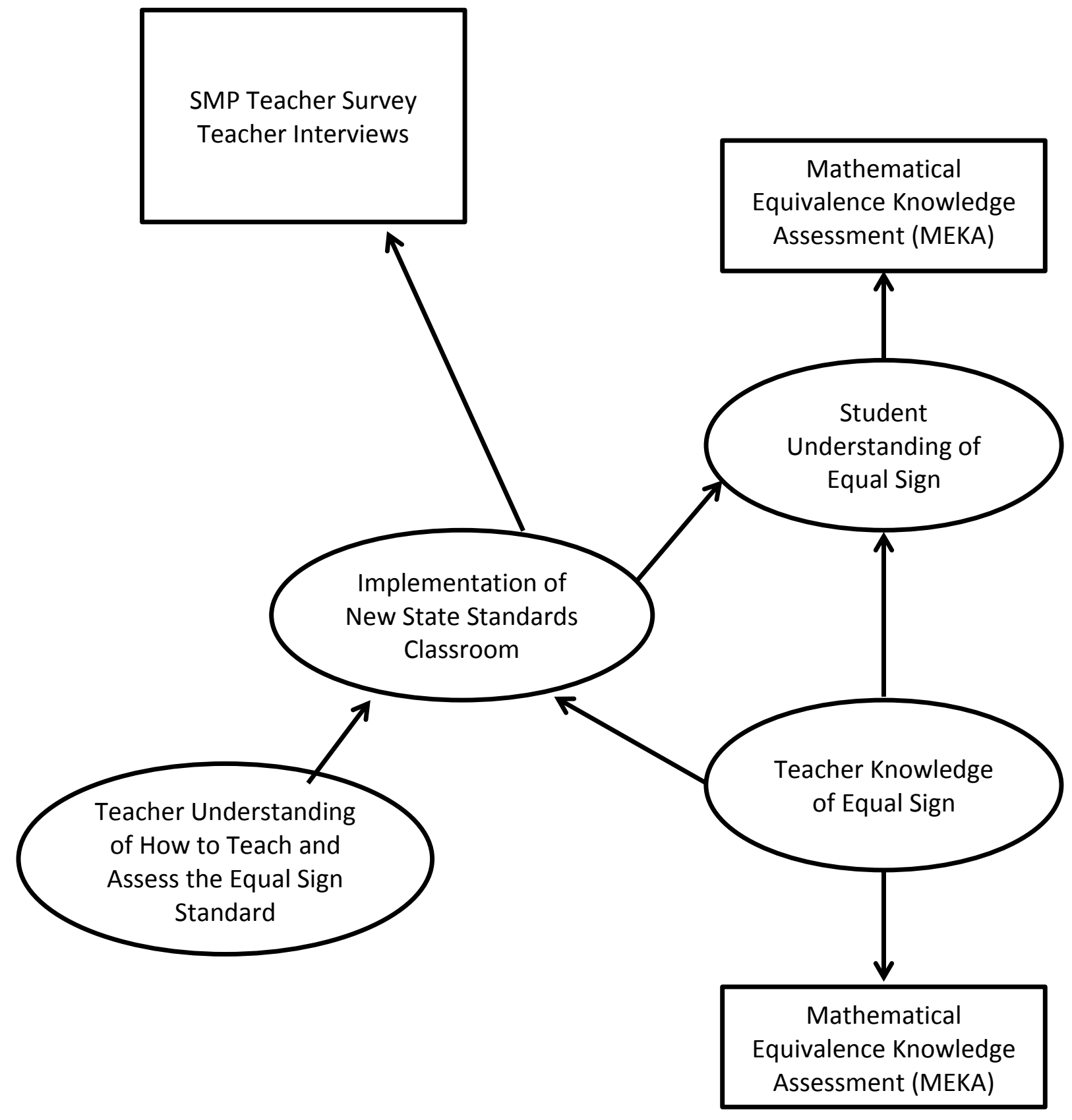




\section{Significance of Study}

The results of this study have potential to provide vital information about teacher knowledge of the equal sign including how to teach and assess it as well as student understanding of the equal sign. Further, the impact of the presence or lack of classroom level implementation due to varied timelines of implementation of the state standard related to the meaning of the equal sign may be determined. The primary audience for the findings of this study includes elementary mathematics teachers. The secondary audience for the findings of this study includes school administrators, policy makers, and teacher educators.

\section{Delimitations}

This study took place during the spring semester of the 2015 academic school year. The location of the study was two elementary schools and one middle school that housed fifth grade located in two adjoining Midwestern states in the United States. The

three schools are considered neighborhood schools situated in rural/suburban areas. The sample for this study included 1,182 students in grades two, three, four and five. The sample included 41 teachers with some teachers instructing two classes at two grade levels. Overall, the results of the study could be generalizable to same-age students attending similar public elementary schools and their teachers.

\section{Assumptions}

This study was based on three assumptions. First, the sample would be representative of other elementary students attending public elementary schools and teachers teaching at public elementary schools. The second assumption was that the 
participants answered all assessment questions to the best of their ability. Finally, the third assumption was that the responses from the teacher participants would be accurate and not merely socially desirable answers.

\section{Definition of Terms}

Computational form: The situation is translated into an equation that has the unknown amount and no other quantities on the right of the equal sign (Caldwell, Karp \& BayWilliams, 2011)

Equal sign: The symbol used to denote equivalence between two expressions (Ginsburg, 1976)

Equation: A mathematical statement that uses an equal sign to show that two quantities are equivalent (Blanton, Levi, Crites, Dougherty, \& Zbiek, 2011)

Equivalence: The principle that two sides of an equation represent the same quantity (Rittle-Johnson \& Alibali, 1999)

Expression: Representation of a single quantity or amount (Blanton, Levi, Crites, Dougherty, \& Zbiek, 2011)

Mathematical equivalence: Values on either side of the equal sign are the same (RittleJohnson, Matthews, Taylor and McEldoon, 2011)

Misconception: Faulty reasoning due to incomplete or incorrect understanding of a mathematical concept (Confrey, 1987)

Numerical equivalence: Sets are equal based on quantity (Johnson et al., 2011) Operational view of the equal sign: interpreting equal sign as command to find total or answer (McNeil et al., 2006) 
Relational view of the equal sign: the equal sign represents a relation between two expressions on either side of the equal sign (Carpenter, Franke, \& Levi, 2003) Semantic equation: An equation with the order of quantities aligned with the order of actions as presented in the word problem (Caldwell et al., 2011)

\section{Overview of the Following Chapters}

In Chapter II a review of the literature is provided concerning algebra, algebraic thinking and students' misconception of the equal sign. Chapter III outlines the research design and methodology of the study along with the instruments to be used for data gathering, implementation procedures, and the data analysis. Chapter IV presents the data and the results of the study. Chapter V comprises the conclusions, discussion, limitations and recommendations for future research. 


\section{CHAPTER II}

\section{LITERATURE REVIEW}

\section{Introduction to the Literature}

This study examined the impact of teacher knowledge of the equal sign on student understanding of meaning of the equal sign. The study also investigated the impact of classroom implementation of the new state standards on student understanding of the meaning of the equal sign at two schools on different implementation schedules for the new mathematics standards. This chapter will review the literature regarding students' understanding of the meaning of the equal sign.

\section{Literature Search Process}

Online databases such as EBSCO Academic Search Premier, Education Resources Information Center (ERIC) and Proquest Research Library were used to find literature for review. Search terms and/or phrases used: equal(s), equality, equivalence, equal(s) sign, algebra, algebraic thinking, learning, elementary mathematics, operational, relational, elementary mathematics students and misconceptions, misconceptions, errors and arithmetic. Google Scholar was also used to locate various peer-reviewed journal articles such as those found in Teaching Children Mathematics (TCM) and the Journal for Research in Mathematics Education (JRME). 


\begin{abstract}
Algebra
Historically speaking, algebra has been a separate course taken at some point after the completion of a "6- to 8-year computational arithmetic curriculum" (Kaput, 2008, p. 5). In more recent years, algebra integration in the early grades and the presence of the development of algebraic thinking skills throughout the pre-kindergarten to grade eight standards is expected for all (NCTM, 2000; NGA, 2010). However, in order for students to successfully learn algebra, Kaput identified four goals for "rethinking and reworking algebra in early grades mathematics" (2008, p. 6).

1. To add a degree of coherence, depth, and power typically missing in K-8 mathematics.

2. To ameliorate, if not eliminate the most pernicious and alienating curricular element of today's school mathematics: late, abrupt, isolated, and superficial high school algebra courses.

3. To democratize access to powerful ideas by transforming algebra from an inadvertent engine of inequity to a deliberate engine of mathematical power.

4. To build conceptual and institutional capacity and open curricular space for new $21^{\text {st }}$-century mathematics desperately needed at the secondary level, space locked up by the $19^{\text {th }}$-century high school curriculum now in place.
\end{abstract}

(Kaput, 2008, p. 6)

The reasoning behind the necessary changes to algebra instruction may be explained by numerous factors such as low success rates as well as student misconceptions created partly as a result of the separated nature of arithmetic and 
algebra. Some of the misconceptions related to algebra that are documented in the research literature are regarding such topics as: variable (Clement, 1982), negative numbers (Vlassis, 2004), exponential expressions (Cangelosi, Madrid, Cooper, Olson \& Hartter, 2013), and the equal sign (Behr, Erlwanger \& Nichols, 1980). Implementing changes in algebra instruction necessitates having a precise description of algebra. Kaput (2008) describes algebra as having two core aspects that are "embodied" in three separate strands (p. 11) as shown in Table 2.

Table 2

Kaput's Core Aspects of Algebra

The Two Core Aspects

(A) Algebra as systematically symbolizing generalizations of regularities and constraints.

(B) Algebra as syntactically guided reasoning and actions on generalizations expressed in conventional symbol systems.

Core Aspects A \& B are Embodied in Three Strands

1. Algebra as the study of structures and systems abstracted from computations and relations, including those arising in arithmetic (algebra as generalized arithmetic) and in quantitative reasoning.

2. Algebra as the study of functions, relations, and joint variation.

3. Algebra as the application of a cluster of modeling languages both inside and outside of mathematics.

(Kaput, 2008, p. 11)

According to the National Mathematics Advisory Panel (NMAP), "the mathematics that children learn from preschool through the middle grades provides the basic foundation for algebra" (2008, p. 17). The NMAP studied multiple data sources 
such as grades 1-8 curricula from high achieving countries including Singapore, Japan and Korea, NCTM's Curriculum Focal Points and various curriculum frameworks in order to make a recommendation for essential skills and concepts to be learned prior to taking formal algebra courses. The NMAP also considered the "structure of mathematics itself" (2008, page 17) before proposing three clusters of concepts and skills which they called the Critical Foundation of Algebra. These proposed concepts and skills represent essential mathematics that should be learned by students before enrolling in algebra courses like Algebra I, for example. See Table 3. The NMAP recommends that "conceptual understanding, computational fluency and problem-solving skills" be simultaneously developed rather than as stand-alone entities (2008, p. 19). Finally, the NMAP devised benchmarks of proficiency to help establish pacing guidelines for the critical skills and concepts (2008, p. 20).

Table 3

NMAP's Critical Foundation of Algebra and Benchmarks

\begin{tabular}{|c|c|c|}
\hline Cluster & Summary of Concepts and Skills & Benchmarks \\
\hline $\begin{array}{l}\text { Fluency with Whole } \\
\text { Numbers }\end{array}$ & $\begin{array}{l}\text { Robust sense of number including place } \\
\text { value, ability to compose and } \\
\text { decompose whole number, meaning of } \\
\text { the basic operations, use of } \\
\text { commutative, associative, and } \\
\text { distributive properties, computational } \\
\text { facility, etc. }\end{array}$ & End of grades 3 and 5 \\
\hline $\begin{array}{l}\text { Fluency with } \\
\text { Fractions }\end{array}$ & $\begin{array}{l}\text { Thorough understanding of positive and } \\
\text { negative fractions, locate fractions on a } \\
\text { number line, represent and compare } \\
\text { fractions, decimals and related percents, } \\
\text { operations with fractions, describe rates, } \\
\text { proportionality and probability, } \\
\text { introduction to use of symbolic notation } \\
\text { and concept of generality. }\end{array}$ & $\begin{array}{l}\text { End of grades 4, 5, 6, } \\
\text { and } 7\end{array}$ \\
\hline $\begin{array}{l}\text { Particular Aspects } \\
\text { of Geometry and }\end{array}$ & $\begin{array}{l}\text { Experience with similar triangles, } \\
\text { analyze properties of two and three- }\end{array}$ & End of grade 5, 6 and 7 \\
\hline
\end{tabular}




$\begin{array}{ll}\text { Measurement } & \text { dimensional shapes using formulas to } \\ \text { determine perimeter, area, volume, and } \\ \text { surface area. Find unknown lengths, angles and } \\ \text { areas. }\end{array}$

(U.S. Department of Education, 2008, p. 17-20)

Algebra has long been labeled as a gatekeeper for advanced high school mathematics courses. In turn, the opportunity for students taking advanced mathematics courses at the college level depends on their success in mathematics at the high school level. Students' future success in mathematics depends on having a strong foundation in algebraic reasoning that includes learning, knowing and analyzing the fundamental properties of number and operations. "The fundamental properties of number and operations are essential to computation" (Blanton, Levi, Crites, Dougherty, \& Zbiek, 2011, p. 17). By using the properties of operations to solve problems, students begin to rely less on computational skill and more upon relational thinking strategies. Algebraic reasoning also includes knowledge of and a complete understanding of the equal sign.

\section{Algebraic Thinking in the Standards}

Many of the standards documents have emphasized the importance of algebra and algebraic thinking in students' mathematical repertoire. In reading NCTM's Principles and Standards for School Mathematics (2000), there is noticeable attention given to the teaching and learning of algebra. Algebra is a prekindergarten through grade 12 content standard and an indication for teachers that understanding important algebraic concepts begins early rather than late. Included in the algebra standard is the expectation that all students are able "to understand patterns, relations, and functions; represent and analyze mathematical situations and structures using algebraic symbols; use mathematical models to represent and understand quantitative relationships; and analyze change in various 
contexts" (NCTM, 2000, p. 37). In contrast to the explicit attention that the algebra standard receives in Principles and Standards for School Mathematics, the equal sign, a key algebraic symbol, is minimally addressed in that document. However, the equal sign itself and the misconception of it are directly mentioned within the algebra standard in that students "come to view the equals sign as a symbol of equivalence" (NCTM, 2000, p. 39), "need to recognize that the equals sign indicates a relationship — that the quantities on each side are equivalent" (NCTM, 2000, p. 94) and "express mathematical relationships using equations" (NCTM, 2000, p. 158). Other indirect references to the equal sign are made throughout PSSM such as within the process standard of communication (NCTM, 2000, p. 131).

The more recent Common Core State Standards for Mathematics (CCSSM) (NGA, 2010) place a continued emphasis upon including algebra in the kindergarten through grade 12 curriculum. However, one key difference between NCTM's Principle and Standards for School Mathematics and CCSSM is that in the CCSSM the equal sign is prominently presented as a standard in first grade. In this way, the idea that teachers should be helping children to understand the commonly used algebraic symbol is made explicit. Understanding the meaning of the equal sign is directly addressed in two standards within the operations and algebraic thinking domain for children in the first grade (1.OA.D.7 and 1.OA.D.8). Two of the eight Standards for Mathematical Practice (MP2 and MP 6) refer to symbols and so include the importance of the equal sign. In particular, the description of the Mathematical Practice attend to precision specifically mentions the equal sign by declaring that students "state the meaning of the symbols they choose including using the equal sign consistently and appropriately" (NGA, 2010, p. 7). 
The description for the other Mathematical Practice, reason abstractly and quantitatively calls for students to "make sense of quantities and their relationships in problem situations" (NGA, 2010, p. 6).

\section{Equivalence}

A distinction is made between understanding numerical equivalence and understanding mathematical equivalence. Understanding mathematical equivalence requires understanding that the values on either side of the equal sign are the same (McNeil, 2008; Rittle-Johnson, Matthews, Taylor \& McEldoon, 2011). Understanding numerical equivalence requires matching sets of objects based on quantity (Gelman \& Gallistel, 1986). As early as preschool, children demonstrate an understanding of numerical equivalence by indicating two or more collections of objects are the same. Children have demonstrated an understanding of modeling a situation to make things equal (Falkner, Levi \& Carpenter, 1999). Although young children have been shown to demonstrate an understanding of numerical equivalence that knowledge does not always transfer when they begin to solve written equations (Falkner, Levi, \& Carpenter, 1999; Sherman \& Bisanz, 2009).

\section{Frequency of the Equal Sign in Learning Arithmetic}

The equal sign is used to denote equivalence between two sides of an equation (Blanton et al., 2011) and is one of the many symbols used in mathematics to represent a relationship. In the teaching and learning of mathematics, the equal sign is omnipresent and may be one of the most used symbols in all of mathematics (Knuth, Alibali, Hattikudur, McNeil \& Stephens, 2008). The equal sign is repeatedly displayed in the context of arithmetic in curricular materials such as textbooks and worksheets (Seo \& 
Ginsburg, 2003). Necessarily, students and teachers regularly write, say and use the equal sign (Falkner, Levi \& Carpenter, 1999). For example, teachers may ask "What does eight add seven equal?" Teachers may direct students to think about and use the equal sign via written problems such as determining the sum and recording it on horizontally aligned arithmetic equations. The commonplace use of the equal sign in the elementary mathematics classroom requires that students and teachers work toward a complete understanding of the symbol.

The equal sign is unavoidable because "equations are plentiful in traditional arithmetic instruction" (Blanton, Levi, Crites, Dougherty \& Zbiek, 2011, p. 25). The equal sign is so frequently used in mathematical communication that it is necessary for students to not only know the meaning of this symbol but also to understand how and when to use the equal sign to represent an idea. The equal sign is a poorly understood, but commonly used convention in mathematics (Behr, Erlwanger, \& Nichols, 1976). The equal sign and the concept of equivalence deserve explicit attention, brought forward through explicit instruction, and engaging lessons, to provide understanding (National Council of Teachers of Mathematics, 2000). According to the CCSSM released in 2010 and currently adopted by 42 states, the District of Columbia, four territories and the Department of Defense Education Activity (DoDEA) (Achieve, 2015), students as early as grade one are expected to demonstrate an understanding of the meaning of the equal sign (NGA, 2010).

\section{The Meaning of the Equal Sign along a Continuum}

Understanding the equal sign and knowledge of mathematical equivalence develops along a continuum as shown in Table 4 (Rittle-Johnson et al., 2011). Students 
at the rigid operational level define the equal sign operationally and are typically successful at solving, evaluating and encoding just those equations that follow the operation-equal sign-answer format. Encoding equations in this case refers to students' ability to look at a written equation for five seconds and then from memory successfully write the equation exactly as it appeared. Students at the flexible operational level may be successful in solving, evaluating and encoding equations that follow a less common format $(c=a+b)$. However, the equations still follow the operational structure that isolates the result to one side or the other. Basic relational knowledge of the equivalence is noted by the ability to successfully solve, evaluate and encode equations with operations on both sides of the equal sign $(a+b=c+d$ or $a+b-c=d+c)$. Recognizing and generating a relational definition of the equal sign are also part of the basic relational knowledge level. Finally, the comparative relational level of knowledge is marked by the ability of students to solve and evaluate equations by making comparisons between the expressions represented on either side of the equal sign, using compensatory strategies and observing that the performing the same operations on both sides will maintain equivalence. Such students are successful in solving equations such as those with operations on both sides with multidigit numbers or multiple instances of a variable. Comparative relational thinkers will rank a relational definition of the equal sign as the best definition (Rittle-Johnson, Matthews, Taylor \& McEldoon, 2011). Students who demonstrate an understanding of the equal sign at the comparative relational level are considered to have a complete and relational view of the equal sign. 
Table 4

Construct Map for Mathematical Equivalence Knowledge

\begin{tabular}{|c|c|c|}
\hline Level & Description & Core equation structures \\
\hline $\begin{array}{l}\text { Level 4: } \\
\text { Comparative } \\
\text { relational }\end{array}$ & $\begin{array}{l}\text { Successfully solve and evaluate } \\
\text { equations by comparing the } \\
\text { expressions on the two sides of the } \\
\text { equal sign, including using } \\
\text { compensatory strategies and } \\
\text { recognizing that performing the same } \\
\text { operations on both sides maintains } \\
\text { equivalence. Recognize relational } \\
\text { definition of equal sign as the best } \\
\text { definition. }\end{array}$ & $\begin{array}{l}\text { Operations on both sides } \\
\text { with multidigit numbers or } \\
\text { multiple instances of a } \\
\text { variable }\end{array}$ \\
\hline $\begin{array}{l}\text { Level 3: Basic } \\
\text { relational }\end{array}$ & $\begin{array}{l}\text { Successfully solve, evaluate, and } \\
\text { encode equation structures with } \\
\text { operations on both sides of the equal } \\
\text { sign. Recognize and generate a } \\
\text { relational definition of the equal sign. }\end{array}$ & $\begin{array}{l}\text { Operations on both sides, } \\
\text { e.g.: } a+b=c+d \\
a+b-c=d+e\end{array}$ \\
\hline $\begin{array}{l}\text { Level 2: } \\
\text { Flexible } \\
\text { operational }\end{array}$ & $\begin{array}{l}\text { Successfully solve, evaluate and } \\
\text { encode atypical equation structures that } \\
\text { remain compatible with an operational } \\
\text { view of the equal sign. }\end{array}$ & $\begin{array}{l}\text { Operations on right: } \mathrm{c}=\mathrm{a}+ \\
\mathrm{b} \text { or No operations: } \mathrm{a}=\mathrm{a}\end{array}$ \\
\hline $\begin{array}{l}\text { Level 1: Rigid } \\
\text { operational }\end{array}$ & $\begin{array}{l}\text { Only successful with equations with an } \\
\text { operations-equals-answer structure, } \\
\text { including solving, evaluating, and } \\
\text { encoding equations with this structure. } \\
\text { Define the equal sign operationally. }\end{array}$ & $\begin{array}{l}\text { Operations on left: } \mathrm{a}+\mathrm{b}=\mathrm{c} \\
\text { (including when blank is } \\
\text { before the equal sign) }\end{array}$ \\
\hline
\end{tabular}

(Rittle-Johnson et al., 2011, p. 87)

Learning the meaning of the equal sign may on the surface appear to be a simple and straightforward task, and therefore beginning teachers have not realized the need to present this topic explicitly and formally. Preservice elementary teachers and middle school teachers alike have demonstrated a lack of awareness regarding students' often incomplete and incorrect understanding of the equal sign (Asquith, Stephens, Knuth, \& Carpenter, 2007; Falkner, Levi, \& Carpenter, 1999; Stephens, 2006). Asquith, Stephens, Knuth and Alibali (2007) compared middle school teacher predictions for student success 
on equal sign items to actual performance by middle school students. Teachers incorrectly predicted that students at all grade levels (6-8) would have a "strong relational understanding of the equal sign" (p. 262). Stephens (2006) conducted semi-structured interviews with preservice elementary teachers to inquire about their knowledge of the misconception of the equal sign held by students. Ten of the 30 participants "proposed that students might demonstrate a misconception about the equal sign" (p. 268).

\section{Students' Misconceptions About the Equal Sign}

Research reveals students across multiple grade levels continue to demonstrate an incomplete and often errant understanding of the equal sign (Behr, Erlwanger, \& Nichols, 1976; Carpenter, Levi, Franke, \& Meringue, 2005; Falkner, Levi, \& Carpenter, 1999; Jacobs, Franke, Carpenter, Levi, \& Battey, 2001; Knuth, Alibali, Hattikudur, McNeil \& Stephens, 2008; McNeil \& Alibali, 2005; Molina, Castro \& Castro, 2009; Rittle-Johnson \& Alibali, 1999; Stephens, Knuth, Blanton, Isler, Gardiner, \& Marum, 2013; Warren \& Cooper, 2009). Students who hold an operational view of the equal sign declare the equal sign as a "write something symbol" (Baroody \& Ginsburg, 1983, p. 198). The operational conception may be less problematic at earlier grade levels but does not set students up for later success. For example, the operational interpretation permits may lead elementary students to correctly solving typical arithmetic equations with operations on the left side of the equal sign and the unknown on the right of the equal sign (Byrd, McNeil, Chesney, \& Matthews, 2015). Yet, as early as sixth grade, mathematics standards extend past arithmetic and include quantitative reasoning as well as solving one-variable equations and inequalities. For example, "apply properties of operations to $y+y+y$ to produce the equivalent expression $3 y(\mathrm{NGA}, 2010, \mathrm{p} .44)$. In the absence of 
learning relational thinking strategies and a complete understanding of the equal sign, elementary students may not be appropriately prepared for the future.

To define it operationally, student responses given through interviews and assessments include interpreting the equal sign as a signal "to compute" or "here comes the answer." To define the equal sign accurately, "the equal sign denotes the relation between two equal quantities" (Carpenter, Franke \& Levi, 2003, p. 9). By administering a written assessment to 290 third, fourth and fifth grade students, Stephens et al. (2013) found the operational definition of the equal sign to be the dominating conception. Between relational and operational notions of the equal sign, they found the operational definition was found to be the overwhelming idea shared by students in third, fourth and fifth grade. Other researchers identified similar operational definitions from elementary students who were asked to explain what the equal sign meant (Behr, Erlwanger, \& Nichols, 1976; Byrd et al., 2015; McNeil, 2008; McNeil \& Alibali, 2005; Molina \& Ambrose, 2008; Molina, Castro, \& Castro, 2009).

The research looking at the misconception that students hold about the equal sign as having an operational definition has been established over many years and is a longstanding problem. Ginsburg (1977) found that when first and second grade students are asked to explain what the equal sign means, an operational definition is typically given. For example, when shown an equation such as $3+4=\square$, students say, "The equal sign means what it adds up to" and $\square=3+4$, "blank equals 3 plus 4" (p. 84). Responses such as not accepting $5=5$ as true before changing it to $2+3=5$ maintained the hypothesis that some children view the equal sign as a direction to perform an action. In a study done more than 30 years later, Byrd, McNeil, Chesney and Matthews (2015) 
indicated that $52 \%$ of the third and fifth graders in their study provided operational definitions of the equal sign prior to receiving instruction on solving mathematical equivalence problems. Knuth, Alibali, Hattikudur, McNeil and Stevens (2008) asked middle school students in sixth through eighth grades to provide a definition for the meaning of the equal sign. Forty-one percent of the students $(n=375)$ in the study provided an operational definition for the meaning of the equal sign. Given that researchers have found that the longstanding operational interpretation continues to hold true today, the recent revision to an explicit standard about the equal sign in new state standards may provide opportunities for improving students' understanding of the equal sign.

\section{Relational Thinking Strategies}

The fundamental properties of number and operations include the properties of addition and multiplication, and the distributive property of multiplication over addition. The fundamental properties are the relationships "that govern how operations work in arithmetic and algebra" By using relational thinking strategies, learners are considering or putting into use the relationships inherent in the structure of these properties (Blanton, Levi, Crites, Dougherty \& Zbiek, 2011, p. 17). Carpenter, Levi, Franke, \& Zeringue (2005) define relational thinking as "attending to relations and fundamental properties of arithmetic operations rather than focusing exclusively on procedures for calculating answers" (p. 1). In other words, when looking for relationships between expressions on either side of the equal sign rather than calculating each side, students are using relational thinking. In the problem, $8+4=\square+5$, a student may reason that 5 is one more than 4 , so the number in the box representing the unknown has to be one less than 8 (Carpenter, 
Franke, \& Levi, 2003). In order for students to develop algebraic reasoning and relational thinking strategies, the properties of addition and subtraction, variables, mathematical equivalence, quantitative reasoning and functional thinking all must be explicitly addressed in the classroom.

\section{Challenges with Equation Formats}

Having an underdeveloped conception of the equal sign may lead to difficulty in future mathematics courses (Carpenter, Franke \& Levi, 2003; Knuth et al. 2008; MacGregor \& Stacey, 1997). When students transition to formal algebra, they often show difficulty in solving equations with operations on both sides of the equal sign as well as solving inequalities. Behr, Erlwanger and Nichol (1980) found that student responses such as rejecting the equation in the form of $a=b$ and changing it to $a+b=\square$ or $a-b=$ $\square$, provided evidence that the students maintained the hypothesis that the equal sign is a directive to perform an action. When asked to solve the problem $8+4=\square+5$, many sixth-grade students will incorrectly answer "12" (Falkner, Levi, \& Carpenter, 1999, p. 19) to situate the answer directly after the equal sign. In the same research, students added all the numbers and put 17 in the box representing the unknown. They also found that more children in fifth and sixth grades were providing incorrect answers to this equation than children in either grades one and two or grades three and four (Falkner, Levi, \& Carpenter, 1999). Some children also do not accept equation formats such as 13 $=7+6$ as correct due to the unfamiliar positioning of what they describe as the answer (in this case 13). In other words, children reject those equation formats that are not in the traditional form of operations -equal sign - answer based on their perception that the equation is written out of order (Baroody \& Ginsburg, 1983). 
Stephens, Knuth, Blanton, Isler, Murphy, Gardiner \& Marum (2013) administered a written assessment designed to assess third, fourth and fifth grade students' understanding of the equal sign in a variety of equation formats. In asking students to determine the correct number in an open number sentence such as $(7+3=\square+4$ and $5+$ $3=\square+3$ ), student performance did improve with grade level. In other words, fifth grade students answered correctly $56 \%$ more often than third grade students at who answered correctly only $2 \%$ of the time. Students were also asked to indicate whether number sentences with operations on both sides of the equal sign $(57+22=58+21)$ were true or false and provide written rationales as to why they chose true or false. Although the proportion of correct responses increased with grade level, the students' strategy use suggested student reliance upon computation rather than relational views of the equal sign and/or knowledge of equation structure. Written student responses were investigated and strategy use was coded as structural, computational or operational. Student responses were coded as structural if their reasoning included the consideration of a relationship between numbers on either side of the equal sign. (Using $7+3=\square+4$ as an example, students may reason that four is one more than three, so six must go in the blank.) Student responses were coded as computational if their responses revealed relational understanding but computed anyway. (Using $7+3=\square+4$ as an example, students may reason that six goes in the blank because the sum on each side is ten.) Finally, student responses were coded as operational if they were prompted to fill in the blank with the total. (Using $7+3=\square+4$ as an example, students using this approach would put ten in the blank.) Third and fourth grade students used the operational strategy more than computational and structural while the most frequently used strategy among 
fifth grade students was the computational strategy. By fifth grade, students appear to be moving away from use of the operational strategy. Finally, students were asked to further consider the meaning of the equal sign in the context of equivalent equations such as if 15 $+8=23$ is true, is $15+8+12=23+12$ ? Once again, success on this task improved from grade three to grade five. For each grade, the operational strategy was used most often. This means students were treating the equal sign as a signal to compute the answer. While third grade students were not found to use the structural strategy to reason through the equation, fifth grade had the highest proportion of students who used the structural strategy.

\section{Origin of Equal Sign Confusion in Instruction}

When students face new problems in different contexts and when the cognitive demand increases as they advance in mathematics, misconceptions may arise because of students' beliefs that the strategies previously learned are always going to work (Hiebert \& Carpenter, 1992). By answering “ 12 ”, to $8+4=\square+5$, the student may simply be mimicking actions remembered from previously solved problems. Students may not have encountered equations with distributed quantities on both sides of the equal sign. However, the CCSSM requires first grade students to evaluate such equation types. Additionally, the students who refute the statement $13=7+6$ because of the format may be drawing upon repeated experiences where the sum (answer) is placed on the right side of the equation.

Many problems presented to elementary students have the equal sign situated only at the right hand side of an equation (Blanton, Levi, Crites, Dougherty \& Zbiek, 2011). Therefore, young students just beginning formalized instruction are likely to form a 
generalized response such as "here comes the answer" whenever they see the equal symbol.

The activities used by the teacher may contribute to how the equal sign is interpreted (Seo \& Ginsburg, 2003). For example, when children are asked to write the answer for standard addition and/or subtraction expressions after the equal sign or to "rename the day" (asking students to create expressions that are equivalent to the date of the month, for example); the operational meaning is reinforced because children see the activities as a request to "make or produce a certain number" (Seo \& Ginsburg, 2003, p. 181). McNeil and Alibali (2005) also found that in the context of standard arithmetic problems the operational misconception is activated. The equal sign should be avoided save for representing an equivalence relationship between two quantities (Carpenter, Franke \& Levi, 2003). For example, "Math = fun" does not help students to develop a complete understanding of the equal sign. Elementary and middle school textbooks may reinforce the operational understanding through frequent presentation of the equal sign in the operation-equals-answer structure (McNeil et al. 2006; Seo \& Ginsburg 2003).

\section{Textbook Analysis of the Appearance of the Equal Sign}

In their analysis of mathematics textbooks for students in grades one through six, Rittle-Johnson, Matthews, Taylor and McEldoon (2011) found that as students transitioned toward sixth grade, their textbooks had more instances of the equal sign per page as shown in Table 5 . The operations-equals-answer $(5+2=\square)$ structure accounted for $97 \%$ of all occurrences in first grade and only $31 \%$ by sixth grade. In comparison, the nonstandard $(3=3$ or $12 \mathrm{in} .=1 \mathrm{ft})$ equation structures showed up zero times in 320 pages of analyzed first grade text and $10 \%$ of the time for second grade students. Percentage of 
instances of the nonstandard equation structure increased to $68 \%$ of all instances by sixth grade. This suggests that younger students see the equal sign less often and in fewer contexts than the sixth grade students. Thus, textbooks may be supporting the development of an incomplete and operational conception of the equal sign.

Rittle-Johnson et al. (2011) also found that no explicit definitions of the equal sign were provided in textbooks included in the study. Ranging from a simple identification of the equal sign, to no mention in the glossary and finally to the description of the equal sign as "having the same value," student textbooks did not appear to support the development of a relational understanding of the equal sign as a sign of mathematical equivalence. In spite of the lack of exposure to the equal sign in multiple equation contexts in their textbooks, many second grade students in the study were reported to correctly answer questions with nonstandard equations (operations on the right or no operations). In addition, many older children also correctly answered similar items. Rittle-Johnson et al. (2011) suggest that success for the students in their study may be in part due to time spent in class with attention to the equal sign. Although teachers were not observed, teachers' self- reported that they spend time in class discussing the meaning of the equal sign as well as devote attention to solving problems with the equal sign presented in nonstandard equations $(7=5+2,12$ in. $=1 \mathrm{ft} ., 3=3)$. 


\section{Table 5}

Textbook analysis results: Percentages of the Equal Sign in Each Equation Structure for Grades 1 Through 6

\begin{tabular}{|c|c|c|c|c|c|c|c|c|}
\hline & \multirow[b]{2}{*}{ Structure type } & \multicolumn{6}{|c|}{ Grade } & \multirow[b]{2}{*}{ Average } \\
\hline & & 1 & 2 & 3 & 4 & 5 & 6 & \\
\hline $\begin{array}{l}\text { Operations-equals-answer } \\
\text { structure }\end{array}$ & & 97 & 82 & 70 & 52 & 38 & 31 & 62 \\
\hline $\begin{array}{l}\text { Unknown at end or } \\
\text { no unknown }\end{array}$ & $\begin{array}{l}\text { Operation(s) on left side of the equal sign } \\
\text { and unknown quantity or answer on right } \\
\text { side (e.g., } 5+2=\square)\end{array}$ & 91 & 75 & 48 & 35 & 18 & 11 & 46 \\
\hline $\begin{array}{l}\text { Unknown on left } \\
\text { side }\end{array}$ & $\begin{array}{l}\text { Operation(s) and an unknown quantity on } \\
\text { left side (e.g., } 4+\square=7 \text { ) }\end{array}$ & 6 & 7 & 22 & 17 & 20 & 20 & 15 \\
\hline $\begin{array}{l}\text { Nonstandard equation } \\
\text { structures }\end{array}$ & & $\mathbf{0}$ & 10 & 24 & 41 & 59 & 68 & 34 \\
\hline $\begin{array}{l}\text { Operation(s) on } \\
\text { right side of equal } \\
\text { sign }\end{array}$ & $\begin{array}{l}\text { Operation(s) on right side of the equal sign } \\
\text { and answer or an unknown quality on left } \\
\text { side (e.g., } 7=5+2)\end{array}$ & 0 & 4 & 3 & 2 & 18 & 11 & 6 \\
\hline $\begin{array}{l}\text { No explicit } \\
\text { operations }\end{array}$ & $\begin{array}{l}\text { No explicit operations on either side of } \\
\text { equal sign (e.g., } 12 \text { in }=1 \mathrm{ft} \text {., } x=4,2 / 4= \\
1 / 2,3=3 \text { ) }\end{array}$ & 0 & 5 & 15 & 33 & 38 & 49 & 23 \\
\hline $\begin{array}{l}\text { Operations on both } \\
\text { sides of equal sign }\end{array}$ & $\begin{array}{l}\text { Operations appear on both sides of equal } \\
\text { sign }(\text { e.g., } 3+4=5+2)\end{array}$ & 0 & 1 & 6 & 6 & 3 & 8 & 4 \\
\hline No equation & $\begin{array}{l}\text { Equal sign appears outside the context of } \\
\text { an equation, such as in the directions (e.g., } \\
\text { "Write }<,>\text {, or = to complete each } \\
\text { statement") }\end{array}$ & 3 & 7 & 6 & 6 & 3 & 1 & 4 \\
\hline $\begin{array}{l}\text { Total instances of equal } \\
\text { sign }\end{array}$ & & 492 & 363 & 606 & 671 & 859 & 1267 & \\
\hline Pages examined & & 320 & 310 & 314 & 314 & 311 & 309 & \\
\hline Instances per page & & 1.5 & 1.1 & 2.2 & 2.0 & 2.7 & 4.0 & \\
\hline
\end{tabular}




\section{Summary}

Misconceptions about the equal sign persist due to many factors. Some of the factors are complex while others may be straightforward. Through the discovery and analysis of the misconceptions related to what students know and understand about the equal sign, teachers can continue to reflect upon current practices in the classroom. By working toward a better understanding of teaching and learning mathematics, educators and researchers help to make it possible for all students to learn at high levels and successfully progress to more advanced mathematical topics. 


\section{CHAPTER III}

\section{METHODOLOGY}

\section{Restatement of Purpose and Research Questions}

The purpose of this research study was to examine the present level of understanding that second, third, fourth and fifth grade elementary students demonstrate regarding the meaning of the equal sign in order to determine the impact of the Common Core State Standards for Mathematics (CCSSM)/College and Career Ready Standards (CCRS) implementation. Teacher knowledge of the equal sign was also investigated. The research questions for this study were the following:

$\mathrm{RQ}_{1}$ : What is the impact of teacher knowledge of the equal sign on student understanding of the equal sign?

$\mathrm{RQ}_{2}$ : What is the impact of the implementation of new state standards on student understanding of the equal sign?

\section{Research Design}

A mixed methods sequential explanatory design using both quantitative and qualitative measures was used to determine the impact of teacher knowledge and new state standards implementation on second, third, fourth and fifth grade students' understanding of the equal sign. Data type and instrumentation are organized by research question in Table 6. 
Table 6

Methodology Organization

\begin{tabular}{lll}
\hline Research Question & Type of Data & Instrumentation \\
\hline $\begin{array}{l}\text { What is the impact of teacher } \\
\text { knowledge of the equal sign on } \\
\text { student understanding of the } \\
\text { equal sign? }\end{array}$ & Quantitative & $\begin{array}{l}\text { Mathematical Equivalence Knowledge } \\
\text { Assessment (MEKA) (students and teachers) }\end{array}$ \\
\hline $\begin{array}{l}\text { What is the impact of the } \\
\text { implementation of the new state } \\
\text { standards on student } \\
\text { understanding of the equal sign? }\end{array}$ & Quantitative & $\begin{array}{l}\text { Mathematical Equivalence Knowledge } \\
\text { Assessment (MEKA) (students) }\end{array}$ \\
& & $\begin{array}{l}\text { Teacher Survey } \\
\text { Process Standards for Mathematics } \\
\text { Proficiency/Standards of Student Practice in } \\
\text { Mathematics Proficiency }\end{array}$ \\
\cline { 2 - 3 } & Qualitative & $\begin{array}{l}\text { Teacher Interviews } \\
\end{array}$ \\
\hline
\end{tabular}

\section{Teacher Demographics}

Teachers in the study completed a general questionnaire designed to collect demographic data such as number of years of teaching, certification area and number of college mathematics courses taken.

\section{Mathematical Equivalence Knowledge Assessment (MEKA)}

The Mathematical Equivalence Knowledge Assessment (MEKA) was administered to students participating in the study as a way to measure student understanding of the equal sign. Teacher knowledge of the equal sign was also measured with the assessment developed and used by Rittle-Johnson and colleagues in 2011 and revised in 2014. 


\section{Teacher Survey}

The classroom level of implementation of the new state standards (Common Core State Standards for Mathematics (CCSSM) for Schulz Elementary and College and Career Ready Standards (CCRS) for Marie Elementary and Thomas Middle) was measured through teacher self-reports on either the Process Standards for Mathematics Proficiency or Standards of Student Practice in Mathematics Proficiency survey. Depending upon the school, a different name is used to refer to the set of student practices. However, the student practices are identical as are the surveys. The developers of the Process Standards for Mathematics Proficiency (Hull et al., 2012) survey did not provide reliability or validity descriptions.

\section{Teacher Interviews}

The classroom level of implementation of CCSSM/CCRS was also examined by asking teachers questions in individual interviews. To explore teacher knowledge of student understanding of the equal sign, participating teachers were also asked in the interviews to predict how their students might perform on mathematical tasks related to the meaning of the equal sign.

\section{Rationale for Research}

As previously discussed, elementary aged children often have difficulty fully understanding the meaning of the equal sign. The reason students in grades two through five were chosen for this study is that CCSSM/CCRS expects instruction on the equal sign in first grade and as such students in grades two through five will be expected to understand the equal sign in their mathematics work. In addition, the cross-grade level analysis allows the examination of whether students continue to understand the meaning 
of the equal sign as the numbers and situations in which they are using equations progresses over the years. Finally, fifth grade is the last grade prior to entering middle school which is "a period that marks a significant transition from the concrete, arithmetic reasoning of elementary school mathematics to the increasingly complex, abstract algebraic reasoning required for high school mathematics and beyond" (Asquith, Stephens, Knuth \& Alibali, 2007, p. 251). First grade students were not included in the study so that the researcher could rule out the possibility of students not yet receiving instruction on the equal sign. Full CCSSM implementation has been in place at Schulz Elementary for current third grade students since their kindergarten year. Current fifth grade students at Schulz Elementary did not receive the treatment as first graders. In this way, fifth grade students at Schulz are similar to the fifth grade students at Thomas Middle. This however, does not mean that fifth grade students were not taught concepts related to the equal sign as teachers may have revisited the standard for the understanding of the equal sign. . In addition, the equal sign may be discussed and used differently in the two states because of the differences between them in mathematics standards implementation timelines.

\section{Appropriateness for this Study}

Indicating the critical nature of grade level expectations, CCSSM/CCRS are not spiral in nature and topics are therefore not revisited year after year. The CCSSM/CCRS are written so that teachers do not return to any of the standards so students must learn the standard at the given grade level and demonstrate a complete understanding of it, that is, in this case, the equal sign. Though the standards are not repeated in other grades, 
they are positioned within trajectories and so teachers should be returning to concepts/ideas and building upon them.

\section{Population and Sample}

\section{Context and Population}

Two adjoining states with two different implementation policies were selected for the current study. Marie Elementary and Thomas Middle are located in a state that began full implementation of new state standards for the 2014/2015 school year. The standards in that state are referred to as College and Career Ready Standards (CCRS). Schulz Elementary is located in a state that began full implementation of CCSSM for the 2011/2012 school year. Although the two sets of standards are not labeled with the same name, a comparison of the sets of standards revealed that they are nearly identical. Slight wording differences between the overall CCSSM and CCRS can be found but both sets of standards are organized in a similar manner and expect the same outcome. The 2014/2015 school year marked year four for full implementation of CCSSM and year one for full implementation of CCRS. Fifth grade students in both states did not have the opportunity to have first grade standards because neither state had the new standards in place. The population for this study include high performing public elementary schools in two states.

\section{Sample}

The sample for the current study include one elementary school that contains kindergarten through grade five, one elementary school that contains kindergarten through grade four and one middle school that contains grade five through eight. The 
schools are located in two Midwestern states. All three schools are considered to be neighborhood schools situated in suburban/rural areas. Each school belongs to a larger district comprised of numerous preschool, elementary, middle and high schools. All school names are pseudonyms. Marie Elementary School and Schulz Elementary School are both one of nine elementary schools in their respective districts. Thomas Middle School is one of three middle schools in the district. In 2005, all fifth grade classrooms in Thomas Middle School's district were moved out of the elementary building to be housed in the middle school building in order to create space for the growing population of younger elementary school students. Fifth grade students at Thomas Middle are considered to be elementary students, are instructed as elementary students and are not departmentalized for mathematics instruction. All schools are considered to be high performing and each has over $97 \%$ attendance rates. Appendix A summarizes additional key demographic data for each school.

Table 7 shows a breakdown of participating grade levels, students and teachers at each school. Forty-one total teachers participated in the study. Appendix B has a complete list of teachers and class totals. At Marie Elementary, one teacher teaches mathematics to both a grade three class as well as a grade four class. In Appendix B, Teacher 7/Teacher 12 is the same person but because she teachers two different classes at two different grades (grade three and grade four), it appears as though she is counted twice in Table 7. Teacher 7 and Teacher 12 indicate and refer to her as the same teacher but the different identification codes allowed the separation of her two classes. At Thomas Middle, six of the seven fifth grade teachers have two classes each. There was no separation of their class data because it was at the same grade level. 
Table 7

Participating School Totals

\begin{tabular}{|c|c|c|c|c|c|c|}
\hline School & $\begin{array}{l}\text { Participating } \\
\text { Grade Level }\end{array}$ & & Number of Classes & $\begin{array}{l}\text { Number of } \\
\text { Students }\end{array}$ & $\begin{array}{l}\text { Number of } \\
\text { Teachers }\end{array}$ & \\
\hline Marie Elementary & 2 & & 5 & 122 & 5 & \\
\hline & 3 & & 5 & 117 & 6 & \\
\hline & 4 & & 4 & 157 & 5 & \\
\hline Total & & 3 & 14 & 396 & & 16 \\
\hline Thomas Middle & 5 & & 13 & 345 & 7 & \\
\hline Total & & 1 & 13 & 345 & & 7 \\
\hline Schulz Elementary & 2 & & 4 & 91 & 4 & \\
\hline & 3 & & 5 & 116 & 5 & \\
\hline & 4 & & 5 & 110 & 5 & \\
\hline & 5 & & 5 & 124 & 5 & \\
\hline Total & & 4 & 19 & 441 & & 19 \\
\hline Grand Total & & & 46 & 1182 & & 42 \\
\hline
\end{tabular}

Schulz Elementary implemented the Common Core State Standards for Mathematics (CCSSM) in the 2011-12 school year and full implementation has continued for all grades without interruption. For the current school year, Marie Elementary and Thomas Middle are both located in a different state from Schulz Elementary and adopted their own academic standards, called College \& Career Ready Standards (CCRS). According to the building principal for Marie Elementary, the CCSSM were initially 
implemented for kindergarten in the 2011-12 school year. The following year, kindergarten and first grade teachers continued implementation of the standards from CCSSM. Refer to Table 8 and Table 9 for each school's standards implementation timeline. Marie Elementary and Thomas Middle followed State Academic Standards (SAS) prior to CCRS implementation while Schulz Elementary followed State Core Content prior to its adoption of CCSSM.

As mentioned, the CCSSM standards currently used by Schulz Elementary are similar in nature to the CCRS used by Marie Elementary and Thomas Middle (CCRS). In particular, the first grade standard related to this study for the equal sign from CCSM reads: Understand the meaning of the equal sign, and determine if equations involving addition and subtraction are true or false. For example, which of the following equations are true and which are false? $(6=6,7=8-1,5+2=2+5,4+1=5+2)$ The first grade CCSSM standard is part of the Operations and Algebraic Thinking domain (1.OA.7). The related and corresponding first grade standard for the equal sign from the 2014 CCRS for Mathematics reads: Understand the meaning of the equal sign, and determine if equations involving addition and subtraction are true or false (e.g., Which of the following equations are true and which are false? $6=6,7=8-1,5+2=2+5,4+1$ $=5+2$ ). The first grade standard is part of the Computation and Algebraic Thinking domain (1.CA.6). There is no difference in the standard meant to address the understanding of the equal sign other than one standard comes from a set of standards labeled CCSSM and the other is from a set of standards labeled CCRS. The main difference with relation to the implementation of the new state standards lies in that Marie Elementary and Thomas Middle finished year one of full implementation and 
Schulz Elementary finished year four of full implementation for the 2014/2015 academic school year.

Table 8

Marie Elementary and Thomas Middle Standards Implementation Timeline

\begin{tabular}{|c|c|c|c|c|c|c|}
\hline $\begin{array}{l}\text { School } \\
\text { Year }\end{array}$ & $\begin{array}{c}\text { Standards } \\
\text { Implemented }\end{array}$ & Grade & & & & \\
\hline 2009-10 & SAS & $\mathrm{K}$ & & & & \\
\hline $2010-11$ & SAS & 1 & K & & & \\
\hline 2011-12 & SAS and CCSSM & 2 (SAS) & 1 (CCSSM) & $\begin{array}{l}\mathrm{K} \\
(\mathrm{CCSSM})\end{array}$ & & \\
\hline $2012-13$ & SAS and CCSSM & 3 (SAS) & 2 (SAS) & $1(\mathrm{CCSSM})$ & $\begin{array}{l}\mathrm{K} \\
(\mathrm{CCSSM})\end{array}$ & \\
\hline 2013-14 & $\begin{array}{l}\text { CCSSM/SAS } \\
\text { (Hybrid) }\end{array}$ & 4 (Hybrid) & 3 (Hybrid) & 2 (Hybrid) & $1(\mathrm{CCSM})$ & $\mathrm{K}(\mathrm{CSSM})$ \\
\hline 2014-15 & CCRS & 5 & 4 & 3 & 2 & 1 \\
\hline
\end{tabular}

Table 9

Schulz Elementary Standards Implementation Timeline

\begin{tabular}{lllllll}
\hline School Year & $\begin{array}{c}\text { Standards } \\
\text { Implemented }\end{array}$ & \multicolumn{2}{l}{ Grade } & & & \\
\hline $2009-10$ & Core Content & $\mathrm{K}$ & $\mathrm{K}$ & & & \\
$2010-11$ & Core Content & 1 & $\mathrm{~K}$ & & \\
$2011-12$ & CCSSM Year 1 & 2 & 1 & 1 & $\mathrm{~K}$ & \\
$2012-13$ & CCSSM Year 2 & 3 & 2 & 2 & 1 & $\mathrm{~K}$ \\
$2013-14$ & CCSSM Year 3 & 4 & 3 & 3 & 2 & 1 \\
$2014-15$ & CCSSM Year 4 & 5 & 4 & & \\
\hline
\end{tabular}

\section{Sampling Procedures}

Purposive sampling was employed in this study in order to "generate a wealth of detail from a few cases" (Teddlie \& Tashakkori, 2009, p. 173). The level of implementation of CCSSM/CCRS is a construct being investigated in this study. A comparison was made between student understanding at one school that has fully implemented CCSSM since the 2011-12 school year and another school that who has just recently begun implementation in 2014/2015. Principals at each school agreed to permit the researcher to administer the short version of the Mathematical Equivalence 
Knowledge Assessment (MEKA) to every second and third grade student (22 items).

Fourth and fifth grade students took the long version of the MEKA (29 items). However, due to the researcher's relationship to one student at Marie Elementary and one student at Thomas Middle, their data were excluded from the study. Table 10 shows a breakdown of the number of classrooms included in the study. Every teacher (41 total) also completed the same version of the MEKA that his or her own students took. Every teacher completed a self-report on the CCSSM/CCRS level of implementation in their own classroom using the Process Standards for Mathematics (CCRS) for Marie Elementary and Thomas Middle. The same survey is labeled Standards for Mathematical Practice Implementation (CCSSM) survey for Schulz Elementary. Teachers at all three schools gave written consent to participate. Parents of all second, third, fourth and fifth grade students at all three schools received notice of the study and had the opportunity to decide about their child's participation. During the administration of the assessment, teachers arranged alternate plans for those students who were not participating in the study. 
Table 10

Breakdown of Classrooms by School and State

\begin{tabular}{|c|c|c|c|c|}
\hline & Grade 2 & Grade 3 & Grade 4 & Grade 5 \\
\hline $\begin{array}{l}\text { Marie Elementary } \\
\text { (State } 1 \text {, state with } \\
\text { one year of } \\
\text { implementation) }\end{array}$ & $\begin{array}{l}\text { Classroom } 1 \\
\text { Classroom } 2 \\
\text { Classroom } 3 \\
\text { Classroom } 4 \\
\text { Classroom } 5\end{array}$ & $\begin{array}{l}\text { Classroom } 6 \\
\text { Classroom } 7 \\
\text { Classroom } 8 \\
\text { Classroom } 9 \\
\text { Classroom } 10 \\
\text { Classroom } 11\end{array}$ & $\begin{array}{l}\text { Classroom } 12 \\
\text { Classroom } 13 \\
\text { Classroom } 14 \\
\text { Classroom } 15 \\
\text { Classroom } 16\end{array}$ & N/A \\
\hline $\begin{array}{l}\text { Thomas Middle } \\
\text { (State } 1 \text {, state with } \\
\text { one year of } \\
\text { implementation) }\end{array}$ & N/A & $\mathrm{N} / \mathrm{A}$ & N/A & $\begin{array}{l}\text { Classroom } 17 \\
\text { Classroom } 18 \\
\text { Classroom } 19 \\
\text { Classroom 20 } \\
\text { Classroom 21 } \\
\text { Classroom 22 } \\
\text { Classroom 23 }\end{array}$ \\
\hline $\begin{array}{l}\text { Schulz Elementary } \\
\text { (State 0, state with } \\
\text { four years of } \\
\text { implementation) }\end{array}$ & $\begin{array}{l}\text { Classroom } 24 \\
\text { Classroom } 25 \\
\text { Classroom 26 } \\
\text { Classroom 27 }\end{array}$ & $\begin{array}{l}\text { Classroom } 28 \\
\text { Classroom } 29 \\
\text { Classroom } 30 \\
\text { Classroom } 31 \\
\text { Classroom } 32 \\
\end{array}$ & $\begin{array}{l}\text { Classroom } 33 \\
\text { Classroom } 34 \\
\text { Classroom } 35 \\
\text { Classroom } 36 \\
\text { Classroom } 37 \\
\end{array}$ & $\begin{array}{l}\text { Classroom } 38 \\
\text { Classroom } 39 \\
\text { Classroom } 40 \\
\text { Classroom } 41 \\
\text { Classroom } 42 \\
\end{array}$ \\
\hline
\end{tabular}

\section{Instrumentation}

\section{Research Question 1 Instrumentation}

\section{Description of Instruments}

The purpose of RQ1 was to determine the impact of teacher knowledge as measured by the Mathematical Equivalence Knowledge Assessment (MEKA) (Fyfe et al., 2014; Rittle-Johnson, Matthews, Taylor \& McEldoon, 2011) on student understanding of the equal sign by comparing teachers' knowledge of the equal sign and their perceptions of their students' knowledge of the equal sign with their students' understanding of the equal sign as measured by the MEKA. The MEKA was used to determine student understanding and teacher knowledge of the equal sign. Permission was obtained to use the MEKA from the Rittle-Johnson et al. study by the author (B. Rittle-Johnson, personal communication, November 7, 2014). Each level of understanding of mathematical 
equivalence knowledge (rigid operational, flexible operational, basic relational, comparative relational) was addressed by at least two items in each of the three item classes (solving equations, evaluating the structure of the equations and defining the equal sign). See Table 11 for a breakdown of question types.

The advice from author Rittle-Johnson was, "I would definitely not use the entire assessment with second graders. We work with second graders and often use a subset of the test. We've been under pressure from the school district to shorten our assessment too," therefore, two versions of the MEKA were used (B. Rittle-Johnson, personal communication, October 20,2014). Although the assessment given to the students at the upper and lower grade levels varied slightly by the number of questions in order to keep the assessment developmentally appropriate, student knowledge of mathematical equivalence was measured with solving equation, equation structure and equal sign definition questions. Second and third grade students took a shorter version containing 22 items, for a possible 23 points. Fourth and fifth grade students took a longer version of the assessment containing 29 items, for a possible 32 points. Both assessments measure understanding of the equal sign; some questions on the longer assessment are more difficult. In alignment with Rittle-Johnson's suggestion, the researcher sought to administer developmentally appropriate assessments for all students. Thus, the reason for giving the younger grades a shorter version of the assessment. There are two forms of each assessment available. However, for the purposes of this study, one form for each assessment was used. See Appendices C and F for Form 1. 
Table 11

Mathematical Equivalence Knowledge Assessment

\begin{tabular}{llll}
\hline \multicolumn{1}{c}{ Item } & \multicolumn{1}{c}{ Example task } & \multicolumn{1}{c}{ Instructions } & \multicolumn{1}{c}{ Notes } \\
\hline $\begin{array}{l}\text { Equation- } \\
\text { solving }\end{array}$ & $67+84=\square+83$ & $\begin{array}{l}\text { Find number } \\
\text { that goes in } \\
\text { the box. }\end{array}$ & $\begin{array}{l}\text { Students encouraged to try and find } \\
\text { shortcut, some time pressure applied to } \\
\text { discourage computation, } n+n+n+2= \\
17 .\end{array}$ \\
$\begin{array}{l}\text { Equation- } \\
\text { structure }\end{array}$ & $5+5=5+6$ & $\begin{array}{l}\text { Circle true or } \\
\text { false. }\end{array}$ & $\begin{array}{l}\text { Test knowledge of valid equation } \\
\text { structures, varied according to criteria } \\
\text { from construct map (4 levels). }\end{array}$ \\
$\begin{array}{l}\text { Equal-sign } \\
\text { definition }\end{array}$ & 10 cents $\square$ One dime & $\begin{array}{l}\text { Indicate } \\
\text { choice to } \\
\text { show that ten } \\
\text { cents is the } \\
\text { same amount } \\
\text { of money as } \\
\text { one dime. }\end{array}$ & \\
& & $\begin{array}{l}\text { Examine explicit knowledge of the equal } \\
\text { sign. }\end{array}$ & \\
& &
\end{tabular}

\section{Rationale for Instrument}

The measure of mathematical equivalence knowledge used in this study has been used in several recent studies (Fyfe, DeCaro \& Rittle-Johnson, 2014; Rittle-Johnson, Matthews, Taylor \& McEldoon, 2011). Fyfe and colleagues used the MEKA assessment with second and third grade students to determine if sequencing of activities impacted student equivalence understanding (Fyfe et al., 2014). Rittle-Johnson, Matthews, Taylor and McEldoon developed the original assessment with students in grades two through six after creating a construct map for mathematical equivalence knowledge (Rittle-Johnson et al., 2011). Studies in the past that have investigated elementary students' understanding of the equal sign have incorporated a variety of assessment methods. For example, Jacobs, Franke, Carpenter, Levi \& Battey interviewed students in grades 1, 3 and 5 to supplement written assessment data (2007). Additional past studies relied on interviews both non-structured and clinical to assess student understanding (Behr, Erlwanger \& 
Nichols, 1976; Seo \& Ginsburg, 2003). The 2011 assessment developed by RittleJohnson and colleagues is the only measure of mathematical equivalence knowledge reported to be valid and reliable (Rittle-Johnson et al., 2011). In addition, there are two forms of the assessment allowing for random distribution in each classroom. As stated previously, one form was used in this study.

\section{Instrument Validity}

Multiple measures of evidence for validity were reported including "based on test content, based on internal structure-dimensionality, based on internal structure-Wright map, based on relation to other variables, and based on response processes" (RittleJohnson et al., 2011, p. 93-96). Face validity was secured by experts who rated most of the test items as important (rating of 3 ) to essential (rating of 5). The mean validity rating for test content was 4.1 (Rittle-Johnson et al., 2011).

Data were fitted to the Rasch model, which accounted for $57.2 \%$ of the variance in the data. The largest secondary factor accounted for $2.2 \%$ of the total variance, corresponding to $5.2 \%$ of the total variance. A single factor accounted for most of the variance and performance on individual assessment items. This suggested to RittleJohnson that their construct was "unidimensional" (Rittle-Johnson, et al., 2011, p. 93). A Wright map was also used to investigate internal structure. The Wright map, which is a visual representation of the comparison of exam item difficulty and student ability, confirmed the correct mapping of item difficulty progressing from rigid operational to comparative relational (Rittle-Johnson et al., 2011). 


\section{Instrument Reliability}

Shadish et al. (2002) identify unreliability of measures as a possible threat to statistical conclusion validity. As determined by Rittle-Johnson and colleagues (2011), internal consistency of the MEKA as assessed by Cronbach's alpha to be high (Form $1=$ .94 ; Form $2=.95$ ) (Webb et al., 2006). In order to measure internal consistency of the MEKA for the current study, Cronbach's alpha was conducted and found to be 0.884 for the 4/5 Student MEKA and 0.896 for the 2/3 Student MEKA. Test-retest reliability was calculated by determining the correlation between performance on the subset of 28 items that were given in both the initial and revised assessment. The test-retest correlation was Form $1, r(26)=.94$ and for Form $2, r(26)=.95$. The values are considered to be high and seem to indicate the two tests "accurately measure the same attribute" (Teddlie \& Tashakkori, 2009, p. 211). Five explanation items on the revised assessment were analyzed for interrater reliability. Responses were coded ( $20 \%$ of the sample) by an independent coder with a mean exact agreement of 0.99 for Form 1 (range $=.96-1.00)$ and .97 for Form 2 (range $=.87-1.00)$. The purpose of having an independent coder is to provide an unbiased evaluation of the assessment items. The calculated correlations indicate the level of consistency between the coders (Teddlie \& Tashakkori, 2009). Student performance appears to have been reliably measured on both forms (RittleJohnson et al., 2011). An examination was conducted for instrumentation that measures adult understanding of the equal sign and there is no such instrumentation. However, in an effort to measure internal consistency for the MEKA used with participating teachers in the current study, Cronbach's alpha was conducted. With respect to the $4 / 5$ Teacher 
MEKA, Cronbach's alpha was 0.4. Cronbach's alpha for the 2/3 Teacher MEKA was 0.2 .

\section{Data Collection Procedures for Research Question 1}

Building principals were contacted at Marie Elementary, Thomas Middle and Schulz Elementary schools in the fall of 2014. Principals worked with their teachers to plan windows of opportunity for the students and teachers to complete the assessments. Data were collected in May of 2015. The written assessments (MEKA) were collected from every student and teacher on the same day they were administered. Teacher assessments were given at the same time of the student assessment so that teachers were working on completing the assessment as children were working. Student and teacher interactions were discouraged during the assessment and the researcher answered all student questions. With the exception of two teacher assessments, all assessments were completed and collected on the same day. Two teachers submitted their assessment on a separate day.

In an effort to align the student assessments with teacher assessments, all teachers took the version of the assessment that coincides with the grade level that they currently teach. For example, teachers of second and third grade took the shorter assessment, just like their students. Teachers of fourth and fifth grade took the longer assessment, just like their students.

The MEKA was administered in the same manner at each school for teachers and students. Both groups of fifth graders took the assessment in their own school cafeteria. Marie Elementary opted to have grades 2 through 4 complete the assessment in the cafeteria. Schulz Elementary opted to have two classrooms of students take the 
assessment at once in the same location such as a neighboring classroom. Because data were collected at the end of the school year, classrooms were void of instructional matter due to preparation for state testing. For example, Schulz Elementary had already prepared for state testing in the spring and therefore, all instructional matter had already been cleared from the walls, desks, floors, and so on.

Students were given the MEKA by the researcher who followed a preplanned script. See Appendix D/G. Time limits were enforced for each of the sections in order to help all children finish the assessment rather than labor over questions for extended amounts of time. The single 45-minute session also helped to discourage computation on equation solving items such as $7=\square+3$ and $4+5+8=\square+8$ which occurred on both the 2/3 Student MEKA and 4/5 Student MEKA (Rittle-Johnson, et al., 2011). Included in the 45-minute session was time to hand papers out to and collect from students, introduction and instructions for the assessment. For the assessment used with students in second and third grade, Section 1 contained eight open-ended problems (i.e. $3+4=$ +5 ), which students were given about eight minutes to finish. Section 2 of the assessment contained equal sign problems, true/false items and conceptual problems. Students were given approximately two and a half minutes to finish the first set of equal sign problems, three minutes for the true/false items, another 2 minutes for a second set of equal sign problems and two more minutes for the conceptual problems. For the assessment used with students in fourth and fifth grade, Section 1 included true/false items and equal sign problems, for which students had approximately five minutes to finish. Section 2 had additional equal sign problems with about five minutes provided to finish. Section 3 had eleven open-ended problems (i.e. $6+2=\square$ ). Students were given 
approximately 10 minutes to finish the final section of the assessment. The researcher read the instructions aloud for each section; administered the assessment and answered student questions. All students were informed, "It is okay to write a question mark and move on" (See script provided in Appendix E). The researcher tried not to move onto the next section of each assessment until most students had stopped working.

Each mathematical equivalence assessment from teachers and students was scored using the scoring process adopted by Rittle-Johnson and colleagues (2011). Each item was scored with a dichotomous scale (i.e., 0 for incorrect and 1 for correct). For computation items, participants earned one point for answers within one number of the correct answer to allow for minor calculation errors. For the five explanation items, participants received one point for mentioning the equivalent relation. The researcher read and scored every student and teacher assessment. An independent scorer read and scored $154(13 \%)$ assessments. After discussions between the researcher and scorer to clarify the scoring protocol, agreement was at $97 \%$. Every teacher for the grades of interest in the study was given the MEKA.

\section{Research Question 2 Instrumentation}

\section{Description of Instruments}

The purpose of RQ2 was to investigate the impact of CCCSM/CCRS implementation on student understanding of the equal sign. As described before, student understanding of the equal sign was measured using the MEKA. In order to determine level of implementation, a rubric was adapted from Hull, Harbin Miles and Balka's Standards of Student Practice in Mathematics Proficiency Matrix (2012). The rubric was used to determine individual degrees of CCSSM/CCRS implementation at the classroom 
level. Teachers in the study were asked to complete the rubric. See Appendix L/M. The Standards for Mathematical Practice from CCSSM (Schulz Elementary) and Process Standards for Mathematics from CCRS (Marie Elementary and Thomas Middle) are listed in the left column. Practices one and three were separated because each "had dual components that were significant enough to merit individual proficiency scales" (Hull et al., 2012, p. 59). Varying degrees of student proficiency are listed across the top with (I) indicating initial, (II) indicating intermediate and (III) indicating advanced proficiency. Each proficiency level is described in terms of student actions that align with a degree of mastery and practice.

Although each state refers to the Standards for Mathematical Practices differently (Standards for Mathematical Practice by school C and Process Standards for Mathematics by school A and B), the process standards are identical. Total scores may range from 0 to 30 on the Process Standards for Mathematics Proficiency/Standards of Student Practice in Mathematics Proficiency survey. These quantitative data serve as one indicator of the level of implementation for the CCSSM/CCRS as reported by classroom teachers. Thus a score of 30 could indicate a higher degree of implementation than a score of 15. A score was derived for each teacher by adding the total for each column. For example, if a teacher indicated an initial level of proficiency for her students on any of the practices outlined in the survey that would score one point. Similarly, if a teacher indicated an intermediate level of proficiency, that would score two points. Finally, an indication of advanced proficiency would score three points.

As stated, the Process Standards for Mathematics Proficiency/Standards of Student Practice in Mathematics Proficiency survey was used to measure individual 
degrees of implementation. Using SPSS version 22, Cronbach's alpha as a measure of internal consistency was determined to be 0.819 for the ten questions. The Pearson correlation between 1b: Persevere in solving them and the other nine items was low at 0.266. After removing 1b: Persevere in solving them, from the analysis, Cronbach's alpha improved to 0.826 . For the purposes of this study, $l b$ was not removed because doing so would not increase the overall alpha to a large degree.

All teachers who participated in the study were asked to complete a questionnaire in order to provide demographic data. For example, teachers were asked such questions as: How many years have you been teaching? How many college level mathematics courses have you taken? Which courses? What is your current teacher certification area? In order to learn more about teacher knowledge of their own students' understanding of the equal sign, all participating teachers in the study were interviewed. Teachers were interviewed and asked to indicate how their students might answer questions similar to the ones asked on the MEKA. During the interviews teachers were invited to share their personal experience with CCSSM/CCSR implementation. Semi-structured interviews included the following planned questions: What answers would you expect your students to give to Task A? If Task A were given to 100 second, third, fourth or fifth grade students, what percent do you think would answer correctly? Each teacher was asked to answer according to the grade he/she currently teaches. How has your teaching changed since your school implemented the new mathematics standards? How do you develop students' algebraic thinking? What does it indicate when we say that students understand the meaning of the equal sign? How do you assess your students' understanding of the 
meaning of the equal sign? See Appendices F and G for the full demographic questionnaire and interview scripts.

\section{Data Collection Procedures for Research Question Two}

The researcher administered a teacher survey and interviews by meeting one on one with each teacher. In some cases the researcher returned to the school on different dates in order to accommodate schedules. However, for each grade, all assessments and teacher interviews occurred on the same day. After securing permission from each teacher, the researcher recorded interviews for the purposes of transcription.

Teachers individually completed the Teacher Demographic Questionnaire and MEKA while their students took the MEKA. By meeting with each teacher, the researcher was able to collect all other teacher data by meeting with them, usually in the teacher's own classroom. Prior to being interviewed, each teacher was asked to complete either the Process Standards for Mathematics Proficiency or Standards of Student Practice in Mathematics Proficiency. Teachers at Marie Elementary and Thomas Middle completed the Process Standards for Mathematics Proficiency survey and teachers at Schulz Elementary completed the Standards of Student Practice in Mathematics Proficiency survey. As mentioned, the surveys are identical except for the name. The researcher explained the directions for each survey and provided support as the teacher participants worked. After the completion of the survey, teacher interviews were conducted and each lasted approximately ten minutes. Other than knowing the researcher was pursuing the topic of mathematics instruction, teachers were not informed ahead of time as to the nature of the questions that were on any of the surveys or included in the interviews. 


\section{Data Analysis}

\section{Research Question 1}

Research question one focused on student understanding of the equal sign and also teacher knowledge of the equal sign, as measured by the Mathematical Equivalence Knowledge Assessment (MEKA). The MEKA data (total number correct) were disaggregated by school, grade and state. In order to conceal the state (location) of each school and for data analysis purposes, Marie Elementary and Thomas Middle are located in State 1 and Schulz Elementary is located in State 0. Descriptive statistics including mean, median, mode, standard deviation, maximum and minimum were computed for student and teacher total number of points. Descriptive statistics included those for each subgroup of teachers and students. For example, all second grade teacher scores from Marie Elementary, all second grade teacher scores from Schulz Elementary, all third grade teacher scores from Marie Elementary and Schulz Elementary, all third grade student scores from Marie Elementary and Schulz Elementary, all fourth grade teacher scores from Marie Elementary and Schulz Elementary, all fourth grade student scores from Marie Elementary and Schulz Elementary and so on. Recall that students in second and third grade took a shortened version of the MEKA while fourth and fifth grade students took a longer version. Younger elementary students (those in second and third grade) took an assessment consisting of 22 items. Older students (those in fourth and fifth grade) took an assessment consisting of 29 items. Thirteen items were identical on all exams. Teachers took the MEKA that aligned with the grade they taught. In this way, there were two sets of data. Student and teacher scores were analyzed using hierarchical linear modeling with MPlus 7.1 with student score as the dependent variable and teacher 
score, grade level, and state as the independent variables. Hierarchical linear modeling was necessary for the nested data to better account for grouping influences on the data. The ANCOVA model did not change the variance within levels but did reduce the variance between levels from $2.3 \%$ to $0.5 \%$. The within level variance with both models was $2.7 \%$.

Teacher interviews included asking teachers to predict their students' understanding of the equal sign. Specifically, teachers were asked to predict what percent of their students would answer correctly on tasks such as defining the meaning of the equal sign and successfully completing open number sentences. The responses from the teachers were then compared to how the students actually performed on those tasks from the MEKA. In order to make the comparison, the percentage of students who answered correctly on each task was computed.

\section{Research Question 2}

Research question two focused upon the impact that the implementation of new state standards may have had on student understanding of the equal sign. As previously mentioned for research question one, student understanding of the equal sign was measured by the MEKA. The analyses for research question one were also used for research question two. Because there are differences in the implementation timelines between State 0 and State 1, the differences in MEKA scores from each state are considered.

Responses reported on the two separate teacher surveys were also analyzed for research question two. The Process Standards for Mathematics Proficiency/Process Standards for Mathematics Proficiency survey addressed research question two by 
providing a proxy measure of level of implementation for CCSSM/CCRS. Each teacher completed the survey and therefore has an implementation score. Descriptive data were computed on the teacher implementation scores (30 possible points) including mean, median, mode, standard deviation, maximum and minimum. An analysis of variance (ANOVA) was conducted so that the amount of variance between state, school and grade groups could be compared to the variance within groups (Shavelson, 1996).

The interview transcriptions were analyzed to "highlight significant statements, sentences, or quotes to provide an understanding of how the participants experienced the phenomenon" (Creswell, 2007, p. 61). Clusters of meaning were then developed into themes (Creswell, 2007). A description of what the teachers experienced including the context of the situation or circumstances, was developed from the themes and statements from the analysis. Personal statements from the researcher are not included. Finally, the "essence" of implementation of CCSSM was developed for the purpose of focusing on what is common among teachers who experienced the implementation of CCSSM (Creswell, 2007, p. 62).

\section{Internal Validity Threats}

Defined by Shadish and colleagues as "the validity of inferences about whether the relationship between two variables is causal" internal validity must be considered. Selection of participants can threaten internal validity (2002, p. 508). Although second grade students are being compared to other second grade students (and the same for grades 3,4 , and 5) there is a chance that the groups vary greatly on a number of factors such as students' IQ or ability. Other than grade and age, individual student data (excluding MEKA data) were not obtained for this study. 
For the current study history as an internal validity threat pertains to all events occurring from the beginning of treatment (in this case CCSSM implementation) and the time the assessment was administered. Suggestions for reducing the likelihood of history include "selecting groups from the same general location and by ensuring that the schedule for testing is the same in both groups" (Shadish, Cook, \& Campbell, 2002, p. 56). In conversation with the school principals, the researcher inquired about events that could impact the results of the study and in both settings, testing windows were agreed to be within the same last few weeks of the school year. However, the students and teachers included in the study are from three separate schools in two separate states. Attrition was not a concern because the researcher was able to meet with every teacher in the study and no teachers dropped out. Students and teachers were assessed one time and therefore maturation was not a threat to internal validity. Considered to "definitionally eliminate selection bias" (Shadish et al., 2002, p. 56) random assignment was not implemented because State 0 and State 1 were chosen on the basis of CCSSM/CCRS implementation.

\section{Generalizability}

The elementary and middle schools selected for the study are fairly representative of other public elementary and middle schools in this region of the U.S. However, there is an acknowledgement that the student demographic data in Appendix A may imply that Marie Elementary, Thomas Middle and Schulz Elementary schools do not represent the population of elementary students in other parts of the United States. For example, the percentage of minority students or students on free or reduced lunch is very low. For this reason, the results of the study may only be generalizable to those schools similar to the 
schools examined in the study. The inclusion of multiple grade level students increases the sample size and breadth and helps to improve the generalization of the results.

Teacher demographics collected from the Teacher Demographic Questionnaire Appendix I, reveal that all three schools have teachers with a wide range of teaching experience, from 2 years to 26 years. The mean number of years teaching for all of the teachers in the sample is 10.45. Including teachers of four different grade levels from three schools should improve the generalizability.

\section{Trustworthiness and Credibility}

Credibility, transferability, dependability, and confirmability are four criteria that could be combined to determine the trustworthiness of a study and "credibility is the most important component in establishing the trustworthiness of the results and inferences from qualitative research"(Tashakkori \& Teddlie, 1998, p. 90). The research methods employed in the current study were based upon previous studies that focused upon equal sign understanding (Matthews et al., 2012; Matthews \& Rittle-Johnson, 2009; RittleJohnson et al., 2011). In addition, the researcher was familiar to some degree with the culture of the three participating schools. As the parent of one student at Marie Elementary, and one student at Thomas Middle and also a former employee at Schulz Elementary, the researcher visited the schools previously and has some familiarity with the overall context of each school. Triangulation of some of the data did occur. Teacher knowledge of the equal sign was assessed on the MEKA as well as in the teacher interviews. Teacher responses to the question "What does it mean for students to understand the meaning of the equal sign?" confirmed teacher performance on the MEKA scores. Conversations and electronic communications with principals at each of 
the schools helped to provide additional data that added to the description of the overall context of each school. As mentioned, participants were able to refuse to participate at any time. The assessments taken by teachers and their students were made anonymous by removing any identifiable information and the interviews were recorded only after securing teacher consent. 


\section{CHAPTER IV}

\section{RESULTS}

Chapter IV provides the analysis of student and teacher performance on the MEKA and some data from the teacher interviews. In addition, an analysis of the open ended teacher interview responses is included. Finally, an analysis of CCSSM/CCRS implementation data is presented.

\section{Introduction}

The purpose of this study was to examine the impact of teacher understanding of the equal sign on student understanding of the equal sign. The study also investigated the impact of two different implementation timelines of new state standards (CCSSM/CCRS) on student understanding of the meaning of the equal sign.

All participating teachers were asked to complete a teacher demographic questionnaire. Forty-one teachers completed the questionnaire. Among the items on the questionnaire, each teacher was asked to indicate their certification area and if they held any additional certifications. Teachers at Marie Elementary, who currently teach grades two through four, all indicated having a K-6 certification. Three teachers have additional certifications including: GT (gifted and talented), Reading Specialist, and Kindergarten endorsement. Teachers at Thomas Middle, who currently teach grade five, four indicated having K-6 certification, one has science/language arts, and two have grades 1-8 (non departmentalized) certification. High ability and Reading endorsement certifications are also held by two of the seven participating teachers at Thomas Middle. 
Sixteen teachers at Schulz Elementary hold K-5 certification, one holds K-6, one holds 18 certification and one holds Middle School certification in mathematics. Eight of the fifteen teachers at Schulz Elementary hold National Board Certification. Marie Elementary and Thomas Middle do not have any National Board Certified teachers.

Teachers were asked if they had received professional development on the teaching of their recently adopted state's mathematics standards and if so, to describe the training. Although all teachers were able indicate a "yes" or "no" that they received training, when they were asked to detail the training, many teachers provided information that was more related to dates than content. All 16 teachers at Marie Elementary reported having professional development on teaching their state's mathematics standards. Some teachers at Marie Elementary replied with comments that named the person leading the professional development such as Jan Christianson, Marilyn Burns or mathematics leaders in the district. Other teachers commented on the frequency or duration of the professional development. Teachers indicated every summer," "three math professional developments," or "each quarter."

Six of the seven teachers at Thomas Middle indicated that they had attended professional development on teaching their state's mathematics standards. One reported not having any professional development. Teachers at Thomas Middle either indicated having "one day," "one and a half days," or "two days" of professional development. Two teachers at Thomas Middle replied that their professional development occurred "at the corporation building."

Seventeen of the 19 teachers at Schulz Elementary indicated that they had received professional development on teaching the recently adopted mathematics 
standards. Two indicated not having the professional development. Teachers at Schulz Elementary described their professional development in terms that indicated the location "district" or duration "2 hours." For those teachers mentioning the duration of the professional development, responses varied from "1 day" to "12-24 hours."

The information gathered from the teacher demographic survey was meant to provide details of the overall sample and context of the current study rather than draw conclusions about individual teacher differences.

\section{Restatement of Research Questions}

Research Question 1: What is the impact of teacher knowledge of the equal sign on student understanding of the meaning of the equal sign?

Research Question 2: What is the impact of new state standards implementation on student understanding of the equal sign?

The intent of research question one was to examine the impact of teacher knowledge of the equal sign on student understanding of the equal sign using the Mathematical Equivalence Knowledge Assessment (MEKA). The MEKA was administered in Marie Elementary, Thomas Middle and Schulz Elementary schools to all 41 participating teachers and 1182 students. Teachers and students in grades two and three took the same assessment. Teachers and students in grades four and five took the same assessment which was slightly different from the one administered to teachers in grades two and three. The assessment for grades two and three had 23 possible points. The assessment for grades four and five had 32 possible points. Teachers were also asked to predict their students' success on items that assessed equal sign understanding. 
The intent of research question two was to examine the impact of new state standards implementation on student understanding of the equal sign. For this research question, student scores on the MEKA were analyzed. Teacher reports on the teacher survey Process Standards for Mathematics Proficiency or Standards of Student Practice in Mathematics Proficiency and data from teacher interviews were also analyzed. For example, teachers were asked to explain how their own teaching of mathematics has changed since implementing new state standards.

\section{Teacher and Student Scores on Mathematical Equivalence Knowledge Assessment}

Overall results from the MEKA that include all scores from teachers and students from the four participating grade levels are presented first. Descriptive statistics for the number of points earned on the MEKA are provided for each school and grade in Table 12.

Table 12

Marie Elementary, Thomas Middle and Schulz Elementary Schools, Grade 2 through Grade 5

Mean Median Mode SD Low High

\begin{tabular}{|c|c|c|c|c|c|c|c|}
\hline \multicolumn{8}{|c|}{ Marie Elementary } \\
\hline & \multicolumn{7}{|c|}{ Grade 2} \\
\hline Teacher & 5 & 21.60 & 21.00 & 21.00 & 1.34 & 20.00 & 23.00 \\
\hline Student & 122 & 7.32 & 6.00 & 5.00 & 3.64 & 2.00 & 20.00 \\
\hline Marie El & \multicolumn{6}{|c|}{ Marie Elementary } & Grade 3 \\
\hline Teacher & 6 & 21.83 & 22.0 & 23.0 & 1.33 & 20.0 & 23.0 \\
\hline Student & 117 & 10.97 & 10.0 & 10.0 & 4.44 & 2.0 & 21.0 \\
\hline \multicolumn{8}{|c|}{ Marie Elementary } \\
\hline Teacher & 5 & 30.00 & 29.00 & 29.00 & 1.87 & 28.00 & 32.00 \\
\hline Student & 157 & 18.80 & 20.00 & 27.00 & 6.73 & 3.00 & 29.00 \\
\hline
\end{tabular}

Thomas Middle

Grade 5 


\begin{tabular}{|c|c|c|c|c|c|c|c|}
\hline Teacher & 7 & 28.14 & 29.00 & 26.00 & 2.41 & 25.00 & 31.00 \\
\hline Student & 345 & 22.59 & 24.00 & 24.00 & 5.04 & 5.00 & 32.00 \\
\hline \multicolumn{8}{|c|}{ Thomas Middle } \\
\hline & Gra & & & & & & \\
\hline Teacher & 4 & 21.50 & 21.50 & 21.00 & 0.58 & 21.00 & 22.00 \\
\hline Student & 91 & 12.37 & 12.00 & 8.00 & 5.15 & 3.00 & 23.00 \\
\hline \multicolumn{8}{|c|}{ Schulz Elementary } \\
\hline & Gra & & & & & & \\
\hline Teacher & 5 & 20.80 & 21.00 & 20.00 & 0.84 & 20.00 & 22.00 \\
\hline Student & 116 & 15.46 & 17.00 & 19.00 & 4.62 & 4.00 & 22.00 \\
\hline \multicolumn{8}{|c|}{ Schulz Elementary } \\
\hline & Gra & & & & & & \\
\hline Teacher & 5 & 28.4 & 29.0 & 29.0 & 1.51 & 26.0 & 30.00 \\
\hline Student & 110 & 22.62 & 24.00 & 25.00 & 5.19 & 6.00 & 30.00 \\
\hline \multicolumn{8}{|c|}{ Schulz Elementary } \\
\hline & Gra & & & & & & \\
\hline Teacher & 5 & 29.20 & 30.00 & 30.00 & 1.64 & 27.00 & 31.00 \\
\hline Student & 124 & 24.90 & 26.00 & 27.00 & 4.07 & 10.00 & 32.00 \\
\hline
\end{tabular}

An unconditional hierarchical linear model that did not include state, grade or teacher score was first conducted to determine the variance among student scores (SSCORE). Within level variance is $0.027(2.7 \%)$ and the between groups variance is $0.023(2.3 \%)$. The estimated mean for all students (SSCORE mean) was 60\% (correct) and the means showed significant differences within and between $(p<.05, .001)$. Table 13 shows the results of the unconditional hierarchical linear model.

Table 13

Unconditional Model Results

\begin{tabular}{lllll}
\hline & Estimate & S.E. & Est./S.E. & Two-Tailed \\
& & & & P-Value \\
\hline \multicolumn{1}{c}{ Within Level } & & & & \\
Variances & 0.027 & 0.002 & 12.203 & 0.000 \\
SSCORE & & & &
\end{tabular}

Between Level 
SSCORE

Variances

0.023

0.004

5.669

0.000

SSCORE

Teacher scores for the second and third grade group as well as for the fourth and fifth grade group could be impacted by a ceiling effect. Most of the teacher scores are clustered above $80 \%$ correct and many above $90 \%$ correct.

An analysis of covariance (ANCOVA) was then conducted that included grade (GRADE), state (STATE), and teacher score (TSCORE) as predictors of student score (SSCORE). The three participating schools are situated in two states with two different implementation schedules so STATE was used in the analysis and will capture difference between the two schools district's implementation schedules in student scores. The three schools are identified by pseudonyms. Marie Elementary and Thomas Middle schools are in one state $(\mathrm{STATE}=1)$ where they were only one year into the implementation of the new standards and Schulz Elementary is in a different state $($ STATE $=0)$ where the implementation of the new mathematics standards was in place for four years. The ANCOVA model did not change the unexplained variance within levels (Table 13), but did reduce the unexplained variance between levels from $2.3 \%$ to $0.5 \%$. Grade was a significant predictor of SSCORE with a $p$-value less than 0.001. This was expected because students in grade 5, for example, would be expected to score higher than students in grade 2 due to maturation and three additional years of exposure to mathematics instruction. STATE (which was the variable that represented the difference in the implementation schedules for the new mathematics standards) was also a significant 
predictor of SSCORE with a $p$-value less than 0.001. Teacher score (TSCORE) on the MEKA was not significant predictor of the students' scores on the MEKA so it will not be used in the interpretation of the results.

An example using the data from Table 13 may be helpful to explain the results. First, the results are shown in Table 13 are about State $0($ STATE $=0)$ and Grade 2 $($ Grade $=0)$. Results for State 1 and Grades 3-5 require some calculation. Starting with State 0 (implementation year four), because that is the default state (STATE $=0$ ), an average student in grade $2(\mathrm{GRADE}=0)$ at school Schulz Elementary (which is in state 0 ) had a mean score of $51.5 \%$ correct ( 0.515 in Table 13$)$. The grade coefficient of 10.4\% (0.104 in Table 13) means that for an increase of one grade level would increase the mean student score by $10.4 \%$. Therefore an average grade $3(\mathrm{GRADE}=1)$ student at Schulz Elementary $($ STATE $=0)$ would score $61.9 \%$ correct $(51.5 \%+10.4 \%)$. An average grade $4(\mathrm{GRADE}=2)$ student at Schulz Elementary $(\mathrm{STATE}=0)$ would score $72.3 \% \operatorname{correct}(51.5 \%+2 \times 10.4 \%)$.

The timeline for implementation (STATE) was also a significant factor contributing a negative $14.9 \%$ (-0.149 in Table 14) students' scores. An average student in grade $2(\mathrm{GRADE}=0)$ at Marie Elementary $(\mathrm{STATE}=1)($ implementation year one) would score $36.6 \%(51.5 \%-14.9 \%)$ and an average student in the same school in grade 3 $($ GRADE $=1)($ STATE $=1)$ would score $47 \%(51.5 \%-14.9 \%+10.4 \%)$. Note that in this case $\mathrm{STATE}=1$ means that 0.149 is multiplied by 1 , rather than 0 . 
Table 14

ANCOVA Model Results

\begin{tabular}{|c|c|c|c|c|c|}
\hline & & Estimate & S.E. & Est./S.E. & $\begin{array}{l}\text { Two-Tailed } \\
\text { P-Value }\end{array}$ \\
\hline \multicolumn{6}{|c|}{ Within Level } \\
\hline \multicolumn{6}{|l|}{ Variances } \\
\hline & SSCORE & 0.027 & 0.002 & 12.227 & 0.000 \\
\hline \multicolumn{6}{|c|}{ Between Level } \\
\hline \multicolumn{6}{|l|}{ SSCORE } \\
\hline & GRADE & 0.104 & 0.012 & 9.010 & 0.000 \\
\hline & STATE & -0.149 & 0.022 & -6.844 & 0.000 \\
\hline & TSCORE & -0.014 & 0.259 & -0.070 & 0.944 \\
\hline \multirow[t]{2}{*}{ Intercepts } & & 0.023 & 0.004 & 5.669 & 0.000 \\
\hline & SSCORE & 0.515 & 0.024 & 21.548 & 0.000 \\
\hline \multicolumn{6}{|c|}{ Residual Variances } \\
\hline & SSCORE & 0.005 & 0.001 & 3.890 & 0.000 \\
\hline
\end{tabular}

\section{Teacher Knowledge}

\section{Understanding the Equal Sign}

During the interview, teachers were asked what would need to be demonstrated for them to know that students understand the meaning of the equal sign. Asking this question was important because "asking a student to understand something means asking a teacher to assess whether the student has understood" (NGA, 2010, p. 4). In making comparisons between the state implementation schedules where the two school systems are located, teacher responses in the interview were similar to the results found on the corresponding test item on the teacher's Mathematical Equivalence Knowledge Assessment (Items $\mathrm{C} 1$ on the $2 / 3$ MEKA and 6 on the 4/5 MEKA). 
Table 15

Percentages and Examples of Teacher Responses, Understanding the Equal Sign

\begin{tabular}{|c|c|c|c|}
\hline Category & $\begin{array}{l}\text { Marie } \\
\text { Elementary/Thomas } \\
\text { Middle }\end{array}$ & Schulz Elementary & $\begin{array}{l}\text { Example(s) of Teacher } \\
\text { Responses }\end{array}$ \\
\hline $\begin{array}{l}\text { Understanding the equal } \\
\text { sign- relational }\end{array}$ & $45 \%$ & $47 \%$ & $\begin{array}{l}\text { Balancing two sides of } \\
\text { equation, reaches into } \\
\text { language arts, as many } \\
\text { representations of the } \\
\text { same concept } \\
\text { Realize it's balanced } \\
\text { like a scale } \\
\text { Being able to explain } \\
\text { that value whatever it } \\
\text { may be, on the left } \\
\text { needs to be the same as } \\
\text { value on right } \\
\text { Same value, not it's } \\
\text { where the answer goes }\end{array}$ \\
\hline $\begin{array}{l}\text { Understanding the equal } \\
\text { sign- operational }\end{array}$ & $0 \%$ & $5 \%$ & $\begin{array}{l}\text { They're able to } \\
\text { legitimately explain the } \\
\text { cause and effect of } \\
\text { math. They have to } \\
\text { understand equal means } \\
\text { I am doing something to } \\
\text { get on the other side }\end{array}$ \\
\hline $\begin{array}{l}\text { Understanding the equal } \\
\text { sign- relational and } \\
\text { operational }\end{array}$ & $27 \%$ & $32 \%$ & $\begin{array}{l}\text { Need to know it doesn't } \\
\text { have just one meaning, } \\
\text { there are multiple } \\
\text { meanings } \\
\text { Ideally they'll know that } \\
\text { both sides have an } \\
\text { equivalency not just the } \\
\text { answer is } \\
\text { Equal doesn't mean just } \\
\text { equal it means that both } \\
\text { sides are the same, not } \\
\text { just what's the answer } \\
\\
\text { I want them to know } \\
\text { that the equal sign is } \\
\text { used to show the answer } \\
\text { to an equation and so it } \\
\text { can be an answer to a } \\
\text { problem or it can also be } \\
\text { the balance of two }\end{array}$ \\
\hline
\end{tabular}




\begin{tabular}{|l|l|l|l|}
\hline $\begin{array}{l}\text { Understanding the equal } \\
\text { sign- unclear }\end{array}$ & 27\% & problems." \\
\hline & & $\begin{array}{l}\text { I think they would have } \\
\text { to be able to use that } \\
\text { logic to figure out those } \\
\text { sides of the equal sign } \\
\text { I think before it was the } \\
\text { equal sign means two } \\
\text { plus two but now it is } \\
\text { forcing us to teach it, a } \\
\text { broader definition }\end{array}$ \\
& & $\begin{array}{l}\text { I like for them to know } \\
\text { how it can be used, it } \\
\text { can be used across the } \\
\text { board, communication } \\
\text { of information, being } \\
\text { able to use it }\end{array}$ \\
& & $\begin{array}{l}\text { I think if you can } \\
\text { understand the concept } \\
\text { of equivalency I think } \\
\text { that it goes through so } \\
\text { much more than just } \\
\text { basic algebra and basic } \\
\text { number sentences, I } \\
\text { think that if you can } \\
\text { understand that concept } \\
\text { of things being } \\
\text { equivalent, things being } \\
\text { proportional I think that } \\
\text { goes all throughout } \\
\text { mathematics and I think } \\
\text { it makes a lot of other } \\
\text { concepts easier to } \\
\text { understand }\end{array}$ \\
\hline
\end{tabular}

From Table 15, Marie Elementary/Thomas Middle and Schulz Elementary teachers had similar responses to "what does it mean for students to understand the equal sign" in that teachers from the both schools viewed relational understanding as the ideal student definition based on their view of student understanding. However, one teacher from Schulz Elementary appeared to indicate that students should provide the operational definition when asked to explain the meaning of the equal sign, when the teacher said, "they're able to legitimately explain the cause and effect of math. They have to 
understand equal means, I am doing something to get on the other side." Similar numbers of teachers at Marie Elementary/Thomas Middle and Schulz Elementary reported that both the operational and relational definitions were needed for them to consider that students showed understanding of the equal sign. A higher percentage of teachers from Marie Elementary/Thomas Middle than Schulz Elementary gave an unclear response that was not categorized in either group in that their definition was either vague or unrelated to either the relational or operational conception of the equal sign.

\section{Predicting Student Success}

Participating teachers were interviewed for the purpose of establishing the knowledge they had of their own students' understanding of the equal sign. During individual teacher interviews, all teachers were asked the same set of questions. However, due to differences in grades taught, the questions pertaining to how students might answer open number sentences, the numbers were modified slightly to match the grade level. For example, second and third grade teachers were asked to predict what number their students would write in the box representing the unknown in $(8+4=\square+$ 5). Fourth and fifth grade teachers were asked to predict what numbers their students would write in the box representing the unknown in $(67+84=\square+83)$.

The responses that teachers gave were compiled and then compared to how the students actually answered on the same questions. The questions from the interview that correspond to the questions on the MEKA are shown in detail in Table 16 and Table 17. Although the grade level indicated in Table 16 is two, each teacher was asked to answer according to the grade level of his or her current students. The same is true for Table 17. 
Table 16

Item Summary: Grade 2 Assessment/Interview

\begin{tabular}{|c|c|c|c|c|}
\hline Question/Task & Question Type & $\begin{array}{l}\text { Question } \\
\text { ID }\end{array}$ & $\begin{array}{l}\text { Grade } \\
\text { Level }\end{array}$ & Student/Teacher \\
\hline What does the equal sign mean? & $\begin{array}{l}\text { Equal sign } \\
\text { definition, level } 3\end{array}$ & $\mathrm{C} 1 \mathrm{~A}$ & $2 / 3$ & Student \\
\hline Can it mean anything else? & $\begin{array}{l}\text { Equal sign } \\
\text { definition, level } 3\end{array}$ & $\mathrm{C} 1 \mathrm{~B}$ & $2 / 3$ & Student \\
\hline $\begin{array}{l}\text { Suppose you gave this task to } 100 \\
\text { second grade students in your school. } \\
\text { Could you indicate what percent } \\
\text { would answer correctly? } \\
\text { Task A: The arrow above points to a } \\
\text { symbol. What is the name of the } \\
\text { symbol? What does the symbol } \\
\text { mean? } \\
3+4=7\end{array}$ & $\begin{array}{l}\text { Equal sign } \\
\text { definition, level } 3\end{array}$ & $\mathrm{C} 1 \mathrm{~A} / \mathrm{C} 1 \mathrm{~B}$ & $2 / 3$ & Teacher \\
\hline $\begin{array}{l}\text { Find the number that goes in the box. } \\
3+4=\square+5\end{array}$ & $\begin{array}{l}\text { Equation-solving, } \\
\text { level } 3\end{array}$ & $\mathrm{P} 2$ & $2 / 3$ & Student \\
\hline $\begin{array}{l}\text { Find the number that goes in the box. } \\
4+5+8=\square+8\end{array}$ & $\begin{array}{l}\text { Equation-solving, } \\
\text { level } 3\end{array}$ & $\mathrm{P} 3$ & $2 / 3$ & Student \\
\hline $\begin{array}{l}\text { Suppose you gave this task to } 100 \\
\text { second grade students in your school. } \\
\text { Could you indicate what percent } \\
\text { would answer correctly? } \\
8+4=\square+5\end{array}$ & $\begin{array}{l}\text { Equation-solving, } \\
\text { level } 3\end{array}$ & $\mathrm{P} 2 \mathrm{P} 3$ & $2 / 3$ & Teacher \\
\hline
\end{tabular}

\section{Table 17}

Item Summary: Grade 4 Assessment/Interview

\begin{tabular}{|l|l|l|l|l|}
\hline Question/Task & Question Type & $\begin{array}{l}\text { Question } \\
\text { ID }\end{array}$ & $\begin{array}{l}\text { Grade } \\
\text { Level }\end{array}$ & Student/Teacher \\
\hline What does the equal sign mean? & $\begin{array}{l}\text { Equal sign } \\
\text { definition, level 3 }\end{array}$ & ES1A & $4 / 5$ & Student \\
\hline Can it mean anything else? & $\begin{array}{l}\text { Equal sign } \\
\text { definition, level 3 }\end{array}$ & ES2B & $4 / 5$ & Student \\
\hline $\begin{array}{l}\text { Suppose you gave this task to 100 } \\
\text { fourth grade students in your school. } \\
\text { Could you indicate what percent } \\
\text { would answer correctly? } \\
\text { Task A: The arrow above points to a } \\
\text { symbol. What is the name of the } \\
\text { symbol? What does the symbol }\end{array}$ & $\begin{array}{l}\text { Equal sign } \\
\text { definition, level 3 }\end{array}$ & ESAB & $2 / 3$ & Teacher \\
\hline
\end{tabular}




\begin{tabular}{|l|l|l|l|l|}
\hline $\begin{array}{l}\text { mean? } \\
3+4=7\end{array}$ & & & & \\
\hline $\begin{array}{l}\text { Find the number that goes in the box. } \\
67+84=\square+83\end{array}$ & $\begin{array}{l}\text { Equation-solving, } \\
\text { level } 4\end{array}$ & OE21 & $4 / 5$ & Student \\
\hline $\begin{array}{l}\text { Find the number that goes in the box. } \\
\square 5=37+54\end{array}$ & $\begin{array}{l}\text { Equation-solving, } \\
\text { level } 4\end{array}$ & OE23 & $4 / 5$ & Student \\
\hline $\begin{array}{l}\text { Suppose you gave this task to } 100 \\
\text { fourth grade students in your school. } \\
\begin{array}{l}\text { Could you indicate what percent } \\
\text { would answer correctly? }\end{array} \\
67+84=\square+83\end{array}$ & $\begin{array}{l}\text { Equation-solving, } \\
\text { level } 4\end{array}$ & OE2123 & $4 / 5$ & Teacher \\
\hline
\end{tabular}

The responses of the teachers are summarized in Tables 18-21 along with the actual percent of students who answered correctly. Students were asked to provide the meaning of the equal sign $(\mathrm{C} 1 \mathrm{~A})$ and also if there were any other definitions they knew (C1B). Student responses were coded as correct and one point was awarded for providing a relational definition of the equal sign for question $\mathrm{C} 1 \mathrm{~A} / \mathrm{C} 1 \mathrm{~B}$ while also declaring no other definition for question C1A/C1B. Question C1A asked "What does the equal sign $(=)$ mean?" Question C1B asked “Can it mean anything else?" A student who writes, "it means both sides are the same" for either question $\mathrm{C} 1 \mathrm{~A} / \mathrm{C} 1 \mathrm{~B}$ and then provides no added non-relational answer for $\mathrm{C} 1 \mathrm{~A} / \mathrm{C} 1 \mathrm{~B}$, the student earns one point each for $\mathrm{C} 1 \mathrm{~A}$ and $\mathrm{C} 1 \mathrm{~B}$. However, if the student indicates at any time, "it means the answer" and also "it means both sides are the same," the score is just one point total. The same coding scheme was maintained for the same questions for students in grades two through five. Correct responses to questions about the meaning of the equal sign are considered to be at the basic relational level from the Construct Map for Mathematical Equivalence 
Knowledge (Rittle-Johnson et al., 2011). Questions where students solve for an unknown when they are given two expressions on either side of the equal sign (P2 and P3 on the MEKA) were selected for analysis because both are at level 3 in the theoretical framework (equation solving items) (see Table 18). Responses for these items were coded as correct and one point was awarded. In determining the actual percent of students in one grade at one school who answered correctly, the number of students who got both these items (P2 and P3 on the MEKA) correct was included. The same coding scheme was used for OE21/OE23.

Table 18

Marie Elementary, Grades 2/3, Teacher Predictions/Actual Correct Responses to Selected Items, Values are in Percent Correct

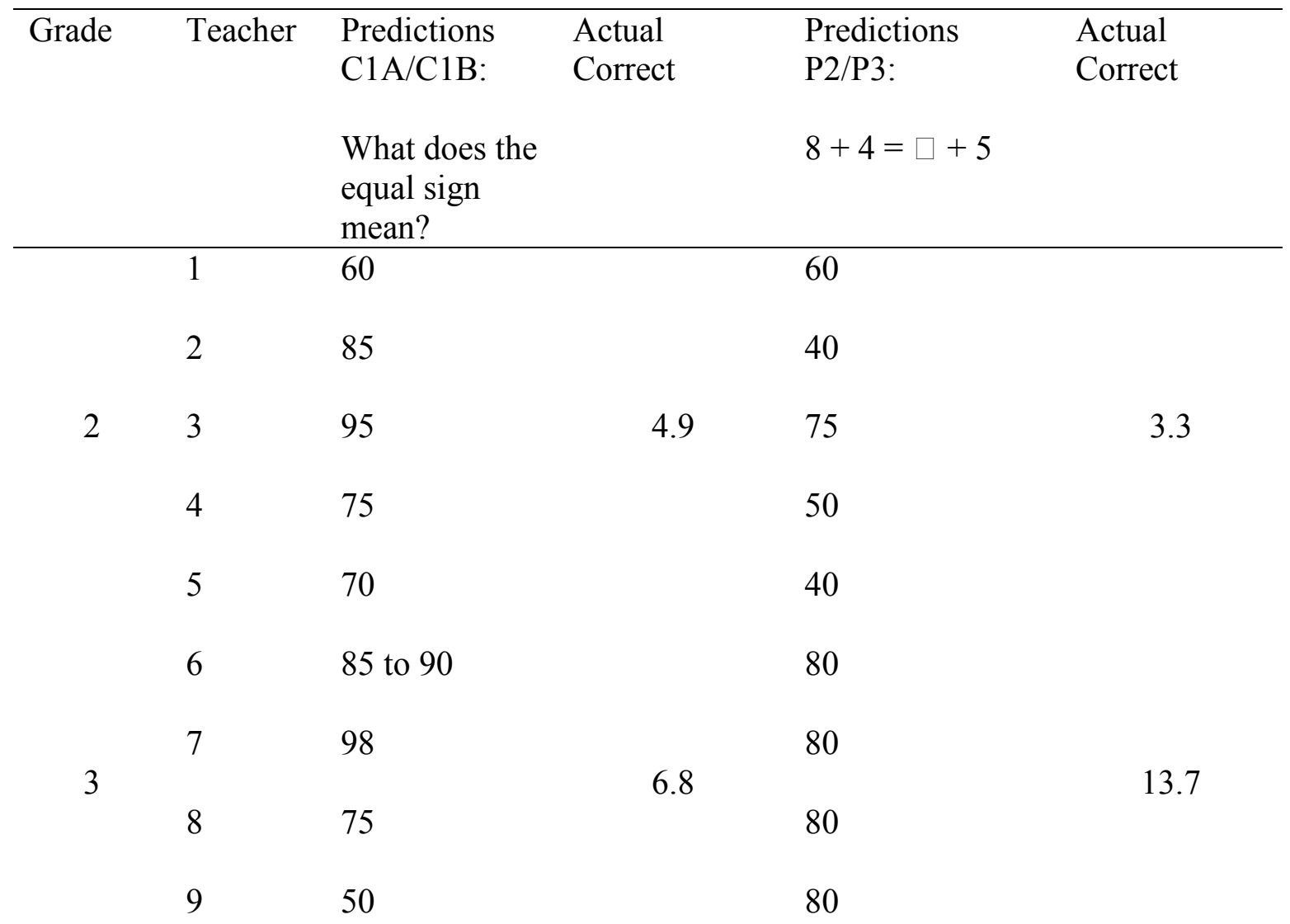




$\begin{array}{lll}10 & 75 & 80 \\ 11 & 90 & 90\end{array}$

Table 19

Schulz Elementary, Grades 2/3, Teacher Predictions/Actual Correct Responses to Selected Items, Values are in Percent Correct

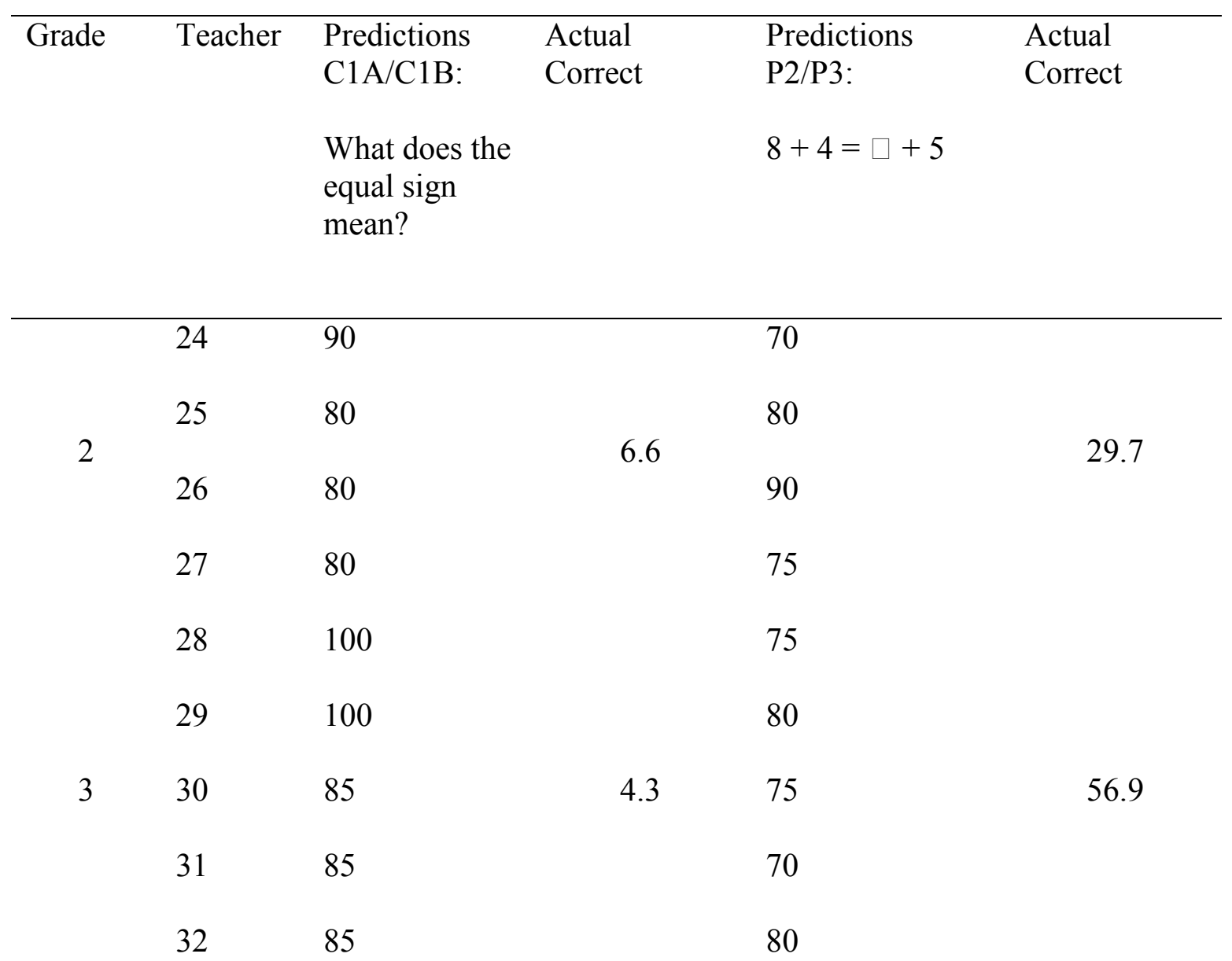


Table 20

Marie Elementary (Grade 4) and Thomas Middle (Grade 5), Teacher Predictions/Actual Correct Responses to Selected Items, Values are in Percent Correct

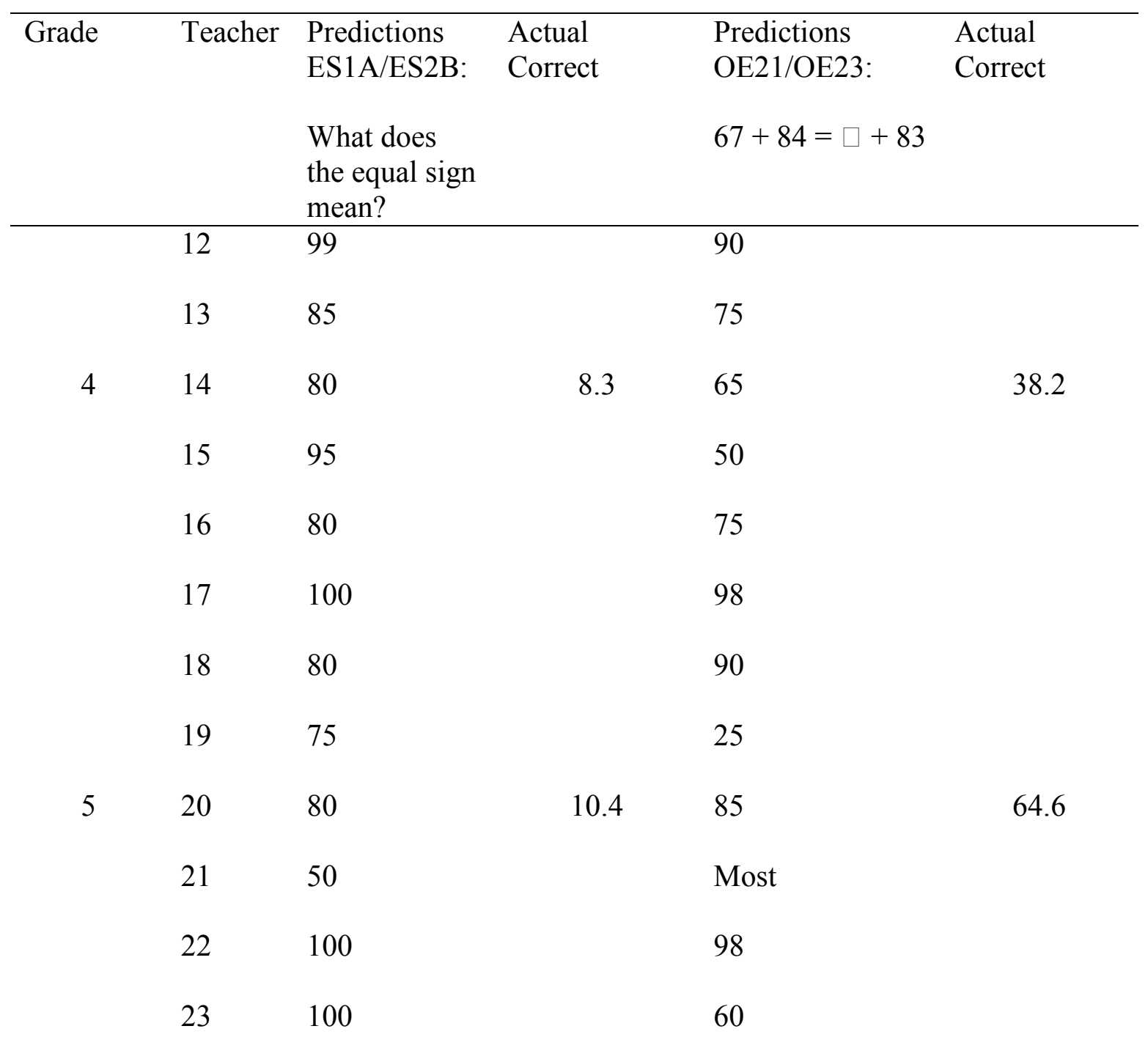


Table 21

Schulz Elementary, Grades 4/5, Teacher Predictions/Actual Correct Responses to Selected Items, Values are in Percent Correct

\begin{tabular}{|c|c|c|c|c|c|}
\hline \multirow[t]{4}{*}{ Grade } & Teacher & $\begin{array}{l}\text { Predictions } \\
\text { ES1A/ES2B: }\end{array}$ & $\begin{array}{l}\text { Actual } \\
\text { Correct }\end{array}$ & $\begin{array}{l}\text { Predictions } \\
\text { OE21/OE23: }\end{array}$ & $\begin{array}{l}\text { Actual } \\
\text { Correct }\end{array}$ \\
\hline & & $\begin{array}{l}\text { What does } \\
\text { the equal sign } \\
\text { mean? }\end{array}$ & & $67+84=\square+83$ & \\
\hline & 33 & 100 & & 80 & \\
\hline & 34 & $15-20$ & & 98 & \\
\hline \multirow[t]{5}{*}{4} & 35 & 95 & 5.5 & 75 & 57.3 \\
\hline & 36 & Less than 10 & & 50 & \\
\hline & 37 & 75 & & 85 & \\
\hline & 38 & 75 & & 85 & \\
\hline & 39 & 100 & & 90 & \\
\hline \multirow[t]{3}{*}{5} & 40 & 95 & 10.5 & 85 & 79 \\
\hline & 41 & 98 & & 95 & \\
\hline & 42 & 95 & & 95 & \\
\hline
\end{tabular}

\section{Summary of Teacher Knowledge}

Teachers performed very high on the Mathematical Equivalence Knowledge Assessment. Additionally, more than $90 \%$ demonstrated a relational understanding in the interview and $59 \%$ demonstrated both a relational and operational understanding. Yet, with only two exceptions, teachers were not able to predict how their students would perform on items related to the equal sign. 


\section{Research Question Two}

\section{Implementation Score}

The intent of research question two was to examine the impact of the implementation of new state standards (CCSSM/CCRS) on student understanding of the equal sign. The MEKA was used to measure student understanding of the equal sign and those results were discussed along with other results for research question one. Level of implementation of CCRS was measured by asking teachers at Marie Elementary and Thomas Middle (implementation year one) to complete the Process Standards for Mathematics Proficiency survey (Appendix L). Teachers at Schulz Elementary (implementation year four) completed the Standards of Student Practice in Mathematics Proficiency survey (Appendix M) as it relates to the level of implementation of CCSSM. To show how each school responded on each of the mathematical practices outlined in the Standards of Student Practice in Mathematics Proficiency/ Process Standards for Mathematics Proficiency survey, descriptive statistics are shown in Table 22. An analysis of variance was conducted in order to compare groups for differences. The test of between-subject effects was not significant $(p=0.99)$ for Marie Elementary/ Thomas Middle and Schulz Elementary. This results means that any difference between the two groups, Marie Elementary/Thomas Middle (implementation year one) $(n=23)$, and Schulz Elementary (implementation year 4) $(n=19)$, was due to chance. 
Table 22

Teacher Self-Reports for CCSSM/CCRS Implementation by Practice

\begin{tabular}{|c|c|c|c|c|c|c|}
\hline & Practice/Process & State & Mean & $\mathrm{SD}$ & $\begin{array}{l}\text { Maxi } \\
\text { mum }\end{array}$ & $\begin{array}{l}\text { Minim } \\
\text { um }\end{array}$ \\
\hline \multirow{2}{*}{$1 \mathrm{a}$} & \multirow[t]{2}{*}{ Make sense of problems. } & 0 & 2.35 & .71 & 3.0 & 1.0 \\
\hline & & 1 & 2.53 & .70 & 3.0 & 1.0 \\
\hline \multirow{2}{*}{$1 b$} & \multirow[t]{2}{*}{ Persevere in solving them. } & 1 & 2.00 & .67 & 3.0 & 1.0 \\
\hline & & 0 & 2.11 & .57 & 3.0 & 1.0 \\
\hline \multirow{2}{*}{2} & \multirow{2}{*}{$\begin{array}{l}\text { Reason abstractly and } \\
\text { quantitatively. }\end{array}$} & 1 & 1.87 & .76 & 3.0 & 1.0 \\
\hline & & 0 & 1.79 & .71 & 3.0 & 1.0 \\
\hline \multirow{2}{*}{$3 \mathrm{a}$} & \multirow[t]{2}{*}{ Construct viable arguments. } & 1 & 2.35 & .78 & 3.0 & 1.0 \\
\hline & & 0 & 2.34 & .60 & 3.0 & 1.0 \\
\hline \multirow{2}{*}{$3 b$} & \multirow{2}{*}{$\begin{array}{l}\text { Critique the reasoning of } \\
\text { others. }\end{array}$} & 1 & 1.78 & .60 & 3.0 & 1.0 \\
\hline & & 0 & 1.95 & .52 & 3.0 & 1.0 \\
\hline \multirow{2}{*}{4} & \multirow[t]{2}{*}{ Model with mathematics. } & 1 & 2.3 & .70 & 3.0 & 1.0 \\
\hline & & 0 & 2.26 & .56 & 3.0 & 1.0 \\
\hline \multirow{2}{*}{5} & \multirow{2}{*}{$\begin{array}{l}\text { Use appropriate tools } \\
\text { strategically. }\end{array}$} & 1 & 2.00 & .60 & 3.0 & 1.0 \\
\hline & & 0 & 1.84 & .83 & 3.0 & 1.0 \\
\hline \multirow{2}{*}{6} & \multirow[t]{2}{*}{ Attend to precision. } & 1 & 2.09 & .73 & 3.0 & 1.0 \\
\hline & & 0 & 2.37 & .60 & 3.0 & 1.0 \\
\hline \multirow{2}{*}{7} & \multirow{2}{*}{$\begin{array}{l}\text { Look for and make use of } \\
\text { structure. }\end{array}$} & 1 & 1.78 & .74 & 3.0 & 1.0 \\
\hline & & 0 & 1.58 & .61 & 3.0 & 1.0 \\
\hline \multirow{4}{*}{8} & Look for and express & 1 & 1.82 & .65 & 3.0 & 1.0 \\
\hline & $\begin{array}{l}\text { regularity in repeated } \\
\text { reasoning. }\end{array}$ & 0 & 1.74 & .45 & 2.0 & 1.0 \\
\hline & \multirow{2}{*}{ TOTAL (30) } & 1 & 20.35 & 4.35 & 26.0 & 12.0 \\
\hline & & 0 & 20.53 & 3.84 & 27.0 & 13.0 \\
\hline
\end{tabular}

\section{Teacher Interviews}

\section{Changes in Teaching}

To examine and compare changes in teaching practices, participating teachers were given an opportunity to describe if and how their teaching had changed since implementing the new state standards. As mentioned, at the time of the interviews the teachers in Marie Elementary and Thomas Middle completed year one of following College and Career Ready Standards (CCRS), which are in essence identical to the 
Common Core State Standards for Mathematics (CCSSM). At the time of the interviews, the teachers in Schulz Elementary completed their fourth year of full CCSSM implementation as shown in Table 23.

Table 23

Percentages and Example Teacher Responses, Change as a Result of CCSSM/CCRS Implementation

\begin{tabular}{|c|c|c|c|}
\hline Categories & $\begin{array}{c}\text { Marie Elementary/ } \\
\text { Thomas Middle } \\
\text { (implementation year } \\
\text { one) }\end{array}$ & $\begin{array}{l}\text { Schulz Elementary } \\
\text { (implementation year } \\
\text { four) }\end{array}$ & $\begin{array}{l}\text { Example(s) Teacher } \\
\text { Responses }\end{array}$ \\
\hline $\begin{array}{l}\text { Change as a result of } \\
\text { CCSSM/CCRS } \\
\text { implementation }\end{array}$ & $95 \%$ & $99 \%$ & $\begin{array}{l}\text { It's conceptual- use of } \\
\text { manipulatives } \\
\text { More algebra- shift } \\
\text { toward more problem } \\
\text { solving and reasoning } \\
\text { A lot more hands-on, } \\
\text { problem sharing and } \\
\text { how you did get that } \\
\text { answer }\end{array}$ \\
\hline $\begin{array}{l}\text { Did not identify change } \\
\text { as a result of } \\
\text { CCSSM/CCRS } \\
\text { implementation }\end{array}$ & $5 \%$ & $.03 \%$ & $\begin{array}{l}\text { For me it has not } \\
\text { changed } \\
\text { I've only taught middle } \\
\text { school, this is first year } \\
\text { teaching elementary, the } \\
\text { change has more to do } \\
\text { with teaching } \\
\text { elementary }\end{array}$ \\
\hline
\end{tabular}

Although a difference does not exist in terms of whether or not changes in teaching occurred, a difference does exist in how teachers in both schools describe those changes in teaching since implementing the new standards. Themes such as changes in teaching practices, impact on students, content changes and shifts in time spent on various concepts like developing algebraic thinking all surfaced as teachers shared their own experiences and perceptions. Teachers in Marie Elementary/Thomas Middle used 
phrases like "conceptual teaching," "conceptual learning," and "conceptual math" in their explanations of how teaching has changed. More specifically, one teacher said "We teach conceptually, they practice conceptually and then we have to take them from conceptual to paper pencil to pass our common formative assessment." Although comments such as those often included the word "conceptual," teachers from the same school used the word differently. Comments included teachers saying, "I am doing conceptual teaching" while other comments referred to students and "conceptual learning." Another teacher from Marie Elementary discussed, "I'm no longer teaching old tricks, rhythms and rhymes, things that would help them memorize and have algorithms in their brain" and yet another from the same school gave an example from her own schooling by saying "no teaching of rhymes, I was taught to go next door and borrow ten more." On the other hand, teachers from Schulz Elementary referred more often to changes in content and the term "conceptual" was not used in their explanations. Teachers from Marie Elementary/Thomas Middle made other comments about changes in their teaching practices since implementation of the new standards (CCRS). For example, they described using "more manipulatives and hands on activities," "more modeling and showing multiple ways to approach and solve problems," and "discussion to bring out the vocabulary." Just one teacher from Schulz Elementary had a similar comment when she stated that her teaching practices were "more hands on."

Teachers from both Marie Elementary/Thomas Middle and Schulz Elementary pointed out their observation of a marked impact on students since implementing CCRS/CCSSM. While one teacher at Thomas Middle noted, "it's a lot different because it seems like what we're doing is we're throwing a lot more [content] than they're really 
ready for. So we're having to teach more now and then go backwards," twelve different teachers from Schulz Elementary made similar comments. For example, teachers mentioned "some of the content like order of operations in third grade is not developmentally appropriate," "having to do more written explanations has been challenging for my students," "the content is too hard for kids," and "too much, feels like a checklist. The new standards don't make curriculum viable, we can't get it all done. Things they [students] are asked to do with fractions and geometry, they are huge concepts." Responses such as these related to how the change impacted their students came from teachers who teach all grade levels.

Teachers from all three schools made comments about the shifts in content or mathematical practices when asked about the change in teaching since the implementation of the new standards. For example, "we are covering more, faster," "before the content was ambiguous, now it is straightforward," and "the units are drastically different." Some of the more specific comments about content shifts include, "an emphasis on vocabulary," "more algebra, problem solving and reasoning," "a lot of time on just decimals," "the new standards require kids to show multiple ways, think through, having to justify why," and that their students spend a lot of time on "problem solving and persevering." Although six of the teachers at Schulz Elementary identified feeling that the new standards (CCSSM) have added to the list of what needs to be taught, “covering more, faster pace, not as deep," there was another opinion when at least one teacher from the same school commented "I am able to slow down more and spend more time on concepts." 


\section{Developing Algebraic Thinking}

Because algebraic thinking is an integral part of elementary mathematics content as outlined in both CCSM/CCRS, teachers were asked to explain how algebraic thinking is developed in the classroom. Included in the Operations and Algebraic Thinking Domain for grades two through five are student standards such as represent and solve problems, understand properties of multiplication, explain patterns in arithmetic, generate and analyze patterns and write and interpret numerical expressions. Teacher responses are summarized in Table 24.

Table 24

Percentages and Example Teacher Responses, Developing Algebraic Thinking

\begin{tabular}{|c|c|c|c|}
\hline Categories & $\begin{array}{l}\text { Marie Elementary/ } \\
\text { Thomas Middle } \\
\text { (implementation year } \\
\text { one) }\end{array}$ & $\begin{array}{l}\text { Schulz Elementary } \\
\text { (implementation year } \\
\text { four) }\end{array}$ & $\begin{array}{l}\text { Example(s) teacher } \\
\text { responses }\end{array}$ \\
\hline $\begin{array}{l}\text { Do develop algebraic } \\
\text { thinking }\end{array}$ & $73 \%$ & $79 \%$ & $\begin{array}{l}\text { Input, output, order of } \\
\text { operations } \\
\text { A lot of patterns } \\
\text { We just started functions } \\
\text { and tasks on the Smart } \\
\text { board } \\
\text { Real world solving } \\
\text { problems with missing } \\
\text { variables }\end{array}$ \\
\hline $\begin{array}{l}\text { Do not develop } \\
\text { algebraic thinking }\end{array}$ & $27 \%$ & $21 \%$ & $\begin{array}{l}\text { We do not have a lot of } \\
\text { that going on } \\
\text { I feel like that is } \\
\text { something I struggle } \\
\text { with to be honest that is } \\
\text { not much on that } \\
\text { standard } \\
\text { One of the last units we } \\
\text { do and do not touch on } \\
\text { it that much } \\
\text { We do not do a lot of } \\
\text { algebra in fifth grade }\end{array}$ \\
\hline
\end{tabular}


As shown in Table 25, a comparison made between Marie Elementary/Thomas Middle and Schulz Elementary indicates that the percentages of teachers who report developing algebraic thinking are similar. The percentages of teachers who report that they do not spend time developing algebraic thinking in their students are also similar from state to state.

When asked to explain how algebraic thinking is developed in the classroom, three teachers of the 41 interviewed (7\%) had difficulty answering the question. This was indicated in responses such as, "Can you give me an example?" and "well, I'll have to develop my own algebraic thinking first.” Schulz Elementary teachers provided specific responses and reported algebraic thinking to be more as an embedded strand of mathematics instead of one that stands alone. For example, the teachers mentioned presenting, "function tables," "a lot of patterns" and that they feel "like algebraic thinking is embedded in number and operations unit." Teachers from Marie Elementary/Thomas Middle indicated in their responses that algebraic thinking is developed through "poster math, multistep problems," "a lot of conversation," and "a lot of manipulatives." Seven individual teachers from the third and fourth grade (32\%) from schools Marie Elementary/Thomas Middle indicated that they had used a balance with students to develop algebraic thinking, "when doing algebraic equations this year, we got out balances, to show them how each side would be equal and it's not really meaning that this is the answer to problem [instead the equal sign indicates a balance between left and right side]." 


\section{Assessing Student Understanding}

The standard for understanding the equal sign is a first grade standard and also explicitly mentioned in the Standards of Student Practice in for Mathematics Proficiency (CCSSM) and Process Standards for Mathematics Proficiency (CCRS). During the interview, classroom teachers were asked to explain how student understanding of the equal sign is assessed in their classrooms. See Table 25.

Table 25

Percentages and Example Teacher Responses, Assessing Student Understanding of the

\section{Equal Sign}

\begin{tabular}{|c|c|c|c|}
\hline Category & $\begin{array}{c}\text { Marie } \\
\text { Elementary/Thomas } \\
\text { Middle } \\
\text { (implementation year } \\
\text { one) } \\
\end{array}$ & $\begin{array}{l}\text { Schulz Elementary } \\
\text { (implementation year } \\
\text { four) }\end{array}$ & $\begin{array}{l}\text { Example(s) Teacher } \\
\text { Responses }\end{array}$ \\
\hline $\begin{array}{l}\text { Do assessments of the } \\
\text { equal sign }\end{array}$ & $55 \%$ & $37 \%$ & $\begin{array}{l}\text { Verbal and written } \\
\text { assessments } \\
\text { By answers of what they } \\
\text { put on questions that } \\
\text { area just number based } \\
\text { and then also being able } \\
\text { to explain using words } \\
\text { Correction of equations } \\
\text { and written work, } \\
\text { solving for } n, x \text { or } y \\
\text { Unit assessment that } \\
\text { team made }\end{array}$ \\
\hline $\begin{array}{l}\text { Do not do assessments } \\
\text { of the equal sign }\end{array}$ & $45 \%$ & $58 \%$ & $\begin{array}{l}\text { I don't think that I do a } \\
\text { very good job of that, I } \\
\text { don't think I check that } \\
\text { understanding } \\
\text { I haven't really assessed } \\
\text { it, its assumed } \\
\text { I can't honestly say that } \\
\text { I have assessed student } \\
\text { understanding of the } \\
\text { equal sign } \\
\text { I guess I never really }\end{array}$ \\
\hline
\end{tabular}




\begin{tabular}{|l|l|c|l|}
\hline & & & $\begin{array}{l}\text { thought about asking the } \\
\text { students what the equal } \\
\text { sign means- even } \\
\text { thought I teach that } \\
\text { every year }\end{array}$ \\
\hline $\begin{array}{l}\text { Does not know if } \\
\text { assessment of equal sign } \\
\text { has occurred }\end{array}$ & & $5 \%$ & $\begin{array}{l}\text { I do not know, that is a } \\
\text { really good question }\end{array}$ \\
\hline
\end{tabular}

More teachers at Marie Elementary/Thomas Middle than at Schulz Elementary stated that they assessed students' understanding of the equal sign. When comparing schools using the two different implementation timelines and the number of teachers at each who report not having assessed student understanding of the equal sign, there is a difference. A greater percentage of teachers from Schulz Elementary indicate the absence of equal sign assessments than the teachers reporting the same at Marie Elementary/Thomas Middle.

One teacher from Schulz Elementary reported asking students directly through formative and summative assessments in statements such as "Exit slips and I'm thinking when I taught it at the beginning of the year, exit slips, summative assessments, things like that, but I don't revisit it." Common formative assessments (CFA) are mandated by Marie Elementary and Thomas Middle's corporation. While two separate Marie Elementary/Thomas Middle teachers indicated the absence of a question about the meaning of the equal sign, "there hasn't been a question about the equal sign on a CFA," another teacher from the same school seems to contradict his or her colleague, "CFAs and initial pre-tests have assessed student understanding of the equal sign." Finally, one teacher from Marie Elementary/Thomas Middle said, "Don't know if the test actually said what does it mean, but I know it was definitely taught, that they understood." 
Some of the teachers from all three schools also indicated making assumptions related to their own students' understanding of the meaning of the equal sign in that understanding has already occurred by the time students reach a particular grade in school. Teachers from grades two through five reported, "it's assumed," "you just infer that they know it when they come to fifth grade," "I don't know if they understand, I'm assuming that they know," and "I guess I make the assumption that by fifth grade, that they know what it is."

Of the teachers who reported having assessed student understanding of the meaning of the equal sign, most do so through the use of verbal responses and/or written assessments. Whether through statements such as "we have questions involving equal sign," "explaining thinking," "discussion" and "we will talk about it large group," twelve responses (55\%) from teachers at Marie Elementary/Thomas Middle cited that evidence of student understanding came from either verbal or written student work. One third grade teacher from Marie Elementary indicated specifically using items/equations similar to the ones used in the teacher interview $(8+4=\square+5)$. For example, the teacher answered that she had assessed student understanding of the equal sign by "giving them problems like this to, to make sure they understand, um that each side needs to be equal, word problems, where they have to balance the equations out themselves."

Similar to Marie Elementary/Thomas Middle, teachers at Schulz Elementary also stated assessing student understanding of the equal sign through "a lot of algebraic expressions, which have the variables," "unit assessments," and "looking for different ways to explain, write, elaborate on the same concept." Seven (37\%) separate responses from teachers at Schulz Elementary pointed to student written and verbal work for 
indications of student understanding. One third grade teacher gave specific examples of assessments that used items similar to those presented in the teacher interview, "I think in various equations like we just discussed whether it's on left or right, $8=8$, in those situations, I see what they say.” 


\section{CHAPTER V \\ DISCUSSION}

\section{Introduction}

Chapter V provides a summary of the study and results, and presents conclusions based upon the findings presented in Chapter IV. Chapter V also presents a discussion of the implications the findings have about teaching children about the meaning of the equal sign. The chapter concludes with the limitations of the study and recommendations for future research.

\section{Summary of the Study}

\section{Restatement of the Problem Statement}

Past research has found that students of all ages demonstrate an incomplete and sometimes incorrect understanding of the equal sign.

\section{Restatement of Purpose and Research Questions}

The purpose of this study was to assess the current level of understanding of the equal sign held by students in second, third, fourth and fifth grade. Teacher knowledge of the equal sign was also examined. Additionally, the impact of CCSSM implementation on student understanding of the equal sign was investigated. The research questions addressed in this study were:

$\mathrm{RQ}_{1}$ : What is the impact of teacher knowledge of the equal sign on student understanding of the equal sign? 
$\mathrm{RQ}_{2}$ : What is the impact of the implementation of the new state standards on student understanding of the equal sign?

\section{Review of Methodology}

A mixed methods design using both quantitative and qualitative measures was used to determine the impact of teacher knowledge and CCSSM/CCRS implementation on second, third, fourth and fifth grade student understanding of the meaning of the equal sign. Teacher knowledge of the equal sign as measured by the Mathematical Equivalence Knowledge Assessment was not found to impact student understanding of the equal sign.

\section{Findings and Relation to the Literature}

This study provides potentially important information about the implementation of standards in schools in states with different timelines for fully requiring the new standards to be taught. Although for a long time major documents related to mathematics education (NMAP, 2008; NRC, 2001) and specific standards related documents (NCTM, 1989; NCTM 2000, NCTM 2006) have emphasized the importance of teaching algebra thinking early as a precursor to success in more formal classes in algebra at the secondary level, this study isolated a concept in early algebra that was unique to the new standards. The first grade standard about the meaning of the equal sign and the corresponding application of that meaning through the examination of equations in a variety of formats provided an opportunity to isolate this content knowledge in schools where two different implementation plans were in place. One school system adopted the CCSSM early and was in the fourth year of implementation, the other adopted CCRS, a clone of the CCSSM, and was only one year into fully putting the standards into practice. Therefore 
the differences between the performances of the second through fifth graders on the topic of the meaning of the equal sign could be examined.

To see if the teachers' knowledge played a role, as often teacher knowledge is pointed to as a link to students' performance they were measured on their knowledge and those scores were linked to the students' scores in their classes. Likely due to a ceiling effect on the measurement tool, the analyses revealed there were no significant differences. The current study used a measurement of mathematical equivalence knowledge designed for and used previously with children not adults (Rittle-Johnson et al., 2011). But other components of the teachers' knowledge revealed important findings to consider. It was important though that the teachers experienced the instrument (MEKA) that their students would be administered as it was thought it would give them a better idea of what was being asked of their students when they completed the MEKA. But, as in the work Asquith et al. (2007), Falkner et al. (1999) and Stephens (2006), teachers were not successful in predicting how their students would perform on the MEKA assessment about the meaning of the equal sign. At Marie Elementary, grade 2 teachers were off on the average of $72.1 \%$, grade 3 were off about $89.5 \%$, and grade 4 teachers were off about 54\%\%. At Schulz Elementary, grade 2 teachers were off on the average of $75.9 \%$, grade 3 were off about $86.7 \%$, grade 4 were off about $79.5 \%$ and grade 5 teachers were off about 73.2\%. At Thomas Middle, grade 5 teachers were off on the average of $82 \%$. Although the teachers were optimistic they may be missing gaps in their students' knowledge that might be ripe for interventions.

Grade was found to be a significant predictor of student score on the MEKA. This was expected because students in grade 5, for example, would score higher than 
students in grade 2 due to maturation and exposure to mathematics instruction. State was also a significant predictor of students' scores. As a method to complement the findings on the MEKA and to possibly account for the difference, teacher interview data. Asking teachers to describe changes in their teaching revealed that nearly all teachers feel as though changes have occurred since the implementation of new state standards at their school. Besides each school having a different timeline for putting the new standards into place, there were also differences in how teachers explained the changes. Marie Elementary and Thomas Middle teachers' comments referred more often to a shift toward conceptual understanding as many mentioned now using manipulatives, asking for more student explanation and that they had discontinued teaching of "tricks and rhymes," for example. On the other hand, teachers from Schulz elementary commented more often than not about content changes such as now teaching more algebra and problem solving and noticing that the new standards had an impact on students. In this way, teachers at Marie Elementary and Thomas Middle appear to be making changes in how they teach and teachers at Schulz Elementary appear to be making changes in what they teach.

In asking teachers about developing algebraic thinking, the numbers of those who do and do not report the development of algebraic thinking were similar among the three schools. Comments from teachers at Marie Elementary and Thomas Middle point toward general math methods while teachers from Schulz Elementary comments were content specific and contained more language aligned with the language from the standards. Analysis of teacher reports regarding assessing the equal sign revealed that there is a difference in the percentage of teachers who report assessing the concept at Marie Elementary/Thomas Middle than do at Schulz Elementary. However, the overall teacher 
comments from the three school have some similarities. For example, teachers report to assess student understanding of the equal sign indirectly through completed math assignments where a correct sum, for example indicates an understanding of the equal sign. Also, teachers from all three schools make assumptions that their students understand the equal sign in spite of not actually asking students to demonstrate an understanding. From all 41 teacher interviews, there were just two teachers who indicated asking students directly to demonstrate understanding of the equal sign with assessments designed for the purpose of assessing understanding of the equal sign.

This study investigated the current level of understanding of the equal sign held by second, third, fourth and fifth grade students. As shown in previous research, a high proportion of students across grade levels demonstrate an operational understanding of the equal sign (Behr et al., 1976; Falkner et al., 1999; Matthews et al., 2012; Molina \& Ambrose, 2008; Sherman \& Bisanz, 2009). A review of student score on the Mathematical Equivalence Knowledge Assessment across grade levels shows that small percentages of students in each grade demonstrate a relational and correct understanding of the equal sign. Recall data from Tables 19 through Table 22 showing both teacher predictions and actual correct student responses to two tasks from the MEKA. Second grade students with correct responses on the equal sign definition task were at $4.9 \%$ (Marie Elementary) and 6.6\% (Schulz Elementary). Third grade students with correct responses on the equal sign definition task were at $6.8 \%$ (Marie Elementary) and $4.3 \%$ (Schulz Elementary). Fourth grade students performed at 8.3\% (Marie Elementary) and 5.5\% (Schulz Elementary). Fifth grade students performed at 10.4\% (Thomas Middle) and $10.5 \%$ (Schulz Elementary). Although the levels increase gradually from second 
grade to fifth grade, with only approximately $10 \%$ of all students at fifth grade having an understanding of the meaning of the equal sign it is clear that there is a difference between what teachers' believe the students know and what they actually understand.

The analysis of the results of the Mathematical Equivalence Knowledge Assessment student scores revealed significant differences in the factor STATE. The level of difference may be unexpected and surprising. The finding indicates that the schools in State 1 are 1.5 grades behind schools in State 0 for understanding the meaning of the equal sign based on the Mathematical Equivalence Knowledge Assessment. In the above ANCOVA analysis, the GRADE estimated coefficient was $10.4 \%$, and the STATE coefficient was estimated at $-14.9 \%$. The 1.5 ratio comes from these figures and means that students in State 0 are outperforming students in State 1.

\section{Implications}

The explicit statement of standards through the newly or recently legislated state documents may direct teachers to explicitly presenting instruction on the equal sign. In many cases the teachers reported that they were not aware of the student misconception about the equal sign and overestimate student performance. In addition students in grades two through five do not understand the meaning of equal sign at a high level although the standard for understanding equal sign is first grade standard (NGA, 2010).

\section{Limitations of this Study}

The standard for understanding the equal sign is a first grade standard in both states and is expected to be learned by the end of first grade. The current study did not incorporate first grade students or their teachers. Including first grade in the study may have yielded more information about what students are doing in the classroom that either 
supports the development of a relational conception of the equal sign or supports the development of the misconception of the equal sign.

Students and teachers were assessed one time using one assessment. Additional measures such as observation of teachers' instruction and the analyses of curriculum documents, assessments used in the classroom, teaching sequences and report cards may have provided further evidence to answer both research questions. Even though STATE (year of implementation) was found to be significant predictor of student score on the MEKA, there is the possibility that other factors were having some effect on student scores. Without knowing more specific details about the enacted curriculum at each school in each classroom, making a determination about other factors is likely not possible.

In the design and implementation of this research, the researcher noticed some possible influences that may have had an impact on the results of the study. First, the time of student and teacher data collection was in fact at the end of the academic school year. The time of year was marked by interruptions to the instructional day such as special celebrations, spirit day and assemblies. Although the researcher observed students working diligently, students may have been less focused on the assessment and more focused on other school related activities. The researcher attempted to meet with teachers and conduct the interview in as little time as possible to reduce inconvenience. Although all teachers agreed to meet, some appeared rushed and may have shortened their responses to interview questions.

Upon reflection, the researcher noticed that some of the interview questions could have been reworded. For example, when teachers answered the question "What answer 
would you expect your students to give to TASK A," it was not possible to make the distinction that the teacher knew what the correct and desired response would be. For example, if a teacher answered that her students would indicate that the equal sign (TASK A) means, "put the answer here," the researcher did not ask if the teacher believed that to be the correct response. To keep each interview the same, the researcher did not ask follow up questions. The researcher realizes that having more time allotted to ask follow up questions may have provided additional supporting details that may have better clarified what the teachers said.

A limitation of the current study includes the fact that there was just one source of data collection for student understanding of the equal sign, the MEKA (Rittle-Johnson et al., 2011; Rittle-Johnson (personal communication, October 20, 2014). Samples of student work from classroom tasks or assignments over the course of the school year were not collected. Students were not interviewed and therefore the finer details of their thinking are unknown. Asking students to provide a relational definition of the equal sign has proven to be problematic in past research (Rittle-Johnson, Matthews, Taylor \& McEldoon, 2011). In other words, children are not as likely to offer a relational definition when asked, as they are to successfully evaluate the correctness of definitions supplied to them. However, interviews have illuminated that especially younger students may perform better when interacting one-on one with a teacher versus completing pencil and paper assessments. However, the difference may be accounted for in the presence or absence of conventional symbols (Sherman \& Bisanz, 2009). 


\section{Recommendations for Future Research}

One recommendation for future research may be to investigate student understanding of other standards found within the Common Core State Standards for Mathematics (CCSSM). Perhaps future research could hypothesize that changing the curriculum is not enough and to then investigate the result when teachers themselves become the unit of study. Further research with older students may also continue the investigation of the development of the misconception and incomplete understanding of the meaning of the equal sign. Perhaps more importantly, future research might investigate closely those students who demonstrate a complete and relational understanding of the equal sign.

By having a larger sample of students take the Mathematical Equivalence Knowledge Assessment, evidence as to the validity of the assessment may be further supported. Additional future research focusing on the impact of implementation of CCSSM may also possibly provide stakeholders with insights about student understanding in other content areas.

\section{Summary}

This study has attempted to determine the impact that teacher knowledge of the equal sign has on student understanding of the equal sign. The study also examined the impact of implementation of the Common Core State Standards for Mathematics in State 0 or the College and Career Ready Standards in State 1 on student understanding of the equal sign. The research was conducted in order to explore if changes in student understanding of the equal sign occurred as a result of either teacher knowledge and or as a result of the implementation of standards. Although changes in student understanding 
of the equal sign were not found to be attributed to teacher knowledge of the equal sign, the data suggest that implementation of the Common Core State Standards may have impacted student understanding. Not only did the teachers in the study predict that students would perform much better on assessment items than they actually did, but some teachers also confirmed never assessing or teaching student understanding of the equal sign.

When the study was conceived, a difference in student understanding of the meaning of the equal sign between states was expected. This expectation arose because before the emergence of the Common Core State Standards for Mathematics no explicit standard existed in either state for teaching the meaning of the equal sign. Teachers are expected to look to the standards among other resources for guidance on which mathematics skills, processes and concepts to teach. Teachers who are implementing CCSSM, therefore, had the best chance of impacting student understanding of the equal sign. The qualitative analysis helped to confirm that teachers do not know students have a misconception of the equal sign. This study began after learning that students do not understand the meaning of the equal sign. Perhaps this study will prompt the thinking of other classroom teachers about what it means for students to understand the meaning of the equal sign. 


\section{REFERENCES}

Achieve, Inc. (2013). Closing the expectations gap 2013 annual report on the alignment of state K-12 policies and practice with the demands of college and careers. Washington, DC: Author.

Asquith, P., Stephens, A.C., Knuth, E.J., \& Alibali, M.W. (2007). Middle school mathematics teachers' knowledge of students' understanding of core algebraic concepts: Equal sign and variable. Mathematical Thinking and Learning, 9(3). $249-272$.

Baroody, A., \& Ginsburg, H. (1983). The effects of instruction on children's understanding of the "equals" sign. The Elementary School Journal, 84(2), 198212.

Behr, M., Erlwanger, S., \& Nichols, E. (1976). How children view equality sentences. PMDC Technical Report, (3). Tallahassee, FL.: Florida State University.

Behr, M., Erlwanger, S., \& Nichols, E. (1980). How children view the equals sign. Mathematics Teaching, 92, 13-15.

Blanton, M., Levi, L., Crites, T., Dougherty, B., \& Zbiek, R.M. (2011). Early Algebra: The big ideas and essential understandings. In Developing essential understanding of algebraic thinking for teaching mathematics in grades 3-5. Reston, VA: National Council of Teachers of Mathematics. 
Byrd, C., McNeil, N., Chesney, D., \& Matthews, P. (2015). A specific misconception of the equal sign acts as a barrier to children's learning of early algebra. Learning and Individual Differences, 38, 61-67.

Caldwell, J., Karp, K., \& Bay-Williams, J. (2011). Challenges: Learning, Teaching and Assessing. In Developing essential understanding of addition and subtraction for teaching mathematics in prekindergarten-grade 2. Reston, VA: National Council of Teachers of Mathematics.

Cangelosi, R., Madrid, S., Cooper, S., Olson, J., \& Hartter, B. (2013). The negative sign and exponential expressions: Unveiling students' persistent errors and misconceptions. Journal of Mathematical Behavior, 32. 69-82.

Carpenter, T.P., Franke, M., \& Levi, L. (2003). Thinking mathematically: integrating arithmetic and algebra in elementary school. Portsmouth, NH: Heinemann.

Carpenter, T.P., Levi, L., Franke, M.L., Zeringue, J.K. (2005). Algebra in elementary school: Developing relational thinking. Zentralblatt fur Didaktik der Mathematik $37(1), 53-59$.

Clement, J. (1982). Algebra word problem solutions: Analysis of a common misconception. Journal for Research in Mathematics Education, 13, 16-30.

Confrey, J. (1987). 'Misconceptions' across subject matters: Science, mathematics and programming. In J. Novak (Ed.), Proceedings of the second international seminar: Misconceptions and educational strategies in science and mathematics (Vol. I, pp. 81-106). Ithaca, NY: Cornell University. 
Creswell, J. (2007). Qualitative inquiry \& research design choosing among five approaches. (2nd ed). Thousand Oaks, CA: Sage Publications, Inc.

Falkner, K.P., Levi, L., \& Carpenter, T.P. (1999). Children's understanding of equality: a foundation for algebra. Teaching Children Mathematics, 6(4), 232-236.

Fyfe, E.R., DeCaro, M.S., Rittle-Johnson, B., (2014). An alternative time for telling: When conceptual instruction prior to exploration improves mathematical knowledge. British Journal of Educational Psychology. (Early view). doi: 10.1111/bjep.12035.

Gelman, R., Gallistel, C.R. (1986). The child's understanding of number. Cambridge, Mass.: Harvard University Press.

Ginsburg, H. (1977). Children's arithmetic: The learning process. Oxford, England: D. Van Nostrand.

Guba, E.G. (1981). Criteria for assessing the trustworthiness of naturalistic inquiries. Educational Communication and Technology Journal, 29, 75-91.

Hull, T.H., Harbin Miles, R., \& Balka, D.S. (2012). The common core mathematics standards. Thousand Oaks, CA: Corwin.

Indiana Department of Education. (2014). Indiana Academic Standards for Mathematics 2014. Indianapolis, IN.

International Association for the Evaluation of Educational Achievement, Trends in International Mathematics and Science Study, 1995, 2003, 2007 and 2011. 
Jacobs, V.R., Franke, M.L., Carpenter, T.P., Levi, L., \& Battey, D. (2007). Professional development focused on children's algebraic reasoning in elementary school. Journal for Research in Mathematics Education, 38(3), 258-288.

Kaplan, R., Alon, S. (2013). Using technology to teach equivalence. Teaching Children Mathematics, 19(6), 382-389.

Kaput, J. (2008). What is algebra? What is algebraic reasoning? In J. J. Kaput, D. W. Carraher \& M. L. Blanton (Eds). Algebra in the early grades (pp. 5-17). New York, NY: Routledge.

Kenney, P.A. \& Silver, E.A. (Eds.). (1997). Results for the sixth mathematics assessment of the national assessment of educational progress. Reston, VA: National Council of Teachers of Mathematics.

Kieran, C. (1981). Concepts associated with the equality symbol. Educational Studies in Mathematics, 12(3), 317-326.

Knuth, E., Alibali, M.W., Hattikudur, S., McNeil, N.M., \& Stephens, A.C. (2008). The importance of equal sign understanding in the middle grades. Mathematics Teaching in the Middle School. 13(9), 514-519.

Knuth, E., Stephens, A., McNeil, N., \& Alibali, M. (2006). Does understanding the equal sign matter? Evidence from solving equations. Journal for Research in Mathematics Education, 37(4), 297-312.

MacGregor, M., \& Stacey, K. (1997). 'Students' understanding of algebraic notation: 1115'. Educational studies in mathematics, 33(1), 1-19. 
McNeil, N. M. (2008). Limitations to teaching children $2+2=4$ : Typical arithmetic problems can hinder learning of mathematical equivalence. Child Development, $79,1524-1537$.

McNeil, N.M. \& Alibali, M.W. (2005). Knowledge change as a function of mathematics experience: All contexts are not created equal. Journal of Cognition and Development, 6(2), 285-306.

McNeil, N.M. \& Alibali, M.W. (2005). Why won’t you change your mind? Knowledge of operational patterns hinders learning and performance on equations. Child Development, 76(4), 883-899.

McNeil, N.M., Grandau, L., Knuth, E.J., Alibali, M.W., Stephens, A.C., Hattikudur, S., \& Krill, D.E. (2006). Middle-School Students' Understanding of the Equal Sign: The Books They Read Can't Help. Cognition and Instruction, 24(3), 367-385.

McNeil, N.M., Rittle-Johnson, B., Hattikudur, S., \& Petersen, L. (2010). Continuity in representation between children and adults: Arithmetic knowledge hinders undergraduates' algebraic problem solving. Journal of Cognition \& Development, 11(4), 437-457. doi: 10.1080/15248372.2010.516421.

Molina, M., \& Ambrose, R. (2008). From an operational to a relational conception of the equal sign third graders' developing algebraic thinking. Focus on Learning Problems in Mathematics, 30(1), 61-80.

Molina, M., \& Ambrose, R. (2006). Fostering relational thinking while negotiating the meaning of the equals sign. Teaching Children Mathematics, 13(2), 111-117. 
Molina, M., Castro, E. [Encarnacion], Castro, E. [Enrique]. (2009). Elementary students' understanding of the equal sign in number sentences. Electronic Journal of Research in Educational Psychology, 7(1), 341-368.

National Council of Teachers of Mathematics. (2000). Principles and standards for school mathematics. Reston, VA.

National Council of Teachers of Mathematics. (2007). Second handbook of research on mathematics teaching and learning. Washington, DC: National Council of Teachers of Mathematics.

National Council of Teachers of Mathematics. (2014). Principles to actions: Ensuring Mathematical success for all. Reston, VA.

National Governors Association Center for Best Practices \& Council of Chief State School Officers. (2010). Common Core State Standards for Mathematics. Washington, DC: Authors. Retrieved from http://www.corestandards.org/Math/ National Mathematics Advisory Panel. (2008). Foundations for success: Final report of the national mathematics advisory panel. Washington, DC: U.S. Department of Education.

National Research Council. (2001). Adding it up: Helping children learn mathematics. J. Kilpatrick, J. Swafford, \& B. Findell (Eds.). Mathematics Learning Study Committee, Center for Education, Division of Behavioral and Social Sciences and Education. Washington, DC: National Academy Press.

National Research Council. Mathematics Learning in Early Childhood: Paths Toward Excellence and Equity. Washington, DC: The National Academies Press, 2009. 
Rittle-Johnson, B., Matthews, P. G., Taylor, R. S., \& McEldoon, K. L. (2011). Assessing knowledge of mathematical equivalence: a construct-modeling approach. Journal of Educational Psychology, 103(1), 85-104. doi: 10.1037/a0021334.

Rittle-Johnson, B., Alibali, M., (1999). Conceptual and procedural knowledge of mathematics: Does one lead to the other. Journal of Educational Psychology, 91(1), 175-189.

Seo, K., Ginsburg, H.P. (2003). You've got to carefully read the math sentence. Classroom context and children's interpretations of the equal sign. In Baroody, A.; Dowker, A. (Eds.), The development of arithmetic concepts and skills constructing adaptive expertise (pp. 161-187). Mahwah, N.J.: Lawrence Erlbaum Associates.

Shadish, W.R., Cook, T.D., \& Campbell, D.T. (2002). Experimental and quasiexperimental designs for general causal inference. Boston: Houghton Mifflin Company.

Shavelson, R. (1996). Statistical reasoning for the behavioral sciences. (3rd ed.). Needham Heights, MA: Allyn \& Bacon.

Sherman, J., \& Bisanz, J. (2009). Equivalence in symbolic and nonsymbolic contexts: Benefits of solving problems with manipulatives. Journal of Educational Psychology, 101(1), 88-100. doi:10.1037/a0013156 
Shenton, A.K. (2004). Strategies for ensuring trustworthiness qualitative research projects. Education for Information, 22, 63-75.

Skemp, R. (2006, September). Relational and instrumental understanding. Mathematics Teaching in the Middle School, 12, 88-95.

Smith, J.P., diSessa, A.A., \& Roschelle, J. (1993). Misconceptions reconceived: A constructivist analysis of knowledge in transition. 3(2), 115-163.

Stephens, A. C., Knuth, E. J., Blanton, M. L., Isler, I., Murphy Gardiner, A., \& Marum, T. (2013). Equation structure and the meaning of the equal sign: the impact of task selection in eliciting elementary students' understandings. The Journal of Mathematical Behavior, 32, 173-182.

Tashakkori, A. \& Teddlie, C. (1998). Mixed Methodology: Combining qualitative and quantitative approaches. Thousand Oaks, CA: Sage Publications, Inc.

Teddlie, C., \& Tashakkori, A. (2009). Foundations of mixed methods research: Integrating quantitative and qualitative approaches in the social and behavioral sciences. Thousand Oaks, CA: Sage Publications, Inc.

U.S. Department of Education, Institute of Education Sciences, National Center for Education Statistics, National Assessment of Educational Progress (NAEP), 2009, 2011 and 2013 Mathematics Assessments.

Van de Walle, J., Karp, K., \& Bay-Williams, J. (2013). Elementary and middle school mathematics: Teaching developmentally. (8th ed.). Upper Saddle River, NJ: 
Pearson.

Vlassis, J. (2004). Making sense of the minus sign or becoming flexible in 'negativity'. Learning and Instruction, 14(5), 469-484.

Warren, E., \& Cooper, T. (2009). Developing mathematics understanding and abstraction: The case of equivalence in the elementary years. Mathematics Education Research Journal, 21(2), 76-95.

Webb, N.M., Shavelson, R.J., \& Haertel, E.H. (2006). Reliability coefficients and generalizability theory. In C. Rao \& S. Sinharay (Eds.), Handbook of Statistics, (pp. 1-44). doi:10.1016/S0169-7161(06)26004-8 
Appendix A:

Summary of student demographic data

\begin{tabular}{|c|c|c|c|c|}
\hline & Marie Elementary & Thomas Middle & Thomas Middle & Schulz Elementary \\
\hline $\begin{array}{l}\text { Enrollment } \\
(2013 / 2014)\end{array}$ & $628(\mathrm{~K}-4)$ & $1515(5-8)$ & $362\left(5^{\text {th }}\right.$ only $)$ & $681(\mathrm{~K}-5)$ \\
\hline American Indian & 1 student $(0.2 \%)$ & 7 students $(0.5 \%)$ & 3 students $(0.8 \%)$ & 1 student $(0.1 \%)$ \\
\hline Asian & 16 students $(2.5 \%)$ & 28 students $(1.8 \%)$ & 13 students $(3.6 \%)$ & 50 students $(7.3 \%)$ \\
\hline White & 577 students $(91.9 \%)$ & $\begin{array}{l}1417 \\
(93.5 \%)\end{array}$ & $\begin{array}{l}323 \text { students } \\
(89.2 \%)\end{array}$ & $\begin{array}{l}584 \text { students } \\
(85.5 \%)\end{array}$ \\
\hline Multiracial & 12 students $(1.9 \%)$ & 25 students $(1.7 \%)$ & $\begin{array}{l}7 \text { students } \\
(1.9 \%)\end{array}$ & 15 students $(2.2 \%)$ \\
\hline Black & 10 students $(1.6 \%)$ & $\begin{array}{l}8 \text { students } \\
(0.5 \%)\end{array}$ & $\begin{array}{l}3 \text { students } \\
(0.8 \%)\end{array}$ & 13 students $(1.9 \%)$ \\
\hline Hispanic & 12 students $(1.9 \%)$ & 30 students $(2.0 \%)$ & 13 students $(3.6 \%)$ & 18 students $(2.6 \%)$ \\
\hline Paid meals & 521 students $(83 \%)$ & $\begin{array}{l}1254 \text { students } \\
(82.8 \%)\end{array}$ & $\begin{array}{l}288 \text { students } \\
(79.6 \%)\end{array}$ & $\begin{array}{l}662 \text { students } \\
(97.2 \%)\end{array}$ \\
\hline Free & 81 students $(12.9 \%)$ & 206 students $(13.6 \%)$ & $\begin{array}{l}59 \text { students } \\
(16.3 \%)\end{array}$ & 19 students $(2.8 \%)$ \\
\hline Reduced & 26 students $(4.1 \%)$ & 55 students $(3.6 \%)$ & 15 students $(4.5 \%)$ & 0 students $(0 \%)$ \\
\hline $\begin{array}{l}\text { Enrollment gen } \\
\text { education }\end{array}$ & 545 students $(86.8 \%)$ & $\begin{array}{l}1301 \text { students } \\
(85.9 \%)\end{array}$ & $\begin{array}{l}307 \text { students } \\
(84.8 \%)\end{array}$ & $*$ \\
\hline $\begin{array}{l}\text { Enrollment special } \\
\text { education }\end{array}$ & 83 students $(13.2 \%)$ & 214 students $(14.1 \%)$ & $\begin{array}{l}55 \text { students } \\
(15.2 \%)\end{array}$ & $*$ \\
\hline ELL & 2 students $(0.3 \%)$ & 5 students $(0.3 \%)$ & 3 students $(0.8 \%)$ & $*$ \\
\hline Non ELL & 626 students $(99.7 \%)$ & $\begin{array}{l}1510 \text { students } \\
(99.7 \%)\end{array}$ & $\begin{array}{l}359 \text { students } \\
(99.2 \%)\end{array}$ & $*$ \\
\hline Attendance & $97.9 \%$ & $97.2 \%$ & $97.5 \%$ & $97.3 \%$ \\
\hline
\end{tabular}

* = Not reported (Indiana Department of Education, 2013; Kentucky Department of Education, 2013) 
Appendix B:

Teacher and Student Total Summary

\begin{tabular}{|c|c|c|c|}
\hline Teacher & School & Grade & Number of students \\
\hline Teacher 1 & A & 2 & 25 \\
\hline Teacher 2 & A & 2 & 26 \\
\hline Teacher 3 & A & 2 & 25 \\
\hline Teacher 4 & A & 2 & 22 \\
\hline Teacher 5 & A & 2 & 24 \\
\hline Teacher 6 & A & 3 & 18 \\
\hline Teacher $7 *$ & A & 3 & 20 \\
\hline Teacher 8 & A & 3 & 20 \\
\hline Teacher 9 & A & 3 & 19 \\
\hline Teacher 10 & A & 3 & 21 \\
\hline Teacher 11 & A & 3 & 19 \\
\hline Teacher 12* & A & 4 & 47 \\
\hline Teacher 13 & A & 4 & 27 \\
\hline Teacher 14 & A & 4 & 27 \\
\hline Teacher 15 & A & 4 & 27 \\
\hline Teacher 16 & A & 4 & 29 \\
\hline Teacher 17 & B & 5 & 29 \\
\hline Teacher 18 & B & 5 & 56 \\
\hline Teacher 19 & B & 5 & 52 \\
\hline Teacher 20 & B & 5 & 49 \\
\hline Teacher 21 & B & 5 & 55 \\
\hline Teacher 22 & B & 5 & 50 \\
\hline Teacher 23 & B & 5 & 54 \\
\hline Teacher 24 & $\mathrm{C}$ & 2 & 22 \\
\hline Teacher 25 & $\mathrm{C}$ & 2 & 22 \\
\hline Teacher 26 & $\mathrm{C}$ & 2 & 23 \\
\hline Teacher 27 & $\mathrm{C}$ & 2 & 24 \\
\hline Teacher 28 & $\mathrm{C}$ & 3 & 23 \\
\hline Teacher 29 & $\mathrm{C}$ & 3 & 24 \\
\hline Teacher 30 & $\mathrm{C}$ & 3 & 23 \\
\hline Teacher 31 & $\mathrm{C}$ & 3 & 21 \\
\hline Teacher 32 & $\mathrm{C}$ & 3 & 25 \\
\hline Teacher 33 & $\mathrm{C}$ & 4 & 22 \\
\hline Teacher 34 & $\mathrm{C}$ & 4 & 24 \\
\hline Teacher 35 & $\mathrm{C}$ & 4 & 24 \\
\hline Teacher 36 & $\mathrm{C}$ & 4 & 20 \\
\hline Teacher 37 & $\mathrm{C}$ & 4 & 20 \\
\hline Teacher 38 & $\mathrm{C}$ & 5 & 25 \\
\hline Teacher 39 & $\mathrm{C}$ & 5 & 26 \\
\hline Teacher 40 & $\mathrm{C}$ & 5 & 24 \\
\hline Teacher 41 & $\mathrm{C}$ & 5 & 25 \\
\hline Teacher 42 & $\mathrm{C}$ & 5 & 24 \\
\hline
\end{tabular}

$*=$ Same person teaches two different grade levels 
Appendix C:

Grades 2 and 3, Mathematical Equivalence Knowledge Assessment, Form 1

\section{SECTION 1}

DIRECTIONS: Find the number that goes in each box. You really need to show your work.

P1

P2

P3

P4

P5

P6

P7

P8

$$
\begin{gathered}
7=\square+3 \\
3+4=\square+5 \\
4+5+8=\square+8 \\
7+6+4=7+\square \\
5+\square=6+2 \\
\square+6=8+5+6 \\
8+5-3=8+\square \\
5-2+4=\square+4
\end{gathered}
$$




\section{SECTION 2}

C1. What does the equal sign $(=)$ mean?

Can it mean anything else?

C2. Which answer below would you put in the empty box to show that ten cents is the same amount of money as one dime?

\section{0 cents $\square$ One dime}
a) $10 \phi$
b) $=$
c) +
d) Don't know 
C3. For each example, decide if the number sentence is true. In other words, does it make sense?

After each problem, circle True, False, or Don't Know.

\section{Samples:}

\begin{tabular}{|c|c|}
\hline $3+4=7$ & True \\
\hline $3+4=12$ & True \\
\hline a) $8=8$ & True \\
\hline b) $7+6=0$ & True \\
\hline c) $7+6=6+6+1$ & True \\
\hline d) $31+16=16+31$ & True \\
\hline e) $7+6=6+6+1$ & True \\
\hline f) $8=5+10$ & True \\
\hline g) $8=5+3$ & \\
\hline
\end{tabular}

False

False

False

False

False

False

False

False

False
Don't Know

Don't Know

Don't Know

Don't Know

Don't Know

Don't Know

Don't Know

Don't Know

Don't Know 
C4. Is this a good definition of the equal sign? Circle good, not good, or don't know.

a. The equal sign means two amounts are the same.

Good Not Good Don't Know

b. The equal sign means count higher.

Good Not Good Don't Know

c.

The equal sign means the total.

Good Not Good Don't Know 
C5. Which of the definitions above is the best definition of the equal sign? Write a, $\mathrm{b}$, or in the box below.

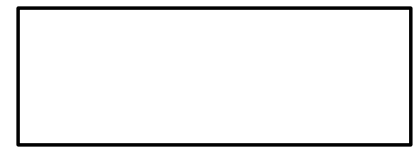

C6. Decide if the number sentence is true.

Then, explain how you know.
$4+1=2+3$
True
False
Don't Know

C7. In this statement:

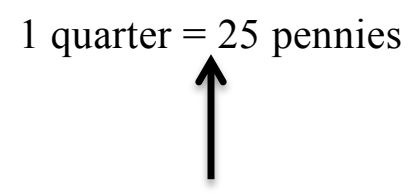

What does the equal sign mean? 
Appendix D:

Script for Grades 2 and 3, Mathematical Equivalence Knowledge Assessment, Form 1

\section{INTRODUCTION}

Today I'm going to have you answer some math questions. I'm mostly interested to see how you think about these kinds of math problems. If you're not sure about something, just make your best guess. If you're really not sure, it's okay to write a question mark and move on.

Please start by writing your first name, the first letter of your last name, and also your grade in the blanks on the very first page.

Please listen carefully when I give directions so you can stay in the right place. We're going to go through most of the problems together. Sometimes you will be working on your own, though. If the directions are confusing or you're having trouble reading them, please raise your hand and I will try to help. We're ready to get started. Please turn to the next page.

OPEN-ENDED PROBLEMS (PAGES 2 \& 3) - about 8 minutes

For this section I'd like you to solve some math problems on your own. You need to figure out what number goes in the box for each problem. We are really interested in how you solve the problem so you need to show your work. So please write down the numbers that you are adding or subtracting while you solve the problem.

Go ahead and begin now.

You will have about 8 minutes to complete this section. Please stop when you get to the stop sign on page 3 .

*After about 7 minutes: You have about one minute to finish this section.

EQUAL SIGN PROBLEMS (PAGE 4) - about 1-2 minutes

For the rest of the time we're going to go through the packet together. I'm going to read each question out loud and give you time to answer each one. Everyone please turn to page 4. The first question at the top of the page: What does the equal sign mean? And can it mean anything else? I want you to write your answer under the questions. You do not need to write in full sentences and don't worry about spelling. Please put your pencil down when you are finished writing.

Give children close to a minute to write their response. If children are still working after 2 minutes, move on.

Okay, now please look at the next question. We're at the bottom of page 4. It says, "Which answer choice below would you put in the empty box to show that ten cents is the same amount of money as one dime? Circle your answer."

Give children about 30 seconds to circle their answer. 


\section{TRUE/FALSE PROBLEMS (PAGE 5) - about 3 minutes}

Okay, everyone please turn to page 5. For each example on this page, decide if the number sentence is true. In other words does it make sense? After each problem, circle True, False, or Don't Know. There are two examples at the top of the page. $3+4=7$ makes sense so True is circled. $3+4=12$ does not make sense so False is circled. Go ahead and get started and please stop when you get to the bottom of the page.

EQUAL SIGN PROBLEMS (PAGE 6) - about 2 minutes.

Please turn to page 6 . The first question says, "Is this a good definition of the equal sign?" Circle good, not good, or don't know. The first definition, a, says, "The equal sign means that two amounts are the same." Circle good, not good, or don't know.

The second definition, b, says, "The equal sign means count higher." Circle good, not good, or don't know.

The third definition, c, says, "The equal sign means the total." Circle good, not good, or don't know.

Okay, the next question on the page says, "Which of the definitions above is the best definition of the equal sign. Write $\mathrm{a}, \mathrm{b}$, or $\mathrm{c}$ in the box below.

CONCEPTUAL PROBLEMS (PAGE 7) - about 2 minutes

Please turn to page 7. The first questions says, "Decide if the number sentence is true. Circle True, False, or Don't' Know. Then, explain how you know. Again, you don't need to write in full sentences or worry about spelling. When you are finished writing please put your pencil down.

Give children close to a minute to write their response. If children are still working after 2 minutes, move on.

Okay, the last question on the pages says, 'In this statement: 1 quarter is equal to 25 pennies, what does this equal sign mean? Write your answer below. Again, you don't need to write in full sentences.

Okay we are finished. Thank you all for your hard work. Please close your packet and pass it forward.

During class administration:

1. Always walk around and answer any questions the children have.

2. Rephrase the question once and tell them to put a question mark if they're not sure.

3. Check to make sure they are showing their work and completing all problems. When prompt to show work say, "Can you show your work - write down the 
numbers you are adding and subtracting?" Only prompt to show work once, and let it go.

4. Ask the teacher to help with questions, if too many children have questions at once.

5. If a child looks too stressed out, make sure they know they do not have to finish. 
Appendix E:

Grades 2 and 3, Mathematical Equivalence Knowledge Assessment, Key, Form 1

\begin{tabular}{|l|l|}
\hline Question & Correct Response \\
\hline P1 & 4 \\
\hline P2 & 2 \\
\hline P3 & 9 \\
\hline P4 & 10 \\
\hline P5 & 3 \\
\hline P6 & 13 \\
\hline P7 & 2 \\
\hline P8 & 3 \\
\hline C1 & $\begin{array}{l}\text { Define equal sign } \\
\text { relationally in any way, } \\
\text { keyword "same". }\end{array}$ \\
\hline & Gives no other definition \\
\hline C2 & B \\
\hline C3 a) & T \\
\hline C3 b) & F \\
\hline C3 c) & T \\
\hline C3 d) & T \\
\hline C3 e) & F \\
\hline C3 f) & T \\
\hline C4 a) & Good \\
\hline C4 b) & Not good \\
\hline C4 c) & Not good \\
\hline C5 & A \\
\hline C6 & True \\
\hline & $\begin{array}{l}\text { Must indicate "true" for C6 } \\
\text { and note that both sides } \\
\text { have the same sum or same } \\
\text { value, or that the inverse is } \\
\text { true. }\end{array}$ \\
\hline C7 & $\begin{array}{l}\text { The equal sign means that } \\
\text { one quarter is the same as } \\
25 \text { pennies. }\end{array}$ \\
\hline & \\
\hline & \\
\hline &
\end{tabular}


Appendix F:

Grades 4 and 5, Mathematical Equivalence Knowledge Assessment, Form 2

1. For each example, decide if the number sentence is true. In other words, does it make sense?

After each problem, circle True, False, or Don't Know.

\section{Samples:}

$3+4=7$

$3+4=12$

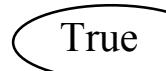

False

False

True

False

Don't Know

a) $8=8$

b) $7+6=0$

True

False

Don't Know

c) $5+3=3+5$

True

False

Don't Know

d) $8=5+10$

True

False

Don't Know

e) $3+1=1+1+2$

True

False

Don't Know

2. For each example, decide if the number sentence is true. Then, explain how you know.
A) $8=5+3$
True
False
Don't Know

How do you know?

B) $4+1=2+3$

True

False

Don't Know

How do you know? 
3. This problem has two sides. Circle the choice that correctly breaks the problem into its two sides.

$$
4+3+6=2+
$$

a.

\begin{tabular}{l|l}
\multicolumn{1}{c}{ Side A } & Side B \\
\hline $4+3+$ & $6=2+$
\end{tabular}

b. Side A Side B \begin{tabular}{c|c}
\hline $4+3+6+2$ & $=$
\end{tabular}

\begin{tabular}{c|c}
\multicolumn{1}{c}{ Side A } & Side B \\
\hline $4+3+6+2$ & $=$
\end{tabular}

d.

\begin{tabular}{l|l} 
Side A & Side B \\
\hline $4+3+6$ & $2+\ldots$
\end{tabular}

e.

\begin{tabular}{c|c}
\multicolumn{1}{c}{ Side A } & Side B \\
\hline $4+3+6=2+\ldots$ & $\ldots+2=6+3+4$
\end{tabular}


4. Without adding $89+44$, can you tell if the statement below is true or false?

$89+44=87+46$

True $\quad$ False $\quad$ Can't tell without adding

How do you know?

5. Without subtracting the 9 , can you tell if the statement below is true or false?

$76+45=121$ is true.

Is $76+45-9=121-9$ true or false?

True $\quad$ False Can't tell without subtracting

How do you know?

\section{SECTION TIME - 5 minutes}

6. What does the equal sign $(=)$ mean?

Can it mean anything else?

7. Which of these pairs of numbers is equal to $3+6$ ? Circle your answer.
a) $2+7$
b) $3+3$
c) $3+9$
d) none of the above 
8. Which answer choice below would you put in the empty box to show that two nickels are the same amount of money as one dime? Circle your answer.
a) $5 \phi$
b) $=$
c) +
d) don't know

9. Is this a good definition of the equal sign? Circle good or not good.
a. The equal sign means two amounts are the same.
Good Not good
b. The equal sign means count higher.
Good Not good
c. The equal sign means what the answer is.
Good Not good

10. Which of the definitions above is the best definition of the equal sign?

Write $\mathrm{a}, \mathrm{b}$, or $\mathrm{c}$ in the box below. 
11. Please circle your choice.

The equal sign $(=)$ is more like:
a) 8 and 4
b) $<$ and $>$
c) + and -
d) don't know 


\section{SECTION TIME - 10 minutes}

DIRECTIONS: Find the number that goes in each box.

12. $6+2=\square$

13. $\square+5=9$

14.

$$
7=\square+3
$$

DIRECTIONS: On these problems, we really need you to show your work by writing down the numbers you add or subtract. Write your answer in the box.

15. $5+\square=6+2$

16. $3+6=8+$<smiles>C1CCC1</smiles>

17. $4+5+8=\square+8$

18. $\square+9=8+5+9$

19.

$$
8+5-3=8+\square
$$

DIRECTIONS: Find the number that goes in each box. You can try to find a shortcut so you don't have to do all the adding. Show your work and write your answer in the box. 
20. $67+84=\square+83$

21. $\square+55=37+54$

22. Find the value of $c$. Explain your answer.

$\mathrm{c}+\mathrm{c}+4=16$

Explain: 
Appendix G:

Script for Grades 4 and 5, Mathematical Equivalence Knowledge, Form 2

INTRODUCTION

I just want to see how you think about some different things in math. Do your best, but if you're not sure about something, just make your best guess. It's ok to write a question mark and move on if your' really not sure.

Please start by writing your first name, the first letter of your last name, and also your grade in the blanks on the very first page.

Do your best, but remember it's ok if you don't get to answer all of the questions. You do not have to write in complete sentences.

Continue until you see a stop sign. When you get to stop sigh, please do not go on. You may look back at your answers or draw on that page, or sit quietly. You have 5 minutes to do the first section. Please begin.

(Notes: If kids have questions, rephrase it once and then tell them to put a question mark if they aren't sure. It is ok if kids work ahead on their own; you don't have to stop them)

During class administration walk around and check for (this applies to open equation section).

- If a student is not showing work, ask, "Can you show the numbers you added or subtracted to come up with that answer?" Just ask this one time per student.

- If a student is writing our explanations (in words) say, "You just need to show the numbers you used, you don't need to write out why."

- If a student looks stressed out, make sure they know they don't have to finish.

Sorting Task: (fine to move on when most kids are done)

"For each example, decide if the number is true. In other words, does it make sense? Some of the problems might not look like ones you usually see in math class, but that doesn't always mean that they're false. After each problem, circle "true" or "false" or "don't know". It might help you to read the number sentence to yourself. Continue until you see a "stop" sign at the bottom of page 3 .

\section{SECTION TIME-10 minutes}

You'll have 10 minutes for this last section. I'd like you to solve some problems on your own and figure out what number goes in the box. On some of the problems, we've asked that you show your work by writing down the numbers that you add or subtract. We are really interested in HOW you sole the problems. Continue until the last page, which is the end of this packet. 


\section{Appendix H:}

Grades 4 and 5, Mathematical Equivalence Knowledge Assessment, Key, Form 2

\begin{tabular}{|l|l|}
\hline Question & Correct Response \\
\hline 1 a) & True \\
\hline 1 b) & False \\
\hline 1 c) & True \\
\hline 1 d) & False \\
\hline 1 e) & True \\
\hline 2 a) & True \\
\hline 2 b) & \\
\hline 3 & D \\
\hline C1 & \\
\hline 4 & True \\
\hline & Must indicate “true" for \\
& first question and then show \\
& some evidence of \\
compensation strategy. \\
\hline 5 & True \\
\hline & Show some evidence of \\
compensation strategy.
\end{tabular}




\section{Appendix I:}

Teacher Demographic Questionnaire

Name:

Current Grade Assignment:

Including this year, how many years have you been teaching?

What is your certification area?

Do you have any other certifications?

How many college level math classes did you take?

Which ones?

Have you had any Professional Development on teaching your state's standards?

Explain (include when, how much and who taught)

Have you had any training since implementation of the new state mathematics standards?

If yes, please explain. 


\section{Appendix J:}

\section{Grades 2 and 3, Teacher Interview}

What answers would you expect your students to give to TASK A and TASK B? What strategies might they have used to get those answers?

What do you believe a student who gives that answer might be thinking?

\section{Task A:}

$3+4=7$

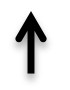

The arrow above points to a symbol.

What is the name of the symbol?

What does the symbol mean?

\section{Task B:}

$8+4=\square+5$

Suppose you gave this TASK to 100 students from your school district that are in the same grade as your current students. Could you indicate what percent would answer correctly?

\section{Task A:}

$3+4=7$

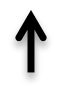

The arrow above points to a symbol.

What is the name of the symbol?

What does the symbol mean? 
Suppose you gave this TASK to 100 students from your school district that are in the same grade as your current students. Could you indicate what percent would answer correctly?

\section{Task B:}

$8+4=\square+5$

How has teaching math changed since the implementation of the new state standards?

How do you develop students' algebraic thinking?

What does it mean for students to "understand the meaning of the equal sign"?

How do you assess students' understanding of the meaning of equal sign? 


\section{Appendix K:}

\section{Grades 4 and 5, Teacher Interview}

What answers would you expect your students to give to TASK A and TASK B? What strategies might they have used to get those answers?

What do you believe a student who gives that answer might be thinking?

\section{Task A:}

$3+4=7$

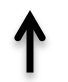

The arrow above points to a symbol.

What is the name of the symbol?

What does the symbol mean?

\section{Task B:}

$67+84=\square+83$

Suppose you gave this TASK to 100 students from your school district that are in the same grade as your current students. Could you indicate what percent would answer correctly?

\section{Task A:}

$3+4=7$

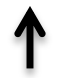

The arrow above points to a symbol.

What is the name of the symbol?

What does the symbol mean? 
Suppose you gave this TASK to 100 2students from your school district that are in the same grade as your current students. Could you indicate what percent would answer correctly?

\section{Task B:}

$67+84=\square+83$

How has teaching math changed since the implementation of the new state standards?

How do you develop students' algebraic thinking?

What does it mean for students to "understand the meaning of the equal sign"?

How do you assess students' understanding of the meaning of equal sign? 


\section{Appendix L:}

Teacher Measure: Process Standards for Mathematics Proficiency, Marie Elementary and Thomas Middle

\begin{tabular}{|c|c|c|c|c|}
\hline & Students: & Initial (1) & Intermediate (II) & Advanced (III) \\
\hline $1 \mathrm{a}$ & $\begin{array}{l}\text { Make sense of } \\
\text { problems. }\end{array}$ & $\begin{array}{l}\text { Explain their thought processes } \\
\text { in solving a problem one way. }\end{array}$ & $\begin{array}{l}\text { Explain their thought processes in solving a } \\
\text { problem and representing it in several ways. }\end{array}$ & $\begin{array}{l}\text { Discuss, explain, and demonstrate solving a problem with } \\
\text { multiple representations and in multiple ways. }\end{array}$ \\
\hline $1 \mathrm{~b}$ & $\begin{array}{l}\text { Persevere in } \\
\text { solving them. }\end{array}$ & $\begin{array}{l}\text { Stay with a challenging problem } \\
\text { for more than one attempt. }\end{array}$ & $\begin{array}{l}\text { Try several approaches in finding a solution, and } \\
\text { only seek hints if stuck. }\end{array}$ & $\begin{array}{l}\text { Struggle with various attempts over time, and learn from } \\
\text { previous solution attempts. }\end{array}$ \\
\hline 2 & $\begin{array}{l}\text { Reason abstractly } \\
\text { and } \\
\text { quantitatively. }\end{array}$ & $\begin{array}{l}\text { Reason with models or pictorial } \\
\text { representations to solve } \\
\text { problems. }\end{array}$ & $\begin{array}{l}\text { Translate situations into symbols for solving } \\
\text { problems. }\end{array}$ & $\begin{array}{l}\text { Convert situations into symbols to appropriately solve } \\
\text { problems as well as convert symbols into meaningful } \\
\text { situations. }\end{array}$ \\
\hline $3 a$ & $\begin{array}{l}\text { Construct viable } \\
\text { arguments. }\end{array}$ & $\begin{array}{l}\text { Explain their thinking for the } \\
\text { solution they found. }\end{array}$ & $\begin{array}{l}\text { Explain their own thinking and thinking of others } \\
\text { with accurate vocabulary. }\end{array}$ & $\begin{array}{l}\text { Justify and explain, with accurate language and vocabulary, } \\
\text { why their solution is correct. }\end{array}$ \\
\hline $3 b$ & $\begin{array}{l}\text { Critique } \\
\text { reasoning of } \\
\text { others. }\end{array}$ & $\begin{array}{l}\text { Understand and discuss other } \\
\text { ideas and approaches. }\end{array}$ & $\begin{array}{l}\text { Explain other students" solutions and identify } \\
\text { strengths and weaknesses of the solutions. }\end{array}$ & $\begin{array}{l}\text { Compare and contrast various solution strategies, and explain } \\
\text { the reasoning of others. }\end{array}$ \\
\hline 4 & $\begin{array}{l}\text { Model with } \\
\text { mathematics. }\end{array}$ & $\begin{array}{l}\text { Use models to represent and } \\
\text { solve a problem, and translate } \\
\text { the solution into mathematical } \\
\text { symbols. }\end{array}$ & $\begin{array}{l}\text { Use models and symbols to represent and solve a } \\
\text { problem, and accurately explain the solution } \\
\text { representation. }\end{array}$ & $\begin{array}{l}\text { Use a variety of models, symbolic representations, and } \\
\text { technology tools to demonstrate a solution to a problem. }\end{array}$ \\
\hline 5 & $\begin{array}{l}\text { Use appropriate } \\
\text { tools strategically. }\end{array}$ & $\begin{array}{l}\text { Use the appropriate tool to find a } \\
\text { solution. }\end{array}$ & $\begin{array}{l}\text { Select from a variety of tools the ones that can be } \\
\text { used to solve a problem, and explain their } \\
\text { reasoning for the selection. }\end{array}$ & $\begin{array}{l}\text { Combine various tools, including technology, explore, and } \\
\text { solve a problem as well as justify their tool selection and } \\
\text { problem solution. }\end{array}$ \\
\hline 6 & $\begin{array}{l}\text { Attend to } \\
\text { precision. }\end{array}$ & $\begin{array}{l}\text { Communicate their reasoning } \\
\text { and solutions to others. }\end{array}$ & $\begin{array}{l}\text { Incorporate appropriate vocabulary and symbols } \\
\text { in communicating their reasoning and solution to } \\
\text { others. }\end{array}$ & $\begin{array}{l}\text { Use appropriate symbols, vocabulary, and labeling to } \\
\text { effectively communicate and exchange ideas. }\end{array}$ \\
\hline 7 & $\begin{array}{l}\text { Look for and } \\
\text { make use of } \\
\text { structure. }\end{array}$ & $\begin{array}{l}\text { Look for structure within } \\
\text { mathematics to help them solve } \\
\text { problems efficiently (such as } 2 \times \\
7 \times 5 \text { has the same value as } 2 \times 5 \\
\times 7 \text {, so instead of multiplying } 14 \\
\times 5 \text {, which is [ } 2 \times 7] \text { x } 5 \text {, the } \\
\text { student can mentally calculate } \\
10 \times 7 \text { ) }\end{array}$ & $\begin{array}{l}\text { Compose and decompose number situations and } \\
\text { relationships through observed patterns in order } \\
\text { to simplify solutions. }\end{array}$ & $\begin{array}{l}\text { See complex and complicated mathematical expressions as } \\
\text { component parts. }\end{array}$ \\
\hline 8 & $\begin{array}{l}\text { Look for and } \\
\text { express regularity } \\
\text { in repeated } \\
\text { reasoning. }\end{array}$ & $\begin{array}{l}\text { Look for obvious patterns, and } \\
\text { use if/then reasoning strategies } \\
\text { for obvious patterns. }\end{array}$ & Find and explain subtle patterns. & $\begin{array}{l}\text { Discover deep, underlying relationships (uncover a model or } \\
\text { equation that unifies the various aspects of a problem such as } \\
\text { discovering an underlying function). }\end{array}$ \\
\hline
\end{tabular}




\section{Appendix M:}

Teacher Measure: Standards of Student Practice in Mathematics Proficiency, Schulz Elementary

\begin{tabular}{|c|c|c|c|c|}
\hline & Students: & Initial (1) & Intermediate (II) & Advanced (III) \\
\hline $1 \mathrm{a}$ & $\begin{array}{l}\text { Make sense of } \\
\text { problems. }\end{array}$ & $\begin{array}{l}\text { Explain their thought processes } \\
\text { in solving a problem one way. }\end{array}$ & $\begin{array}{l}\text { Explain their thought processes in solving a } \\
\text { problem and representing it in several ways. }\end{array}$ & $\begin{array}{l}\text { Discuss, explain, and demonstrate solving a problem with } \\
\text { multiple representations and in multiple ways. }\end{array}$ \\
\hline $1 \mathrm{~b}$ & $\begin{array}{l}\text { Persevere in } \\
\text { solving them. }\end{array}$ & $\begin{array}{l}\text { Stay with a challenging problem } \\
\text { for more than one attempt. }\end{array}$ & $\begin{array}{l}\text { Try several approaches in finding a solution, and } \\
\text { only seek hints if stuck. }\end{array}$ & $\begin{array}{l}\text { Struggle with various attempts over time, and learn from } \\
\text { previous solution attempts. }\end{array}$ \\
\hline 2 & $\begin{array}{l}\text { Reason abstractly } \\
\text { and } \\
\text { quantitatively. }\end{array}$ & $\begin{array}{l}\text { Reason with models or pictorial } \\
\text { representations to solve } \\
\text { problems. }\end{array}$ & $\begin{array}{l}\text { Translate situations into symbols for solving } \\
\text { problems. }\end{array}$ & $\begin{array}{l}\text { Convert situations into symbols to appropriately solve } \\
\text { problems as well as convert symbols into meaningful } \\
\text { situations. }\end{array}$ \\
\hline $3 a$ & $\begin{array}{l}\text { Construct viable } \\
\text { arguments. }\end{array}$ & $\begin{array}{l}\text { Explain their thinking for the } \\
\text { solution they found. }\end{array}$ & $\begin{array}{l}\text { Explain their own thinking and thinking of others } \\
\text { with accurate vocabulary. }\end{array}$ & $\begin{array}{l}\text { Justify and explain, with accurate language and vocabulary, } \\
\text { why their solution is correct. }\end{array}$ \\
\hline $3 b$ & $\begin{array}{l}\text { Critique } \\
\text { reasoning of } \\
\text { others. }\end{array}$ & $\begin{array}{l}\text { Understand and discuss other } \\
\text { ideas and approaches. }\end{array}$ & $\begin{array}{l}\text { Explain other students" solutions and identify } \\
\text { strengths and weaknesses of the solutions. }\end{array}$ & $\begin{array}{l}\text { Compare and contrast various solution strategies, and explain } \\
\text { the reasoning of others. }\end{array}$ \\
\hline 4 & $\begin{array}{l}\text { Model with } \\
\text { mathematics. }\end{array}$ & $\begin{array}{l}\text { Use models to represent and } \\
\text { solve a problem, and translate } \\
\text { the solution into mathematical } \\
\text { symbols. }\end{array}$ & $\begin{array}{l}\text { Use models and symbols to represent and solve a } \\
\text { problem, and accurately explain the solution } \\
\text { representation. }\end{array}$ & $\begin{array}{l}\text { Use a variety of models, symbolic representations, and } \\
\text { technology tools to demonstrate a solution to a problem. }\end{array}$ \\
\hline 5 & $\begin{array}{l}\text { Use appropriate } \\
\text { tools strategically. }\end{array}$ & $\begin{array}{l}\text { Use the appropriate tool to find a } \\
\text { solution. }\end{array}$ & $\begin{array}{l}\text { Select from a variety of tools the ones that can be } \\
\text { used to solve a problem, and explain their } \\
\text { reasoning for the selection. }\end{array}$ & $\begin{array}{l}\text { Combine various tools, including technology, explore, and } \\
\text { solve a problem as well as justify their tool selection and } \\
\text { problem solution. }\end{array}$ \\
\hline 6 & $\begin{array}{l}\text { Attend to } \\
\text { precision. }\end{array}$ & $\begin{array}{l}\text { Communicate their reasoning } \\
\text { and solutions to others. }\end{array}$ & $\begin{array}{l}\text { Incorporate appropriate vocabulary and symbols } \\
\text { in communicating their reasoning and solution to } \\
\text { others. }\end{array}$ & $\begin{array}{l}\text { Use appropriate symbols, vocabulary, and labeling to } \\
\text { effectively communicate and exchange ideas. }\end{array}$ \\
\hline 7 & $\begin{array}{l}\text { Look for and } \\
\text { make use of } \\
\text { structure. }\end{array}$ & $\begin{array}{l}\text { Look for structure within } \\
\text { mathematics to help them solve } \\
\text { problems efficiently (such as } 2 \times \\
7 \times 5 \text { has the same value as } 2 \times 5 \\
\times 7 \text {, so instead of multiplying } 14 \\
\times 5 \text {, which is }[2 \times 7] \times 5 \text {, the } \\
\text { student can mentally calculate } \\
10 \times 7 \text { ) }\end{array}$ & $\begin{array}{l}\text { Compose and decompose number situations and } \\
\text { relationships through observed patterns in order } \\
\text { to simplify solutions. }\end{array}$ & $\begin{array}{l}\text { See complex and complicated mathematical expressions as } \\
\text { component parts. }\end{array}$ \\
\hline 8 & $\begin{array}{l}\text { Look for and } \\
\text { express regularity } \\
\text { in repeated } \\
\text { reasoning. }\end{array}$ & $\begin{array}{l}\text { Look for obvious patterns, and } \\
\text { use if/then reasoning strategies } \\
\text { for obvious patterns. }\end{array}$ & Find and explain subtle patterns. & $\begin{array}{l}\text { Discover deep, underlying relationships (uncover a model or } \\
\text { equation that unifies the various aspects of a problem such as } \\
\text { discovering an underlying function). }\end{array}$ \\
\hline
\end{tabular}


CURRICULUM VITA

Victoria Miller Bennett

\section{Education}

Doctor of Philosophy Curriculum and Instruction specializing in Mathematics

University of Louisville (in progress)

Master of Arts in Teaching Early Elementary Education

University of Louisville (2000)

Bachelor of Arts Indiana University Bloomington, IN (1995)

\section{Experience}

University of Louisville, Graduate Research Assistant

2013-2015

University of Louisville, Elementary Mathematics Methods

2012-2014

Instructor

South Oldham Middle School, Grade 7 Mathematics

2011-2012

Gifted \& Talented Educational Services Committee

Goshen Elementary, Grade 5 Teacher

2005-2011

National Board Mentor

Kentucky Teacher Internship Program Resource Teacher

Math Facilitator \& Team Leader

Student Teacher Mentor

Gifted and Talented Cluster Teacher

Site Based Decision Making Council Member

GATES Committee (Gifted \& Talented Educational

Services)

Curriculum Committee

Comprehensive School Improvement Planning Committee

Mathematics and Practical Living/Vocational Studies

Curriculum Framework Team-District

Collaborated with University of Louisville School of

Education to review Conceptual Framework, Assessment \&

Program Documents

Goshen Elementary, Grades 1 and 2 Teacher

2000-2004

School Climate Committee 
Student Teacher Mentor

Instructional Practices Committee

ESS Teacher

Evaluator for Reading First Grant

Kentucky Reading Project

Belize, Central America

Collaborated with team to plan and implement instruction in impoverished schools

\section{Certifications}

Cognitive Coach

National Board Certified Teacher

Teaching in Elementary School, Primary

2000

through Grade 5

\section{Publications}

\section{Published Refereed Journal Articles}

Bush, S., Karp, K., Miller Bennett, V., Popelka, E., \& Nadler, J. (2013). Art Gallery Installation: Measurement in Action. Mathematics Teaching in the Middle School.

Bush, S., Karp, K., Popelka, E., \& Miller Bennett, V. (2012). What's on your plate? Thinking proportionally. Mathematics Teaching in the Middle School.

\section{$\underline{\text { Journal Article Under Review }}$}

Peters, S., Miller Bennett, V., Young, M., \& Watkins, J. (2015). Fair and Balanced Approach to Mean. Mathematics Teaching in the Middle School. 


\section{$\underline{\text { Presentations }}$}

\section{International Conference}

Peters, S. Watkins, J., \& Miller Bennett, V. (2014). Middle and high school teachers' transformative learning of center. Presentation at the $9^{\text {th }}$ International Conference on Teaching Statistics, Flagstaff, Arizona.

\section{National Conference}

Peters, S., \& Miller Bennett, V., (2015). Middle and secondary teachers' transformative learning: measures of central tendency. Presentation at the Association of Mathematics Teacher Educators (AMTE) Conference, Orlando, Florida.

Peters, S., Watkins, J.D. \& Miller Bennett, V. (2014). Middle and high school teachers' transformative learning of average. Paper presented at the 2014 Research Presession of the National Council of Teachers of Mathematics Annual Meeting and Exposition, New Orleans, Louisiana.

\section{State and Regional Conferences}

Miller Bennett, V. (2014). Developing understanding of the equal sign in Kindergarten

- Grade 2. Presentation at The National Council of Teachers of Mathematics Regional Conference, Indianapolis, Indiana.

Miller Bennett, V. (2013). Social Networking in math! Makin' it Real! Presentation at The National Council of Teachers of Mathematics Regional Conference, Louisville, Kentucky.

Livers, S.D. \& Miller Bennett, V. (2004). Communication with Families. Presentation at Kentucky Association for National Board Certified Teachers Conference, Bowling Green, Kentucky.

\section{Invited Local Presentations and Workshops}

Miller Bennett, V. (2014). Technology in the math classroom. Presentation for preservice teachers at the University of Louisville, Kentucky.

Miller Bennett, V. (2010) Equitable Mathematics Instruction. Presentation for teachers at Goshen Elementary, Prospect, KY.

Miller Bennett, V., \& Higgins, R. (2010). High Stakes Testing and the English Language Learner. Presentation at ESL Newcomer Academy, Louisville, Kentucky. 
Miller Bennett, V. (2007). Math Workshop for Families. Presentation for families at Goshen Elementary, Prospect, KY.

Miller Bennett, V. (2005). Teaching Mathematics with Investigations. Presentation for teachers at Crestwood Elementary, Crestwood, Kentucky.

Miller Bennett, V. (2005). Teaching Mathematics with Investigations. Presentation for teachers at Goshen Elementary, Crestwood, Kentucky.

Miller Bennett, V., \& Livers, S.D. (2004) Math the Goshen Way. Presentation for parents at Goshen Elementary, Prospect, Kentucky.

Livers, S.D., \& Miller Bennett, V. (2004). Reading and Writing, Presentation for New Castle Elementary, New Castle, Kentucky.

\section{$\underline{\text { Service }}$}

\section{National Service}

National Council of Teachers of Mathematics

Review manuscripts - Teaching Children Mathematics \& Mathematics Teaching in the Middle School

\section{$\underline{\text { State Service }}$}

Greater Louisville Council of Teachers of Mathematics (2015)

Professional Memberships

National Council of Teachers of Mathematics

Greater Louisville Council of Teachers of Mathematics

Association of Mathematics Teacher Educators

\section{Honors/Achievement/Other}

- Graduate Dean's Citation (2015)

- Apple Award North Oldham High School (2015 and 2012)

- Graduate Student Travel Grant (2015)

- Samuels Family Scholarship (2009-2013)

- Harmony Academy Lacrosse Camp Instructor (2011 and 2012)

- Pyramid Award, Fifth grade team (2010) 
- Selected as Demonstration Site for Kentucky Reading Project (2003)

- Summer Portfolio Institute Teacher Leader (2004)

- Lacrosse Coach (2000-2007) 